\title{
ILANA HALPERN
}

Células dendríticas plasmocitoides, dendrócitos dérmicos Fator XIIla positivos, macrófagos e expressão da forma induzida da óxido nítrico sintase na resposta tecidual cutânea da leishmaniose tegumentar americana

\author{
Tese apresentada à Faculdade de Medicina da \\ Universidade de São Paulo para obtenção do \\ título de Doutora em Ciências \\ Programa de Patologia \\ Orientadora: Profa. Dra. Mirian Nacagami Sotto
}

(Versão corrigida. Resolução CoPGr 5890, de 20 de Dezembro de 2010. A versão original está disponível na Biblioteca FMUSP)

\author{
São Paulo
}


Dados Internacionais de Catalogação na Publicação (CIP)

Preparada pela Biblioteca da

Faculdade de Medicina da Universidade de São Paulo

Creprodução autorizada pelo autor

\section{Halpern, Ilana}

Células dendríticas plasmocitoides, dendrócitos dérmicos Fator XIIIa positivos, macrófagos e expressão da forma induzida da óxido nítrico sintase na resposta tecidual cutânea da leishmaniose tegumentar americana / Ilana Halpern. -- São Paulo, 2012.

Tese(doutorado)--Faculdade de Medicina da Universidade de São Paulo. Programa de Patologia.

Orientadora: Mirian Nacagami Sotto.

Descritores: 1.Leishmaniose cutânea 2.Macrófagos 3.Óxido nítrico sintase tipo II 4.Células dendríticas 5.Imuno-histoquímica

USP/FM/DBD-151/12 
Aos meus pais, Sima e Arie, com todo o meu amor e respeito, e aos meus filhos, Nathan e Esther, que carregam consigo tudo aquilo que considero precioso - valores, visão e sonhos. 
AGRADECIMENTOS 
Agradeço especialmente à Profa. Dra. Mirian Nacagami Sotto, por todos seus ensinamentos e o constante estímulo; desde as aulas de Patologia Geral, na época da graduação, em que já era para mim o maior exemplo de didática; durante a residência médica, por mostrar ser possível um ensino de alta qualidade, com seriedade e respeito pelos alunos; por me acolher como colaboradora no laboratório de Dermatopatologia, proporcionando meu aprofundamento nesta área; por me dar a honra de trabalhar ao seu lado, como parceira, neste mesmo laboratório, onde não há um dia sequer em que eu não aprenda algo novo; pela orientação desta Tese, sempre presente, sempre disponível; pela realização da Estatística deste trabalho. Também pelo coleguismo, pela convivência diária, pelas dicas de dietas e por muitos ingressos para concertos. Um exemplo de mulher, médica, patologista, professora, chefe, mãe e avó. Muito obrigada.

Ao Wellington Luiz Ferreira da Silva pelo capricho e dedicação na realização das reações imuno-histoquímicas, pelo auxílio na contagem de células e pelas dicas sobre como usar o programa Excel.

À Ana Maria Gonçalves da Silva e à Dra. Fernanda Guedes pelo apoio técnico nos estudos imuno-histoquímicos. 
Ao Dr. Luiz Fernando Ferraz da Silva, pelo treinamento para a utilização do programa de análise de imagens, e por me ensinar truques de fotografia ao microscópio, visando melhorar a nitidez das reações.

Ao CNPq - Conselho Nacional de Desenvolvimento Científico e Tecnológico (processo 307573/2006-0) e à FAPESP- Fundação de Amparo à Pesquisa do Estado de São Paulo (processo 2010/16758-1) pelo apoio financeiro.

À Profa. Dra. Maria Irma Seixas Duarte, ao Prof. Dr. Gil Benard e à Profa. Dra. Jane Tomimori Yamashita, por fazerem parte da minha banca de qualificação e contribuírem para o enriquecimento deste trabalho.

Aos meus filhos, Nathan e Esther Halpern Salomon, que me emprestaram seus "notebooks" quando o meu pifou; e muito obrigada à Esther por me lembrar de fazer o "backup" desta Tese, uma semana antes do meu "hard drive" queimar.

À Rosana Cardoso, por cuidadosamente separar lâminas antigas de imunohistoquímica, pela simpatia e disponibilidade, até para servir café para a minha banca de qualificação.

Às Dras. Maria Apparecida Constantino Vilela, Neusa Yuriko Sakai Valente e Marina Sandoval, que também me proporcionaram o treinamento 
em Dermatopatologia; em especial à Dra. Neusa, muito querida, com quem continuo aprendendo, todos os dias.

Às queridas colegas dermatopatologistas Dra. Alice Coelho Lobo Siqueira e Dra. Cinara Prata Soares, pelas trocas de experiências e preciosa amizade.

Ao Dr. Fabiano Mesquita Callegari, que estimulou minha incursão pela Dermatopatologia e me ensinou muito sobre Patologia Cirúrgica e trabalho em laboratório privado.

Aos professores, colegas e funcionários do Departamento e Divisão de Clínica Dermatológica, Departamento de Patologia e da Divisão de Anatomia Patológica do HCFMUSP, pelo convívio e pela oportunidade de aprendizado.

Aos médicos residentes e estagiários de Dermatologia e Patologia, de todas as partes do Brasil, da América Latina e até de outros continentes, para os quais tenho grande prazer em transmitir meus conhecimentos e com quem sempre tenho algo a aprender, também. Tornam a nossa rotina no laboratório muito mais divertida e interessante.

Aos meus familiares e amigos, pela compreensão, paciência e estímulo constantes. 
"Ama-se mais o que se conquista com esforço".

Benjamin Disraeli (1804-1881) 
Esta tese está de acordo com as seguintes normas, em vigor no momento desta publicação:

Referências: adaptado de International Committee of Medical Journals Editors (Vancouver).

Universidade de São Paulo. Faculdade de Medicina. Divisão de Biblioteca e Documentação. Guia de apresentação de dissertações, teses e monografias. Elaborado por Anneliese Carneiro da Cunha, Maria Julia de A. L. Freddi, Maria F. Crestana, Marinalva de Souza Aragão, Suely Campos Cardoso, Valéria Vilhena. 3a ed. São Paulo: Divisão de Biblioteca e Documentação; 2011.

Abreviaturas dos títulos dos periódicos de acordo com List of Journals Indexed in Index Medicus. 
SUMÁRIO 
Lista de abreviaturas

Lista de Quadros

Lista de Figuras

Lista de Gráficos

Lista de Tabelas

Resumo

Summary/Abstract

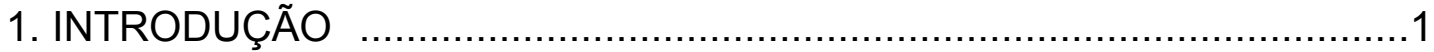

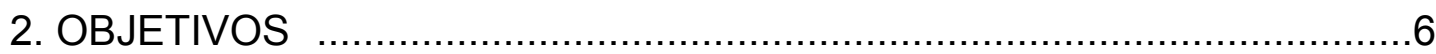

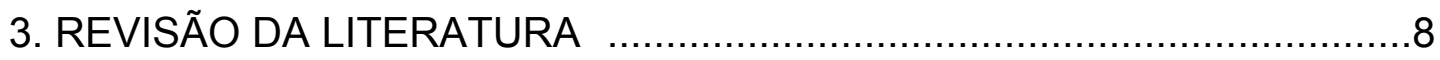

3.1. Leishmania e leishmanioses ...................................................... 9

3.2. Células dendríticas cutâneas .................................................14

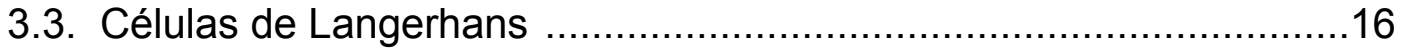

3.4. Células dendríticas dérmicas ..............................................19

3.5. Células dendríticas plasmocitoides .....................................23

3.6. A interação Leishmania-hospedeiro ....................................30

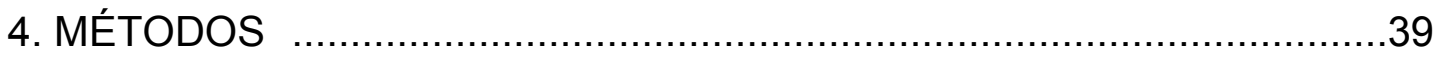

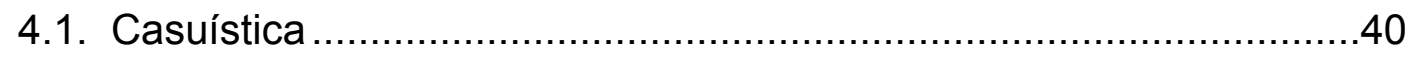

4.2. Demonstração de células dendríticas plasmocitoides ....................49

4.3. Quantificação de células dendríticas plasmocitoides .......................51

4.4. Demonstração de expressão de iNOS por dendrócitos dérmicos Fator XIIla+ (reação imuno-histoquímica de dupla marcação) .........................52

4.5. Quantificação de dendrócitos dérmicos fator XIIla+ ......................55

4.6. Demonstração de expressão de iNOS por macrófagos CD68+ (reação imuno-histoquímica de dupla marcação) .................................56

4.7. Quantificação de macrófagos CD68+ ......................................58

4.8. Análise estatística dos resultados .......................................59 
5.1. Demonstração e quantificação de células dendríticas plasmocitoides nas lesões cutâneas de leishmaniose tegumentar americana

5.2. Demonstração e quantificação de expressão de iNOS por dendrócitos dérmicos Fator XIIla+

5.3. Demonstração e quantificação de expressão de iNOS por macrófagos CD68+

5.4. Comparação do número de dendrócitos dérmicos Fator XIIla+ e de macrófagos, sem e com coexpressão de iNOS nas lesões cutâneas da leishmaniose tegumentar americana

5.5. Comparação da porcentagem de dendrócitos dérmicos Fator XIIla+ e de macrófagos com coexpressão de iNOS nas lesões cutâneas da leishmaniose tegumentar americana

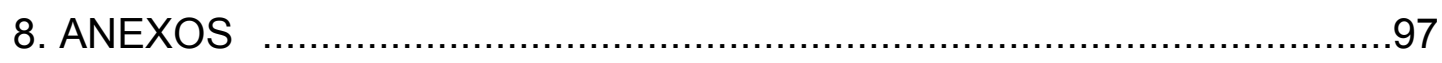

ANEXO A: Documento de aprovação da CAPPesq ..............................98

ANEXO B: Informações adicionais sobre a casuística .............................99

ANEXO C: Quadro 3 - Leishmaniose tegumentar americana. Média do número de células $/ \mathrm{mm}^{2}$ em biópsias de pele com resposta inflamatória não específica e granulomatosa 109

ANEXO D: Quadro 4 - Leishmaniose tegumentar americana. Média do número de dendrócitos dérmicos Fator Xllla+ e de células com coexpressão de Fator XIIIa/iNOS $/ \mathrm{mm}^{2}$ em biópsias de pele com resposta inflamatória não específica e granulomatosa 110

ANEXO E: Quadro 5 - Leishmaniose tegumentar americana. Média do número de macrófagos CD68+ sem e com coexpressão de iNOS $/ \mathrm{mm}^{2}$ em biópsias de pele com resposta inflamatória não específica e granulomatosa

ANEXO F: Quadro 6 - Leishmaniose tegumentar americana. Porcentagem de dendrócitos dérmicos Fator XIIla+ e de macrófagos CD68+ com coexpressão de iNOS em biópsias de pele com resposta inflamatória não específica e granulomatosa 


\section{LISTA DE ABREVIATURAS}

APC - célula(s) apresentadora(s) de antígenos

ATPase - enzima catalisadora da hidrólise de adenosina trifosfato BDCA - antigeno de células dendríticas sanguíneas (do inglês "blood dendritic cell antigen")

BSA - soroalbumina bovina

CCR - receptor de quimiocina

CD - "cluster of differentiation"

CD - célula(s) dendrítica(s)

CDP - célula(s) dendrítica(s) plasmocitoide(s)

$\mathrm{CL}$ - célula(s) de Langerhans

CR - receptor do complemento

DD - dendrócito(s) dérmico(s)

DD Fator XIIla+ - dendrócito(s) dérmico(s) Fator XIIla positivo(s)

DNA - ácido desoxirribonucleico

GM-CSF - fator estimulador de colônias de granulócitos e macrófagos

gp63 - glicoproteína 63 da superfície da forma promastigota de Leishmania

GR - resposta inflamatória crônica granulomatosa

$\mathrm{HE}$ - hematoxilina-eosina

HIV - vírus da imunodeficiência adquirida humana

HLA - antígenos leucocitários humanos

ICAM-1 - molécula de adesão intercelular - 1

IDO - indoleamina 2,3-dioxigenase 
IFN - interferon

IH - imuno-histoquímica

$\mathrm{IL}$ - interleucina

iNOS - forma induzida da óxido nítrico sintase

LCA - antígeno leucocitário comum

LPG- lipofosfoglicano

LPS - lipopolissacarídeo

LTA - leishmaniose tegumentar americana

MHC - complexo principal de histocompatibilidade

NE - resposta inflamatória crônica não específica

NF-kB - fator nuclear de transcrição kappa B

NK - células "natural killer"

NO - óxido nítrico

PAMP - padrão molecular associado a patógenos

PBS - solução salina tamponada com fosfatos

$\mathrm{PTI}$ - células dendríticas produtoras de TNF e iNOS

SALT - tecido linfoide associado à pele (do inglês "skin-associated lymphoid tissue"

$\mathrm{TdT}$ - terminal deoxinucleotidil transferase

TGF $\beta$ - fator transformador de crescimento beta

Th - célula T "helper" (auxiliadora)

TLR - receptor "toll-like"

TNF - fator de necrose tumoral

TRAIL - ligante indutor de apoptose associado a TNF 


\section{LISTA DE QUADROS}

QUADRO 1 - Casos de leishmaniose tegumentar americana: idade, sexo, localização e tipo de lesão e resultado da reação intradérmica de Montenegro 41

QUADRO 2 - Leishmaniose tegumentar americana. Tipo de resposta inflamatória e pesquisa de Leishmania nos preparados de biópsia corados pela hematoxilina-eosina e pela técnica imuno-histoquímica para pesquisa de antígeno parasitário.

QUADRO 3 - Leishmaniose tegumentar americana. Média do número de células $/ \mathrm{mm}^{2}$ em biópsias de pele com resposta inflamatória não específica e granulomatosa 109

QUADRO 4 - Leishmaniose tegumentar americana. Média do número de dendrócitos dérmicos Fator XIlla+ e de células com coexpressão de Fator $\mathrm{XIIla} / \mathrm{iNOS} / \mathrm{mm}^{2}$ em biópsias de pele com resposta inflamatória não específica e granulomatosa. 110

QUADRO 5 - Leishmaniose tegumentar americana. Média do número de macrófagos CD68+ sem e com coexpressão de iNOS $/ \mathrm{mm}^{2}$ em biópsias de pele com resposta inflamatória não específica e granulomatosa

QUADRO 6 - Leishmaniose tegumentar americana. Porcentagem de dendrócitos dérmicos Fator XIIla+ e de macrófagos CD68+ com coexpressão de iNOS em biópsias de pele com resposta inflamatória não específica e granulomatosa 


\section{LISTA DE FIGURAS}

Figura 1. Leishmaniose tegumentar americana. Coloração pela hematoxilinaeosina. Padrão de resposta tecidual inflamatória crônica não específica (caso 27). A. Aumento original x100. B. Aumento original x400 ....

Figura 2. Leishmaniose tegumentar americana. Coloração pela hematoxilinaeosina. Padrão de resposta tecidual inflamatória crônica granulomatosa (caso 37). A. Aumento original x40. B. Aumento original x400

Figura 3. Leishmaniose tegumentar americana. Coloração pela hematoxilinaeosina. Presença de numerosas formas amastigotas no citoplasma de macrófagos (caso 37 - aumento original $\times 1000$ ) 45

Figura 4. Leishmaniose tegumentar americana. Reação imuno-histoquímica - sistema EnVision peroxidase/diaminobenzidina. Presença de numerosas formas amastigotas $(3+/ 3+)$ no citoplasma de macrófagos, coradas em marrom (caso 37 - aumento original $x 400$ )

Figura 5. Leishmaniose tegumentar americana - Resposta inflamatória crônica não específica (caso 32). Células dendríticas plasmocitóides e células endoteliais (seta) evidenciadas pelo anticorpo anti-CD123. Reação imuno-histoquímica com o sistema Advance peroxidase/diaminobenzidina (aumento original $\mathrm{x} 200$ )

Figura 6. Leishmaniose tegumentar americana. A (caso 30) - Células CD123+ em agrupamentos celulares. B (caso 36) - Células CD123+ alinhadas na junção dermoepidérmica e permeando a epiderme. Reação imuno-histoquímica - sistema Advance peroxidase/ diaminobenzidina ( $\mathrm{A}$ e B - aumento original $\times 200$ ).

Figura 7. Leishmaniose tegumentar americana (caso 49). Células CD123+ com morfologia dendrítica ao redor de granuloma. Reação imunohistoquímica - sistema Advance peroxidase/diaminobenzidina (aumento original $\times 200$ )

Figura 8. Leishmaniose tegumentar americana. A (caso 26) - Dendrócitos dérmicos fator XIIla+ corados pelo cromógeno vermelho, apresentando coexpressão citoplasmática de iNOS, evidenciada pelo cromógeno negro. B (caso 38) - Expressão epidérmica de iNOS (seta). Reação imunohistoquímica de dupla marcação - sistema EnVision peroxidase/ "permanent red" / diaminobenzidina com níquel (A - aumento original $\times 1000$, B - aumento original $\mathrm{x} 200$ ) 
Figura 9. Leishmaniose tegumentar americana. A (caso 38) - Resposta tecidual granulomatosa. B (caso 5) - Resposta tecidual não específica. Notar dendrócitos dérmicos fator XIIla+ (marcados em vermelho) com coexpressão de iNOS (corados em negro). Reação imuno-histoquímica de dupla marcação - sistema EnVision peroxidase/"permanent red"/diaminobenzidina com níquel (A e B - aumento original $\times 200$ ). 68

Figura 10. Leishmaniose tegumentar americana (caso 32). Macrófagos com coexpressão de CD68 (marcação em vermelho) e iNOS (negro) presentes no infiltrado inflamatório dérmico. Reação imuno-histoquímica de dupla marcação - sistema EnVision peroxidase/"permanent red"/diaminobenzidina

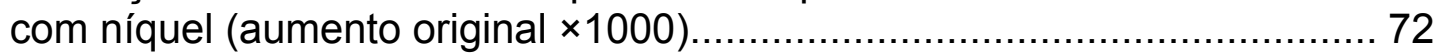

Figura 11. Leishmaniose tegumentar americana. A. Padrão de resposta tecidual granulomatoso (caso 4). B. Padrão de resposta tecidual não específico (caso 5). Ambos apresentam macrófagos (CD68+ imunomarcados em vermelho) com coexpressão de iNOS (marcação citoplasmática em negro). Reação imuno-histoquímica de dupla marcação sistema EnVision peroxidase/"permanent red"/diaminobenzidina com níquel. (A e B aumento original $\times 200$ ) 


\section{LISTA DE GRÁFICOS}

Gráfico 1. Leishmaniose tegumentar americana. Comparação do número de células dendríticas plasmocitoides (CD123+) nas lesões cutâneas com resposta inflamatória crônica granulomatosa (GR) e crônica não específica $(\mathrm{NE})$. Barra - mediana. Teste de Mann-Whitney $(p>0,05)$.

Gráfico 2. Leishmaniose tegumentar americana. Comparação do número de dendrócitos dérmicos Fator XIIla+/mm2 nas lesões cutâneas com resposta inflamatória crônica granulomatosa (GR) e crônica não específica (NE). Barra - mediana. Teste de Mann-Whitney $(p=0,055)$............................... 69

Gráfico 3. Leishmaniose tegumentar americana. Comparação do número de dendrócitos dérmicos Fator XIIla+ com coexpressão de iNOS, nas lesões cutâneas com resposta inflamatória crônica granulomatosa (GR) e crônica não específica (NE). Barra - mediana. Teste de Mann-Whitney $(p=0,04) .70$

Gráfico 4. Leishmaniose tegumentar americana. Comparação do número de macrófagos (CD68+) nas lesões cutâneas com resposta inflamatória crônica granulomatosa (GR) e crônica não específica (NE). Barra - mediana. Teste

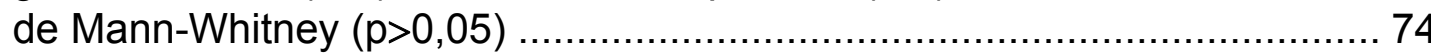

Gráfico 5. Leishmaniose tegumentar americana. Comparação do número de macrófagos (CD68+) com coexpressão de iNOS nas lesões cutâneas com resposta inflamatória crônica granulomatosa (GR) e crônica não específica $(\mathrm{NE})$. Barra - mediana. Teste de Mann-Whitney $(p>0,05)$.

Gráfico 6. Leishmaniose tegumentar americana. Comparação do número de dendrócitos dérmicos fator XIIla+e de macrófagos (CD68+) nas lesões cutâneas. Barra - mediana. Teste de Mann-Whitney $(p<0,0001) \ldots \ldots \ldots \ldots . . . .77$

Gráfico 7. Leishmaniose tegumentar americana. Comparação do número de dendrócitos dérmicos fator XIlla+e de macrófagos (CD68+) nas lesões cutâneas com resposta tecidual granulomatosa. Barra - mediana. Teste de Mann-Whitney $(p=0,0004)$ 78

Gráfico 8. Leishmaniose tegumentar americana. Comparação do número de dendrócitos dérmicos fator XIlla+e de macrófagos (CD68+) nas lesões cutâneas com resposta tecidual não específica. Barra - mediana. Teste de

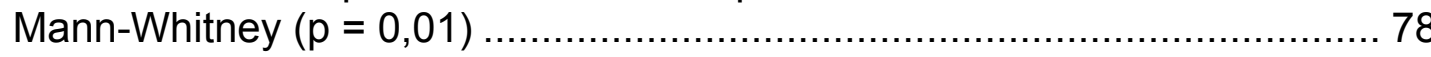

Gráfico 9. Leishmaniose tegumentar americana. Comparação do número de dendrócitos dérmicos fator XIIla+ e de macrófagos (CD68+) com coexpressão de iNOS. Barra - mediana. Teste de Mann-Whitney $(p<0,0001)$ 
Gráfico 10. Leishmaniose tegumentar americana. Comparação do número de dendrócitos dérmicos fator XIlla+ e de macrófagos (CD68+) com coexpressão de iNOS nos casos de resposta granulomatosa. Barra mediana. Teste de Mann-Whitney $(p<0,0001)$.

Gráfico 11. Leishmaniose tegumentar americana. Comparação do número de dendrócitos dérmicos fator XIlla+ e de macrófagos (CD68+) com coexpressão de iNOS nos casos de resposta não específica. Barra mediana. Teste de Mann-Whitney $(p=0,0006)$.....

Gráfico 12. Leishmaniose tegumentar americana. Comparação da porcentagem de dendrócitos dérmicos fator XIIla+ e de macrófagos (CD68+) com coexpressão de iNOS. Barra - mediana. Teste de Mann-Whitney $(p=0,0412)$

Gráfico 13. Leishmaniose tegumentar americana. Comparação da porcentagem de dendrócitos dérmicos fator XIlla+ e de macrófagos (CD68+) com coexpressão de iNOS nos casos de resposta granulomatosa. Barra mediana. Teste de Mann-Whitney $(p=0,0618)$.

Gráfico 14. Leishmaniose tegumentar americana. Comparação da porcentagem de dendrócitos dérmicos fator XIIla+ e de macrófagos (CD68+) com coexpressão de iNOS nos casos de resposta não específica. Barra mediana. Teste de Mann-Whitney $(p=0,5350)$

Gráfico 15. LEISHMANIOSE TEGUMENTAR AMERICANA. DISTRIBUIÇÃO DOS DOENTES POR GÊNERO .................................................... 99

Gráfico 16. LEISHMANIOSE TEGUMENTAR AMERICANA. DISTRIBUIÇÃO DOS DOENTES POR FAIXA ETÁRIA. 100

Gráfico 17. LEISHMANIOSE TEGUMENTAR AMERICANA. DISTRIBUIÇÃO TOPOGRÁFICA DAS LESÕES CUTÂNEAS

Gráfico 18. LEISHMANIOSE TEGUMENTAR AMERICANA.

CARACTERÍSTICA DAS LESÕES.

Gráfico 19. LEISHMANIOSE TEGUMENTAR AMERICANA. RESULTADO

DA REAÇÃO DE MONTENEGRO.

Gráfico 20. LEISHMANIOSE TEGUMENTAR AMERICANA. TIPO DE RESPOSTA TECIDUAL.

Gráfico 21. LEISHMANIOSE TEGUMENTAR AMERICANA. PRESENÇA OU AUSÊNCIA DE FORMAS AMASTIGOTAS ENTRE OS PADRÕES DE RESPOSTA TECIDUAL (HE) 
Gráfico 22. LEISHMANIOSE TEGUMENTAR AMERICANA. DISTRIBUIÇÃO DA QUANTIDADE DE ANTÍGENO DE Leishmania (IH) ENTRE OS PADRÕES DE RESPOSTA TECIDUAL

Gráfico 23. LEISHMANIOSE TEGUMENTAR AMERICANA. TIPOS DE RESPOSTA TECIDUAL EM DIFERENTES FAIXAS ETÁRIAS DOS DOENTES

Gráfico 24. LEISHMANIOSE TEGUMENTAR AMERICANA. TIPOS DE LESÕES CUTÂNEAS E PADRÃO DE RESPOSTA TECIDUAL.

Gráfico 25. LEISHMANIOSE TEGUMENTAR AMERICANA. RESULTADOS DE LEITURA DE REAÇÃO INTRADÉRMICA DE MONTENEGRO EM RELAÇÃO AOS PADRÕES DE RESPOSTA TECIDUAL........................... 108 


\section{LISTA DE TABELAS}

Tabela 1. Leishmaniose tegumentar americana. Comparação do número de células dendríticas plasmocitoides (CD123+) nas lesões cutâneas com resposta inflamatória crônica granulomatosa e crônica não específica 65

Tabela 2. Leishmaniose tegumentar americana. Comparação do número de dendrócitos dérmicos fator XIIla+ nas lesões cutâneas com resposta inflamatória crônica granulomatosa e crônica não específica.

Tabela 3. Leishmaniose tegumentar americana. Comparação do número de dendrócitos dérmicos fator XIIIa+ que coexpressam iNOS nas lesões cutâneas com resposta inflamatória crônica granulomatosa e crônica não específica.

Tabela 4. Leishmaniose tegumentar americana. Comparação do número de macrófagos (CD68+) nas lesões cutâneas com resposta inflamatória crônica granulomatosa e crônica não específica.

Tabela 5. Leishmaniose tegumentar americana. Comparação do número de macrófagos (CD68+) que coexpressam iNOS nas lesões cutâneas com resposta inflamatória crônica granulomatosa e crônica não específica

Tabela 6. Leishmaniose tegumentar americana. Comparação do número de células dendríticas fator XIIla+ e de macrófagos (CD68+) em 34 biópsias de lesões cutâneas

Tabela 7. Leishmaniose tegumentar americana. Comparação do número de células dendríticas fator XIIla+ e de macrófagos (CD68+) que expressam iNOS, em 34 biopsias de lesões cutâneas

Tabela 8. Leishmaniose tegumentar americana. Comparação da porcentagem de células dendríticas fator XIIla+ e de macrófagos (CD68+) que expressam iNOS, em 34 biopsias de lesões cutâneas 


\section{RESUMO}

Halpern I. Células dendríticas plasmocitoides, dendrócitos dérmicos Fator XIlla positivos, macrófagos e expressão da forma induzida da óxido nítrico sintase na resposta tecidual cutânea da leishmaniose tegumentar americana [tese]. São Paulo: "Faculdade de Medicina, Universidade de São Paulo"; 2012.

Em todas as formas clínicas da leishmaniose tegumentar americana os macrófagos são as células efetoras mais importantes na destruição do parasita intracelular. As células dendríticas são células apresentadoras de antígeno localizadas nos sítios de inoculação, como pele e mucosa. Os dendrócitos dérmicos Fator XIIla positivos são células derivadas de linhagem mielomonocítica e consideradas complementares às células de Langerhans no processo de apresentação de antígenos e indução da resposta imune. As células dendríticas plasmocitoides representam um subgrupo de células dendríticas precursoras presentes no sangue periférico e órgãos linfoides. Estas células são identificadas pela alta expressão de receptor da cadeia alfa da interleucina-3 (CD123) e são fortes produtoras de interferon tipo I. Elas são raramente observadas na pele humana normal, e foram demonstradas em dermatoses inflamatórias e virais. O óxido nítrico e seus derivados atuam como moléculas efetoras da citotoxicidade macrofágica contra parasitas. A expressão da enzima óxido nítrico sintase induzida (iNOS) e a geração de óxido nítrico é importante no controle da infecção por diferentes espécies de Leishmania. Cinqüenta e dois espécimes de biópsias cutâneas de pacientes diagnosticados com leishmaniose tegumentar americana foram classificados histologicamente de acordo com o padrão de resposta tecidual, se granulomatoso ou inflamatório difuso não específico. O objetivo deste estudo foi demonstrar e quantificar a presença de células dendríticas plasmocitoides em 36 das biópsias, através de estudo imuno-histoquímico com anticorpo anti-CD123, comparando os achados entre os diferentes tipos de resposta tecidual; verificar a expressão de iNOS por dendrócitos dérmicos Fator XIlla positivos e comparar com a expressão de iNOS por macrófagos nas lesões cutâneas, através de estudo imuno-histoquímico com dupla marcação pelos anticorpos anti-CD68 e antiiNOS em 43 biópsias cutâneas, e pelos anticorpos anti-Fator XIIla e antiiNOS em 34 amostras, comparando os achados entre os diferentes padrões de resposta tecidual.

Foram evidenciadas células dendríticas CD123+ em todos espécimes de lesões cutâneas de leishmaniose tegumentar americana estudados. Em 22/36 amostras, as células dendríticas plasmocitoides estavam dispostas isoladamente entre outras células inflamatórias; em 14/36 amostras estavam agrupadas, pelo menos focalmente, principalmente no grupo granulomatoso (13 amostras) e em um caso do grupo não específico; dez amostras exibiram células na junção dermoepidérmica, sendo oito no grupo granulomatoso e duas no grupo não específico. Entretanto, não houve diferença no número de células $\mathrm{CD} 123+/ \mathrm{mm}^{2}$ entre os dois grupos estudados. Esses resultados sugerem que as células dendríticas 
plasmocitoides participam da resposta imune nas lesões cutâneas de leishmaniose tegumentar americana.

A expressão de iNOS por dendrócitos dérmicos Fator XIlla positivos foi evidenciada em todos os espécimes estudados, sendo que a maioria dos macrófagos expressou iNOS. Não houve diferença estatisticamente significativa entre o número de células CD68+/ $\mathrm{mm}^{2}$ e CD68+iNOS $+/ \mathrm{mm}^{2}$ nos diferentes padrões de resposta tecidual, tampouco no número de células Fator XIIla+/mm², mas o número de células FatorXIIla+iNOS $+/ \mathrm{mm}^{2}$ foi maior no grupo granulomatoso. Quando comparadas 34 amostras, todas elas submetidas a estudos com anticorpos anti-Fator XIIla, anti-CD68, antiFatorXIIla/iNOS e anti-CD68/iNOS, foi maior o número total de macrófagos que dendrócitos dérmicos Fator XIIla positivos, expressando ou não iNOS, e a porcentagem de macrófagos coexpressando iNOS foi maior que a coexpressão de iNOS por dendrócitos dérmicos Fator XIIla positivos, mas esta diferença não foi estatisticamente significativa quando comparados os grupos histológicos separadamente. Os resultados demonstram que os dendrócitos dérmicos Fator XIIla positivos expressam iNOS, menos que os macrófagos, mas proeminentemente no grupo granulomatoso, sugerindo a sua participação na patogênese de lesões cutâneas de leishmaniose tegumentar americana, como células com capacidade leishmanicida e/ou apresentadoras de antígeno.

Descritores: 1. Leishmaniose cutânea; 2. Macrófagos; 3. Óxido nítrico sintase tipo II; 4. Células dendríticas; 5. Imuno-histoquímica. 


\section{SUMMARYIABSTRACT}

Halpern I. Plasmacytoid dendritic cells, Factor XIIla-positive dermal dendrocytes, macrophages and inducible nitric oxide synthase expression in American tegumentary leishmaniasis skin lesions [thesis]. São Paulo: "Faculdade de Medicina, Universidade de São Paulo"; 2012.

In all forms of American tegumentary leishmaniasis lesions, macrophages are the most important effector cells involved in intracellular parasite destruction. Dendritic cells are antigen-presenting cells that are localized at the entry sites, such as skin and mucosa. Factor XIIla+ dermal dendrocytes are bone marrow-monocytic lineage-derived cells and considered complementary cells to Langerhans cells in the process of antigen presentation and inducing immune response. Plasmacytoid dendritic cells constitute a subset of dendritic cells precursors in peripheral blood and organized lymphoid tissue. These cells are identified by their high levels of interleukin-3 receptor alpha chain (CD123) and are vigorous type I interferon producing cells. They are rarely present in normal human skin, and have been demonstrated in inflammatory and viral dermatoses. Nitric oxide radical and derivatives act as effector molecules of macrophage cytotoxicity against invading parasites. Expression of inducible nitric oxide synthase (iNOS) and generation of nitric oxide is important in control of infection in different Leishmania species. Fifty-two samples of skin biopsies obtained from American tegumentary leishmaniasis patients were histologically classified as granulomatous reaction or non specific diffuse inflammatory reaction. The aim of the study was to demonstrate and quantify the presence of plasmacytoid dendritic cells in thirty-six skin biopsies, by immunohistochemistry with anti-CD123, comparing findings in both patterns of tissue response; to verify the expression of iNOS by Factor XIIla+ dermal dendrocytes and compare to the expression of iNOS by macrophages in cutaneous lesions, by doublestaining technique with anti-CD68 and antiiNOS antibodies in forty-three skin biopsies and anti-factor XIIla and antiiNOS antibodies in thirty-four biopsies, comparing findings between different tissue response patterns. Dendritic CD123+ cells were demonstrated in all specimens of American tegumentary leishmaniasis lesions. The number of CD123+ cells $/ \mathrm{mm}^{2}$ in the two groups did not differ. In 22/36 samples, plasmacytoid dendritic cells were intermingled with other inflammatory cells, and were grouped, at least focally, in 14/36 samples. Thirteen cases from the granulomatous group and one non specific case showed clusters of cells in the dermal inflammatory infiltrate. Ten biopsies displayed plasmacytoid dendritic cells at the dermoepidermal junction, two in the non specific group and eight in the granulomatous group. The findings suggest that plasmacytoid dendritic cells participate in the immune response of American tegumentary leishmaniasis skin lesions.

Expression of iNOS by Factor XIIla+ dermal dendrocytes was shown in all specimens, and most of the macrophages expressed iNOS. The total 
number of CD68+ cells $/ \mathrm{mm}^{2}$ and CD68+iNOS+ cells $/ \mathrm{mm}^{2}$ in the two groups did not differ, nor the total number of FactorXIIla+ cells $/ \mathrm{mm}^{2}$, but the number of FactorXIIla+iNOS+ cells $/ \mathrm{mm}^{2}$ was higher in the granulomatous group. When comparing thirty-four samples that were all tested to anti-Factor XIIla, anti-CD68, anti-FactorXIIla/anti-iNOS and anti-CD68/anti-iNOS, it was higher the total number of macrophages, either non-expressing or expressing iNOS than iNOS-expressing Factor XIlla+ dermal dendrocytes, and the total percentage of iNOS-expressing macrophages was higher than iNOSexpressing Factor Xllla+ dermal dendrocytes, but this percentage was not significant when granulomatous and non specific groups were separately analyzed. The results demonstrate that FactorXIIla+ dermal dendrocytes express iNOS, less than macrophages, but prominently in the granulomatous group, suggesting they play a role in the pathogenesis of American tegumentary leishmaniasis skin lesions as immune effectors and/or antigenpresenting cells.

Keywords: 1. Leishmaniasis, cutaneous; 2. Macrophages; 3. Nitric oxide synthase type II; 4. Dendritic cells; 5 . Immunohistochemistry. 
1. INTRODUÇÃO 
A leishmaniose é uma doença causada por diferentes espécies de Leishmania, resultando em formas distintas da doença (cutânea, mucocutânea e visceral).

Nos últimos 30 anos houve grandes avanços no conhecimento da patogênese da leishmaniose. A maioria das contribuições neste campo foca o papel da resposta imune do hospedeiro no sentido de proteção ou doença.

Antes de 1980 muito pouco era conhecido em pesquisa básica de leishmaniose. A constatação de que o interferon-gamma (IFN-y) produzido pelos linfócitos T CD4+ é o mecanismo mais potente de promoção de morte da Leishmania foi uma das observações mais relevantes para o entendimento da doença $(1,2)$. Sabe-se que a citotoxicidade mediada por células T também pode destruir células infectadas pelo parasita $(3,4)$, mas faltam estudos funcionais e dados correlacionando a citotoxicidade mediada por linfócitos T CD8+ e a expressão clínica da doença.

Nos últimos anos houve um interesse crescente sobre o papel da imunidade inata no controle da infecção por Leishmania, com estudos realizados em modelos experimentais. Entretanto, os estudos sobre imunidade inata na leishmaniose humana são escassos.

A pele, como interface entre o corpo e o meio ambiente, representa a primeira linha de defesa contra patógenos microbianos e insultos físicos e químicos. A imunovigilância de um órgão tão grande e tão exposto como a pele é um desafio ímpar para as células sentinelas e efetoras do sistema 
imune. Se a resposta imune é ineficiente, pode ocorrer o surgimento de infecções avassaladoras ou neoplasias, mas se a resposta imune é excessiva, pode promover o desenvolvimento de inflamação crônica e autoimunidade. O controle da amplitude da resposta imune é, portanto, um grande desafio na manutenção da integridade cutânea, que é essencial para a sobrevivência do hospedeiro. Mecanismos de defesa ativos e vias tolerogênicas são utilizados para alcançar a homeostase imunológica.

Apesar dos primeiros estudos sobre a imunidade em ambiente cutâneo terem abordado tipos celulares individuais da pele, foi o conceito visionário de tecido linfoide associado à pele (SALT - "skin-associated lymphoid tissue"), descrito por Streilein em 1983 (5), que levou à interpretação moderna dos investigadores interessados em imunologia cutânea. O conceito inicial do SALT introduziu a ideia de um circuito distinto de células em tráfego contínuo entre a pele, os linfonodos locais e a corrente sanguínea. Esse sistema determina a imunovigilância cutânea ideal. Apesar de a maior atenção ter sido direcionada às células de Langerhans (CL), tornou-se evidente que outros tipos de células dendríticas (CD) e células da imunidade inata presentes na derme também apresentavam papel essencial no SALT (6).

A heterogeneidade e complexidade das CD levaram à dificuldade de compreensão destas células. Entretanto, ferramentas novas têm sido desenvolvidas para aprimorar o seu estudo. Uma ideia emergente é a de que as CD residentes na derme seriam essenciais para o processo de 
ativação imune, enquanto as CL seriam mais importantes na sustentação da tolerância imunológica (7). As CD são as células que regem a resposta imune inata e adaptativa, sendo importantes na manutenção da homeostase cutânea. Estudos aprofundados das CD são essenciais devido ao seu potencial terapêutico, tanto para aumentar como para atenuar a inflamação nas doenças humanas.

$\mathrm{Na}$ leishmaniose tegumentar experimental e humana a $\mathrm{CL}$ é a $\mathrm{CD}$ melhor estudada. Entretanto, pareceu-nos interessante verificar o comportamento de outras CD nas lesões cutâneas da LTA. Dentre elas, em particular, as células dendríticas plasmocitoides, cujo papel em doenças inflamatórias, infecciosas e neoplásicas da pele vem sendo alvo de estudos recentes (8-21) e os dendrócitos dérmicos FXIIla+ (DD FXIIla+) que como os macrófagos, podem albergar formas amastigotas de Leishmania na pele (22).

As interações entre a Leishmania e as CD são complexas e envolvem funções paradoxais que podem estimular ou bloquear as respostas dos linfócitos T. Do balanço dessas interações resulta o controle ou a progressão da doença. Os mecanismos que permitem a sobrevivência ou o crescimento dos parasitas precisam ser melhor caracterizados, pois representam uma etapa crucial no desenvolvimento da base lógica das imunointervenções. $O$ melhor conhecimento dos mecanismos através dos quais são reguladas as funções das células do sistema imune, em particular das CD, e o 
crescimento do patógeno, poderá permitir o desenvolvimento de novas terapias para o controle do agente infeccioso. 
2. OBJETIVOS 
Com o objetivo de verificar o envolvimento de células dendríticas dérmicas na resposta tecidual cutânea da leishmaniose tegumentar americana, procuramos:

1) Demonstrar as células dendríticas plasmocitoides em biópsias de pele de doentes com leishmaniose tegumentar americana.

2) Quantificar e comparar as células dendríticas plasmocitoides na resposta tecidual granulomatosa e não específica das lesões cutâneas da leishmaniose tegumentar americana.

3) Verificar a participação dos dendrócitos dérmicos FXIIla+ e sua capacidade de expressão de iNOS.

4) Quantificar e comparar a população de dendrócitos dérmicos Fator XIIla+ que coexpressam iNOS, nas lesões cutâneas com reposta tecidual granulomatosa e não específica.

5) Comparar o número de dendrócitos dérmicos Fator XIIla+ que coexpressam iNOS com o de macrófagos que coexpressam iNOs nas lesões cutâneas da leishmaniose tegumentar americana. 
3. REVISÃO DA LITERATURA 


\subsection{Leishmania e LEISHMANIOSES}

A leishmaniose é uma doença causada por aproximadamente 21 espécies de protozoários do gênero Leishmania (ordem Kinetoplastida). É transmitida por 30 espécies de flebotomíneos (Phlebotomus no Velho Mundo e Lutzomyia no Novo Mundo), mas há também outros modos raros de transmissão, como as vias congênita e parenteral, por transfusão sanguínea, compartilhamento de agulhas ou acidentes em laboratórios $(23,24)$. Constitui problema de saúde pública em 88 países de quatro continentes (Américas, Europa, África e Ásia), sendo de notificação compulsória em apenas 32 deles, segundo a Organização Mundial de Saúde (OMS), com registro anual de 2 milhões de casos, que é um número subestimado, e assim seu impacto em saúde pública permanece negligenciado $(25,26)$.

A leishmaniose humana consiste de um espectro de doenças que varia desde uma forma simples autolimitada ou cutânea assintomática, passando pela forma mucocutânea desfigurante, até a forma visceral, que é fatal se não tratada. A infecção pode ser classificada em três síndromes clínicas: leishmaniose cutânea, leishmaniose mucocutânea e leishmaniose visceral. Pela diversidade de situações epidemiológicas, não há uma forma única de diagnóstico, tratamento e controle que se aplique a todas as formas da doença. 
Segundo dados da Organização Mundial de Saúde (OMS), do ano de 2000, a incidência anual estimada da forma visceral é de 500.000 em 61 países, sendo $90 \%$ destes casos restritos a cinco países - Índia, Bangladesh, Nepal, Sudão e Brasil (região Nordeste). Em relação à forma cutânea, 1 a 1,5 milhão de casos são relatados anualmente, e $90 \%$ dos casos são limitados a oito países, sendo seis no Velho Mundo (Afeganistão, Argélia, Irã, Iraque, Arábia Saudita e Síria), e dois no Novo Mundo (Brasil e Peru). Em contrapartida, $90 \%$ da forma mucocutânea ocorre na Bolívia, Brasil e Peru $(27,28)$. A partir do ano de 1993 , as regiões endêmicas para leishmaniose expandiram principalmente à custa de desenvolvimento econômico não planejado e alterações ambientais iatrogênicas, que resultaram em aumento da exposição humana ao flebotomíneo. Podem ser citados o estabelecimento de novos assentamentos, urbanização não planejada, desmatamento, extração de madeira, mineração, construção de represas, aumento de áreas de cultivo, novos esquemas de irrigação e migração excessiva de áreas rurais para urbanas. Mais recentemente, durante a guerra no Iraque foram vistos 522 casos de leishmaniose cutânea e cinco casos de leishmaniose visceral em indivíduos do exército americano. Também é importante citar o aumento da incidência de coinfecção HIVleishmaniose $(29,30)$. O aumento da interface entre a leishmaniose e os países mais desenvolvidos, e a ameaça de coinfecções, fizeram aumentar o interesse na doença, chamando a atenção para a necessidade de métodos rápidos para diagnóstico e identificação das espécies, terapias, profilaxia e 
medidas de controle que sejam eficazes, seguros, acessíveis e facilmente administráveis $(31,32)$.

A incidência da forma cutânea no Brasil aumentou progressivamente de 21.000 casos em 1998 para 30.550 casos em 1999 e mais de 35.000 casos em $2000(27,28)$. Quarenta por cento dos casos de leishmaniose tegumentar americana (LTA) no Brasil ocorre na região Norte, $31 \%$ na região Nordeste, $16 \%$ na região Centro-Oeste, $10 \%$ na região Sudeste e $3 \%$ na região Sul (33).

A leishmaniose cutânea é causada no Velho Mundo por L. tropica, $L$. major e L. aethiopica, sendo também implicados L. infantum e L. donovani; no Novo Mundo por espécies do complexo L. mexicana e subgênero Viannia, mas também L. major e L. chagasi. A doença mucocutânea é causada pelo subgênero Viannia, em geral L. (V) braziliensis, mas também L. (V) panamensis, L. (V) guayanensis e L. amazonensis. Os parasitos isolados de todos os casos são morfologicamente semelhantes, mas não idênticos entre si. O gênero Leishmania caracteriza-se por apresentar duas formas durante seu ciclo vital: amastigota (quando é parasito intracelular em tecidos de hospedeiros vertebrados) e promastigota (quando se desenvolve no tubo digestivo de hospedeiros invertebrados - flebotomíneos - bem como em meios de cultura) (34).

Subgênero Viannia - Complexo "Leishmania braziliensis": os parasitos intracelulares têm tamanho relativamente pequeno, em torno de 2$4 \mu \mathrm{m}$, e a distribuição é limitada à região neotropical. Não apresentam 
tropismo visceral. Os parasitos não costumam ser abundantes nas lesões e crescem pobremente em meios de cultura. A doença que determina constitui a leishmaniose tegumentar americana. Os membros do complexo são considerados, por alguns autores, como subespécies de Leishmania braziliensis e, por outros, como espécies independentes. São eles:

Leishmania (Viannia) braziliensis - apresenta ampla distribuição no Brasil, Venezuela, Guiana Francesa, América Central e áreas florestais dos Andes, caracterizando-se por formar úlceras cutâneas (raramente múltiplas), expansivas e persistentes, muitas vezes acompanhadas de lesões nasofaringeanas destrutivas e desfigurantes. A doença recebe o nome de leishmaniose mucocutânea, espúndia, úlcera de Bauru e ferida brava.

Leishmania (Viannia) guayanensis - ocorre na Venezuela, Guianas, Suriname e Brasil (na calha norte do Vale Amazônico). Os que a consideram uma subespécie dizem L. braziliensis guayanensis. Causa ulcerações simples ou, mais frequentemente, múltiplas, com lesões ao longo dos trajetos linfáticos.

Outras Leishmanias - Leishmania (Viannia) panamensis, Leishmania (Viannia) peruviana e outras espécies isoladas de animais silvestres, na região amazônica e países vizinhos, mas que nunca ou raramente infectam o homem, como L. lainsoni, L. shawi, L. naifi, L. colombiensis e $L$. equatoriensis. 
Subgênero Leishmania - Complexo "Leishmania mexicana": na forma amastigota, os parasitos são maiores e medem cerca de 3-6 $\mu \mathrm{m}$ de comprimento. As lesões localizam-se na pele e são benignas. Ocorre na região neotropical e planície litorânea do Golfo do México, e vários tipos integram este complexo: Leishmania (Leishmania) mexicana, Leishmania (Leishmania) pifanoi, Leishmania (Leishmania) amazonensis (encontrada nas regiões Nordeste, Centro-Oeste e Sudeste do Brasil, raramente atinge o homem), Leishmania (Leishmania) venezuelensis, Leishmania (Leishmania) garnhami (34).

Diante da prevalência elevada, expansão nas áreas tradicionalmente endêmicas, ressurgimento em áreas novas, dificuldade na intervenção do ciclo no ambiente onde ocorre a transmissão, resistência dos insetos a inseticidas e a repercussão socioeconômica, as leishmanioses são um grande problema de saúde pública no mundo e no Brasil. Desta forma, é considerada pela OMS entre as seis endemias prioritárias para investimento em pesquisa. Dentre as áreas de pesquisa, a imunopatologia é uma área abrangente, abordando desde questões relacionadas à suscetibilidade ou resistência à infecção, até mecanismos que determinam as alterações da resposta imune e aqueles que determinam lesão tecidual na evolução das leishmanioses (35). 


\subsection{CÉLULAS DENDRÍTICAS CUTÂNEAS}

A resposta imune frente aos agentes infecciosos apresenta particularidades de acordo com o órgão alvo e a pele tem um sistema integrado e especializado para interagir frente aos agentes infecciosos. Os patógenos penetram através da pele e sua presença é notada pelas células imunes inatas. A inflamação induzida pela infecção induz o rápido recrutamento de neutrófilos e monócitos, e de uma densa rede de células dendríticas (CD) presentes habitualmente na pele, que tem uma importante função na indução de tolerância periférica, na mediação do reconhecimento inicial da infecção e na indução da imunidade protetora (36).

O termo "célula dendrítica" surgiu em 1973 quando as CD no linfonodo foram descobertas por Ralph Steinman e Zanvil Cohn (37), ganhadores do prêmio Nobel de Medicina no ano de 2011. Foram necessários vários anos para os cientistas entenderem o significado e papéis potenciais destas células, e agora sabemos da sua função central na geração e regulação das respostas imunes.

Esta população heterogênea é definida inicialmente pela sua aparência, mas também mais especificamente pela sua potente habilidade de apresentar antígenos às células T. A caracterização das populações de CD cutâneas em humanos é complicada pelo pleomorfismo de fenótipos e funções, pelo grande número de antígenos intracelulares e de superfície 
presentes nestas células e pelas diferenças entre as redes de CD murinas e humanas. As populações de CD têm sido historicamente classificadas pela sua distribuição espacial (circulantes, linfonodais, epidérmicas ou dérmicas), pela sua origem presumida (mieloides, plasmocitoides), pelo estado fisio/patofisiológico (steady-state, inflamatórias) ou pela expressão antigênica (langerina, CD205, CD123, etc...) (7).

Portanto, as CD são um grupo heterogêneo de leucócitos apresentadores de antígeno que são importantes tanto na imunidade inata quanto na adaptativa. As CD são globalmente definidas pela sua potente capacidade de apresentação antigênica e ativação de células $T$ naive. $A$ pele no seu estado habitual exibe três principais populações de CD: as células de Langerhans (CL) epidérmicas, as CD dérmicas mieloides e as CD dérmicas plasmocitoides (CDP) (7). Durante a inflamação foi identificado um quarto tipo, as CD dérmicas mieloides inflamatórias, que seriam um alvo potencial para o desenvolvimento de novas terapias que aumentem ou diminuam a resposta inflamatória nas doenças humanas (38). 


\subsection{CÉLULAS DE LANGERHANS}

As CL foram descritas por Paul Langerhans, em 1868 (39). Elas estão localizadas nas camadas suprabasais da epiderme, entre os queratinócitos, e exibem aspecto estrelado, que levaram os pesquisadores a acreditarem que elas possuíam origem neural até 100 anos depois, quando o seu papel na apresentação de antígenos foi elucidado (40). Também estão presentes na derme, em torno dos vasos do plexo superficial. Foram identificadas pela presença de uma organela elétron-densa, o grânulo de Birbeck, que tem aspecto de "raquete de tênis". A sua função não é clara ainda, mas inclui endocitose mediada por receptores e transporte de materiais celulares ao espaço extracelular (41)

CD1a foi o primeiro anticorpo monoclonal que identificou as $\mathrm{CL}$, sendo uma molécula MHC-I "like" que apresenta lípides microbianos às células $T(42,43)$. Mais recentemente, $\mathrm{o}$ anticorpo monoclonal antilangerina/CD207 foi utilizado para reconhecer especificamente as $C L$, sendo o antígeno uma lectina membranosa tipo C que reconhece ligantes manosilados encontrados na superfície de uma gama de patógenos, incluindo vírus, bactérias, fungos e protozoários (44).

São células derivadas de precursores CD34+ da medula óssea (45, 46), exibem atividade ATPase positiva e expressão de proteína S-100 citoplasmática e nuclear, o que as distingue de outras células do sistema 
reticuloendotelial. Têm a capacidade de induzir a proliferação primária de linfócitos T em resposta a estímulo antigênico.

Estudos recentes esclareceram a origem e o tráfego de CL no estado de equilíbrio e durante a inflamação, sendo agora evidente que as CL epidérmicas são continuamente substituídas por células residentes precursoras durante toda a vida, nas situações estáveis (47). No entanto, na inflamação, as CL são repovoadas por células precursoras da corrente sanguínea, provavelmente monócitos (48).

O interesse nas CL aumentou após três observações: primeiro, foi descoberta uma população de CL langerina+ na derme e nos linfonodos que drenam a pele (49-51). Estas populações de CL dérmica e epidérmica têm capacidades fenotípicas e mitóticas distintas, e as CL langerina+ dérmicas não parecem ser simplesmente $\mathrm{CL}$ epidérmicas em trânsito para os linfonodos (52-54). Segundo, há muita controvérsia em relação ao papel fisiopatológico das CL. Até recentemente, admitia-se que os antígenos cutâneos eram processados localmente pelas CL epidérmicas, que então migravam para os linfonodos, onde haveria uma apresentação de antígenos eficiente às células $\mathrm{T}$. Neste trajeto até o linfonodo, as CL alteram seu fenótipo de superfície e "maturam", fazendo uma regulação de "feedback" negativo do processamento de antígenos e adquirindo maior habilidade para coestimulação de células $\mathrm{T}$ (55). Estudos recentes questionaram o significado biológico desta via, já que a ativação de células T antígenoespecíficas permanece intacta em modelos que se utilizam de murinos 
deficientes em CL $(56,57)$. Entretanto, resultados inconsistentes foram obtidos nestes estudos, devido a múltiplos fatores. Até hoje, não há nenhum modelo que evidencie um papel redundante das $C L$ na indução de imunidade e que tenha utilizado um patógeno estritamente epidermotrópico, como o papilomavírus, por exemplo. E em terceiro lugar, um outro grupo publicou recentemente sobre um novo papel para estas células, descrevendo como CL que expressam ligantes para células T citotóxicas promoveram carcinogênese murina inesperadamente (58).

Estas novas observações sugerem que há uma migração de CL aos linfonodos nas situações de equilíbrio, talvez para induzir e manter tolerância aos antígenos cutâneos (59). Uma hipótese emergente questiona se as CD que residem na derme são essenciais para o processo de ativação imune cutânea, enquanto as CL seriam mais importantes na sustentação da tolerância imunológica cutânea (7). 


\subsection{CÉLULAS DENDRÍTICAS DÉRMICAS}

Os chamados dendrócitos dérmicos (DD) (60), que também são participantes do sistema imune da pele, têm função de apresentação antigênica $(61,62)$. Não há um marcador único ou específico para estas células, embora a integrina CD11c seja provavelmente a melhor ferramenta atualmente disponível para a sua identificação (7). Vários grupos de pesquisa tentaram identificar em humanos moléculas de superfície que possam ser utilizadas para distinguir os vários subgrupos de CD dérmicas (63-65). A molécula CD1c (também conhecida como BDCA-1) é um marcador útil para as $\mathrm{CD}$ dérmicas mieloides $(6,63,66)$.

Por muitos anos, anticorpos contra o fator de coagulação XIIla, a transglutaminase A, fator estabilizador da fibrina (FXIIla), foram utilizados para identificar uma população dérmica de células que exibem corpo celular estrelado com protrusão de múltiplos processos dendríticos, e por isso o termo dendrócito dérmico foi proposto por Headington em 1986 (60). Exibem perfil imunofenotípico que sugere função de APC (célula apresentadora de antígenos), entretanto, constituem população celular distinta das CL. Os dendrócitos dérmicos Fator XIIla positivos (DD FXIIla+) estão presentes na pele humana normal e foram descritos aumentados em número em processos inflamatórios e infecciosos da pele (22, 67-72). Recentemente, foi demonstrado que o FXIlla é induzido em cultura e seria portanto um marcador macrofágico, e não um marcador específico das $\operatorname{CD}(63,73)$, no 
entanto mais estudos seriam necessários para reavaliar a classificação das células dérmicas apresentadoras de antígenos como FXIIla+ (7). O FXIIla pode ser detectado em material tecidual fixado em formalina e incluído em parafina (74).

Na pele humana normal os DD assemelham-se morfologicamente aos fibroblastos quando examinados ao microscópio óptico. Na derme papilar mostram corpos celulares volumosos e longos prolongamentos citoplasmáticos dendríticos e, na derme reticular, são mais delgados e seus dendritos mais curtos. Apresentam-se junto à derme adventicial que envolve os anexos cutâneos e também são observados nos espaços peri e endoneural, e nos septos conjuntivos interlobulares da hipoderme (75). Apresentam ao microscópio eletrônico mais de dois prolongamentos citoplasmáticos que se estendem na matriz dérmica. Exibem vesículas de pinocitose e placas adensadas nas membranas plasmáticas. Cerca de 20 a $40 \%$ dos DD são perivasculares e estão em íntima associação com mastócitos (76).

Os DD apresentam atividades lisozima, alfa-1 antitripsina e fosfatase ácida positivas. As atividades ATPase, alfa-naftil butirato esterase e alfa-1 antiquimotripsina são moderadas, e a atividade fosfatase alcalina, ausente (60).

Exibem também marcadores de superfície que sugerem sua origem na medula óssea, função monocitária/macrofágica e de células apresentadoras de antígeno. São HLA-DR+; CD36/OKM5+; LFA-1+; HLA- 
DQ+; CD14+. Por outro lado, não exibem positividade para a proteína S-100, são CD1a, CD15, CD2, Fator VIII e CD34 negativos. São também negativos para o antígeno MAC387. Não expressam antígenos comuns aos fibroblastos. O IFN-y induz a expressão de ICAM-1 (molécula de adesão intercelular 1) pelos DD, o que facilitaria sua adesão aos linfócitos T. São também produtores de fator de necrose tumoral - alfa (TNFa) (67).

Os DD FXIIla+ constituem uma porcentagem considerável das células dérmicas. Entretanto, o seu papel na pele normal não é ainda conhecido. São células com propriedades fagocíticas (fagocitam carbono, melanina e hemossiderina). Representam a população de "macrófagos" residentes da pele. A sua origem na medula óssea e perfil imunofenotípico apontam para uma função de APC. Teriam talvez uma função imunológica complementar à das APC epidérmicas (67). Especula-se se não poderiam representar as células precursoras das CL na derme $(61,62)$. Diferem, entretanto, das CL por serem CD1a e proteína S-100 negativas e por não exibirem grânulos de Birbeck no seu citoplasma (77). Representam uma reserva tissular de fator XIIla que é importante nos processos de cicatrização (75) e atuariam em associação com os mastócitos nos processos de remodelamento da matriz extracelular (76).

Na psoríase, os DD FXIIla+ estão aumentados em número na derme papilar e exibem expressão aumentada de HLA-DR (receptor da superfície celular do complexo principal de histocompatibilidade classe II, codificado pelo complexo de antígenos leucocitários humanos) e de ICAM-1 na sua 
superfície (67). Seriam as principais células acessórias na fase de indução da hipersensibilidade de contato ao dinitroclorobenzeno (78). Mostram-se numerosas e hipertrofiadas em doenças cutâneas relacionadas aos processos imunológicos de perfil Th1 $(68,69)$. O seu provável papel como APC é embasado por trabalhos experimentais $(6,67)$.

As CD dérmicas ativadas participam da resposta inflamatória (79) secretando citocinas e quimiocinas, criando uma rede de citocinas que por vezes é benéfica e contribui para a erradicação de um agente infeccioso, mas em outras situações pode ser a causa de uma resposta tecidual patológica com inflamação persistente. As CD dérmicas que produzem fator de necrose tumoral (TNF) e a forma induzida por citocinas da enzima óxido nítrico sintase (iNOS) são conhecidas como CD inflamatórias (CDI) ou PTI (produtoras de TNF e iNOS) $(80,81)$. Foi proposto que este tipo celular teria um papel importante na psoríase (81). 


\subsection{CÉLULAS DENDRÍTICAS PLASMOCITOIDES}

Lennert e Remmele (apud Jahnsen et al.) (82) identificaram, na zona paracortical de linfonodos reativos, um tipo celular de morfologia plasmocitoide.

A célula dendrítica plasmocitoide (CDP), ao exame de cortes histológicos corados pela hematoxilina-eosina, tem morfologia semelhante ao plasmócito produtor de imunoglobulinas e pode ser identificada, no sangue e nos tecidos, por expressar o receptor de interleucina 3 (IL-3) CD123, CD45RO (antígeno leucocitário comum), CD68 e HLA-DR, mas não exibe marcadores mieloides como o CD11c. Essas células teriam origem em linfócitos T (83), tendo sido designadas como "plasmócitos associados a células T" em 1973, pela sua localização em áreas ricas em células T nos linfonodos e pela presença de retículo endoplasmático rugoso bem desenvolvido (84). Após 10 anos, por serem positivas para CD4, foram renomeadas como "células $\mathrm{T}$ plasmocitoides" e consideradas como a contrapartida de células $T$ aos plasmócitos $B$, secretando citocinas ao invés de imunoglobulinas (85). No entanto, como CD4 também é um marcador de células mielomonocíticas, a demonstração da expressão de marcadores mielomonocíticos como CD15 e CD68, com ausência de outros marcadores 
de células T, levaram à denominação de "monócito plasmocitoide" em 1988 (86).

A caracterização funcional destas células tornou-se possível no final da década de 90. Após estimulação com o ligante CD40 e IL-3, ou uma variedade de estímulos microbianos em cultura, as células plasmocitoides desenvolvem longos dendritos e assumem uma morfologia típica de célula dendrítica madura e, funcionalmente, são capazes de estimular células T naive, tanto $\mathrm{CD} 4+$ como $\operatorname{CD} 8+(87,88)$. Sendo assim, foi então introduzido o termo "célula dendrítica plasmocitoide", apesar dos termos "plasmocitoide" e “dendrítica" indicarem estados discrepantes.

As células plasmocitoides CD4+CD11c- produzem grandes quantidades de interferon I (IFN-I), mas quando diferenciadas em células dendríticas em cultura, perdem esta capacidade $(89,90)$. As células no estado "plasmocitoide" expressam baixos níveis de MHC classe II, e no estado "dendrítico" expressam altos níveis de MHC classes I e II, além de uma variedade de moléculas coestimulantes de células $T$, como CD80 e CD86 (87, 91, 92). Para contemplar estes dois estados morfológicos e funcionais distintos descritos em cultura, surgiu uma nomenclatura alternativa que utiliza os termos "célula plasmocitoide pré-dendrítica", que designa a célula produtora de IFN-I, e "célula dendrítica derivada de célula plasmocitoide pré-dendrítica”, que designa o estado “dendrítico" (93).

Em resposta a uma variedade de vírus ou receptor "toll-like" 9 (TLR9) e agonistas de TLR7, as CDP secretam rapidamente grandes quantidades 
de IFNa e, em menor quantidade, outras citocinas, incluindo IL-6, IL-8 e TNFa (94). Através de mecanismos dependentes ou não de IFN, as CDP estão envolvidas no recrutamento de células "natural killer" (NK) e células T ativadas, ativação de células NK e macrófagos, diferenciação de células T CD4+ naive em células efetoras que secretam IFN-y e IL-10, desenvolvimento de células $\mathrm{T}$ secretoras de IL-4 e diferenciação de plasmócitos. $(91,95-98)$

Desse modo, as CDP, aparentemente, podem ter funções múltiplas na imunidade inata e adaptativa, e seriam capazes de integrar esses dois braços do sistema imune. Dados mais recentes sugerem que as CDP podem ter funções tolerogênicas, particularmente induzindo células $T$ regulatórias CD4+CD25+. $(99,100)$

Pela eficiente produção de IFN-I, as CDP têm importante papel imunomodulatório, mas o seu papel na apresentação de antígenos tem sido debatido (101). Apesar da morfologia e marcadores dendríticos adquiridos descritos em cultura, a morfologia das CDP em cortes histológicos de linfonodos é semelhante à observada na medula óssea e sangue periférico (102). No entanto, estudos recentes sugerem que em camundongos as CDP podem funcionar como APC (103), e um modelo de doença enxerto-versushospedeiro utilizando camundongos sem MHC demonstrou indiretamente apresentação de antígenos "in vivo" por CDP na ausência de outras células dendríticas (104). 
As CDP correspondem a 0,01\%-0,05\% das células mononucleares do sangue periférico e se acumulam nos sítios inflamatórios onde contribuem para a resposta inflamatória (90). Em resposta a sinais quimiotáticos, as CDP são recrutadas aos tecidos, onde se apresentam como células isoladas, pequenos agrupamentos ou agregados (105). A CDP apresenta tamanho intermediário entre um pequeno linfócito e um monócito, com núcleo redondo a ovalado, levemente excêntrico, com cromatina finamente dispersa ou reticulada, nucléolo inconspícuo e citoplasma moderado, eosinofílico à coloração de hematoxilina-eosina (HE). As CDP são mais facilmente identificadas com estudo imuno-histoquímico, particularmente com anticorpos anti-CD123 (cadeia a do receptor de IL-3) $(97,106,107)$, anti-CD68 (86), anti-TCL1 (leucemia/linfoma de células T 1) (108), anti-LCA (antígeno leucocitário comum) (109), anti-CD2AP (102) e anti-BDCA-2 (antígeno de células dendríticas sanguíneas)/CD303 (110). A expressão de LCA, que adere à E-selectina nas células endoteliais da derme, pode aumentar o recrutamento de CDP na pele em algumas condições inflamatórias (8). As CDP não expressam marcadores de células B (CD19, CD20, PAX5), de células T (CD3, TCR) e de células NK (CD16, CD94), porém expressam CD56 e alguns marcadores de células T (CD2, CD5 e CD7) (111-113). Elas também não exibem marcadores mieloides ou monocíticos, como mieloperoxidase, lisozima e CD14. CD11c, CD13 e CD33 são negativos nas CDP circulantes, mas podem ser expressos na diferenciação "in vitro" (88). As CDP são negativas para marcadores de células progenitoras como CD34, CD117 e TdT. Não expressam perforina, 
mas podem expressar granzima B $(112,114)$, e sua função nas CDP não está completamente elucidada, mas pode estar relacionada à imunossupressão de células $T$ regulatórias $C D 4+C D 25+$ no contexto de tolerância periférica (115).

As CDP foram raramente (116) demonstradas na pele humana normal. Podem ser encontradas nos tecidos linfoides reativos das tonsilas palatinas, gânglios linfoides e na mucosa de vias aéreas superiores (117). Foram evidenciadas em processos inflamatórios cutâneos, com perfil de citocinas de padrão Th1, como o lúpus eritematoso, dermatite de contato alérgica, psoríase e líquen plano (8-11). Neste, foi atribuído papel patogenético ao herpesvírus humano 7 , e as CDP parecem albergar proteínas e DNA deste vírus nas lesões de líquen plano (118).

As CDP estão presentes em processos virais com envolvimento cutâneo como a varicela (12) e podem ser parasitadas pelo vírus da imunodeficiência adquirida (13). As CDP podem suprimir a replicação do HIV-1, e a fusão do HIV com as CDP parece induzir apoptose e necrose (14, 15).

Os estudos sobre a patogenia de processos virais demonstram que o estímulo que induz as CDP a produzirem IFNa é mediado via TLR7 e 9 (12). TLRs são receptores de reconhecimento de padrões microbianos altamente conservados entre as espécies, desde a Drosophila até humanos, e padrões distintos de expressão de TLR ocorrem em diferentes grupos de CD. Estes receptores reconhecem vários padrões moleculares associados a patógenos 
(PAMPs), e seu estímulo leva à ativação de NF-kB (fator nuclear de transcrição kappa B), que promove no núcleo a transcrição de citocinas próinflamatórias (119). Nas CDP, a ocupação de TLR7 e 9 resulta em abundante secreção de IFN-I (120).

Nos mecanismos patogenéticos das infecções por protozoários, o TLR9 é importante para induzir citocinas pró-inflamatórias (121). Em estudos experimentais, observou-se que a vacinação com DNA de Salmonella enterica serovar Typhimurium, que induz resposta Th1, aumentou a proteção contra Leishmania major de camundongos infectados. Nesse mecanismo estaria envolvido TLR9 de CDP (122). Também foi demonstrada a expressão de TLR9 em granulomas de lesões de leishmaniose cutânea (123).

Além do papel na imunidade antimicrobiana, as CDP infiltram uma variedade de neoplasias e podem estar envolvidas com a imunidade antitumoral. Em melanomas há evidências que sugerem que as CDP elicitam respostas de células T citotóxicas tumor-específicas $(16,17)$. O uso de agonista sintético de TLR9, resultando na ativação de CDP, é uma esperança no tratamento de pacientes com melanoma metastático (124). Aumento das CDP também foi descrito em carcinomas espinocelulares, carcinomas basocelulares, linfoma cutâneo de células $T$, carcinoma de mama e carcinoma ovariano $(18-20,125)$. O uso de imiquimod, um agonista sintético de TLR7, no tratamento tópico de carcinoma basocelular, melanoma "in situ" e condiloma acuminado, parece ter correlação com o 
recrutamento de CDP e aumento da atividade do ligante indutor de apoptose associado a TNF (TRAIL), resultando na morte de células tumorais (19, 21, 126). Estes achados sugerem que as CDP podem ser exploradas para maximizar a resposta imune antitumoral, utilizando agonistas de TLR7 e 9 para desenvolver estas estratégias terapêuticas. No entanto, há também evidências sugerindo que as CDP estariam envolvidas em funções tolerogênicas, com potente supressão das respostas de células T antitumorais, presumidamente pela ativação de células T regulatórias (127, 128). Com o estímulo do TLR9, as CDP expressam grandes quantidades de indoleamina 2,3-dioxigenase (IDO), que tem papel essencial na geração de células T regulatórias (129). 


\subsection{A INTERAÇÃO Leishmania-HOSPEDEIRO}

A pele é a porta de entrada para a Leishmania no hospedeiro mamífero, onde se alberga e se replica nos macrófagos e CL sob a forma amastigota, sendo um parasita intracelular obrigatório. Ambas as células expressam o receptor do complemento CR3 que se liga ao parasita quando, então, é incorporado por endocitose $(130,131)$.

As alterações patológicas que caracterizam as diferentes formas de manifestação da doença são o reflexo da balança entre a multiplicação dos parasitas, a resposta imune do hospedeiro e as alterações degenerativas e lesivas teciduais resultantes (132). O sucesso da infecção depende da sobrevivência às atividades microbicidas do macrófago e da prevenção da ativação de uma resposta imune efetiva. A Leishmania desenvolveu numerosas estratégias para manipular várias funções macrofágicas, incluindo a apresentação de antígenos, geração de óxido nítrico e radicais de oxigênio, e produção de citocinas. A interação das moléculas de superfície da Leishmania, particularmente gp63 e LPG, com os receptores de superfície do macrófago, causam a distorção das cascatas sinalizadoras intracelulares específicas (133).

Após entrar no hospedeiro mamífero durante o repasto sanguíneo do flebotomíneo fêmea, as promastigotas precisam primeiro escapar da lise 
mediada pelo complemento, até serem engolfadas pelos macrófagos, sendo internalizadas para o ambiente relativamente benigno do fagossomo, onde começam a se diferenciar em amastigotas. Uma das táticas de sobrevivência é a inibição de enzimas hidrolíticas e de outras moléculas destrutivas que são secretadas no fagolisossomo. O reconhecimento de patógenos pelos fagócitos depende em grande parte de TLR. As primeiras evidências surgiram quando camundongos desprovidos de TLR4 demonstraram incapacidade de controlar a infecção cutânea por L. major $(134,135)$. No entanto, poucos estudos abordaram o significado das interações entre a Leishmania e os TLR na superfície do macrófago. Macrófagos desprovidos de TLR4, bem como os do tipo "selvagem", são capazes de erradicar $L$. major na presença de IFN-Y, porém a eficiência é menor na presença de IL-4 (136). Este fato estaria associado à indução aumentada de arginase e indução diminuída de iNOS, sugerindo que o TLR4 protegeria contra a infecção através da promoção de produção de óxido nítrico (NO) pelo macrófago infectado.

Também o papel do TLR9 tem sido estudado nas leishmanioses. Este receptor reconhece fragmentos de DNA, e não lípides antigênicos, como o TLR4. Já foi demonstrada a importância do TLR9 na manutenção dos granulomas da tuberculose e de doenças pulmonares crônicas granulomatosas, e também nos granulomas da LTA (123).

A relação parasita-hospedeiro na leishmaniose cutânea pode ser melhor compreendida através de modelos experimentais em camundongos 
de linhagens resistentes $(\mathrm{C} 57 \mathrm{BI} / 6 \mathrm{j})$ e suscetíveis $(\mathrm{BALB} / \mathrm{c})$ à Leishmania. $A$ resolução da infecção depende da eficiência da resposta imune do hospedeiro. A imunidade mediada por células é importante para esse controle. Tanto a resistência como a suscetibilidade ao parasita são mediadas pelos linfócitos T CD4+ e dependem do perfil de citocinas por eles produzidas. A secreção de interferon-gamma (IFN-ү) pelos linfócitos T CD4+ Th1 promove a proteção à doença, enquanto que a de interleucinas 4 (IL-4) e 10 (IL-10) produzidas pelas células CD4+ Th2 facilitam a disseminação do parasita. $\quad \mathrm{O}$ IFN-ץ media a eliminação dos parasitas por estimular os macrófagos. A IL-4, IL-10 e o fator transformador de crescimento beta (TGFß) são citocinas inibidoras da ação macrofágica (137).

Sendo assim, outra estratégia de sobrevivência utilizada pela Leishmania é prevenir a ativação de uma resposta imune efetiva através da inibição da produção de várias citocinas, particularmente daquelas envolvidas na resposta inflamatória (IL-1 e TNFa) ou na ativação de linfócitos (IL-12) (138). A IL-12 possui papel crítico na regulação da resposta imune celular, sendo essencial para a ativação do linfócito $T$ e subsequente secreção de IFN- $\gamma$, levando à ativação do macrófago e produção de moléculas microbicidas (139).

A capacidade da Leishmania de infectar macrófagos sem induzir citocinas pró-inflamatórias, e depois inibir sua indução em resposta a vários agonistas provavelmente representa o mecanismo de sobrevivência pelo qual os parasitas impedem uma reação inflamatória prejudicial (140). 
Além da inibição das funções dos macrófagos, os parasitas são capazes de induzir a produção e secreção de várias moléculas sinalizadoras imunossupressoras, como os metabólitos do ácido araquidônico e as citocinas TGFß e IL-10. Esta é outra citocina anti-inflamatória produzida por macrófagos infectados, e sua produção pode ser responsável pela supressão da atividade microbicida macrofágica que envolve a produção de NO e várias citocinas (IL-1, IL-12 e TNFa (141).

O parasitismo de CL foi descrito na leishmaniose cutânea experimental $(142,143)$. CL parasitadas foram observadas na derme dos modelos murinos e no homem (144). Desse modo, na leishmaniose tegumentar, parecem ter a função especializada de fagocitose e processamento de antígenos parasitários. A carga parasitária das CL, entretanto, é bem menor que a de macrófagos. A sua função principal é como APC. Foi demonstrado que a ocupação de cerca de 100 a 300 moléculas MHC-II pelos peptídeos antigênicos é suficiente para estimular os linfócitos T. Além disso, as CL estimulam os linfócitos T a produzir citocinas de modo mais eficaz do que o fazem os macrófagos. As APC podem influenciar o desenvolvimento de subtipos de linfócitos Th. Na leishmaniose experimental foi observado que as CL são capazes de estimular tanto linfócitos T produtores de IFN-y como aqueles produtores de IL-4, ou seja, linfócitos Th1 e Th2. Estudos "in vitro" demonstraram que células dendríticas infectadas por Leishmania produzem IL-12 que é crítica para o desenvolvimento de resposta imune protetora de tipo Th1 (145). 
Após a cura, parasitas podem persistir nos linfonodos, em células dendríticas e em macrófagos. As CL iniciam a resposta primária aos linfócitos $T$ na pele e as células dendríticas de linfonodos mantêm a imunidade, após a recuperação da doença $(146,147)$.

$\mathrm{Na}$ leishmaniose tegumentar americana o macrófago (CD68+) é a célula alvo principal. A atividade leishmanicida dos macrófagos é resultado de sua capacidade de produzir derivados tóxicos do oxigênio e $\mathrm{NO}$ em resposta ao IFN-y. O NO é crítico para o "clearance" do parasita, já que camundongos desprovidos de iNOS são incapazes de controlar a infecção, e macrófagos destes camundongos são incapazes de eliminar promastigotas em cultura (148). A inibição da produção de NO pode resultar da produção de IL-10 e/ou TGFß (133).

Os parasitas induzem o macrófago a produzir TNFa, o que potencializa a ação do IFN-ץ e, desse modo, ocorre um aumento de sua ativação $(149,150)$. A produção de NO se faz a partir de L-arginina pela ação da iNOS. Esse é um mecanismo chave de defesa dos fagócitos dos mamíferos. A iNOS está aumentada nas lesões de leishmaniose cutânea localizada com pequeno número de parasitas, entretanto, na forma cutânea disseminada poucas células expressam a iNOS. As células iNOS positivas nos sítios de lesão são os macrófagos (151). Vieira et al. observaram igual número de células iNOS positivas nas formas localizada e disseminada da LTA (152). 
Quanto à capacidade de produção de iNOS por células dendríticas há controvérsias na literatura. Blank et al. (153) demonstraram que na leishmaniose experimental as CL epidérmicas não expressam iNOS. Segundo os autores, os mecanismos para impedir a multiplicação dos parasitas nas CL seriam independentes de NO, assim como da ação de NO exógeno. Haveria mecanismos relacionados com a produção de metabólitos reativos do oxigênio, $\mathrm{pH}$ dos fagolisossomos não adequado para a multiplicação dos parasitas e a fatores nutricionais dependentes de ferro e depleção de triptofano. Por outro lado, Qureshi et al. (154) demonstraram a produção de iNOS por células dendríticas e CL, isoladas da pele através de técnica molecular de reação em cadeia da polimerase. Em condições experimentais foi verificado que LPS (lipopolissacarídeo), TNFa e GM-CSF induzem aumento de expressão de iNOS em células dendríticas obtidas da pele de feto (155).

$\mathrm{Na}$ leishmaniose os parasitas induzem o macrófago a produzir TNFa que potencializa a ação do IFN-y na sua ativação (149). Lembramos que os DD FXIlla+ também, sob determinados estímulos, que no caso da LTA poderiam ser os parasitas, têm a capacidade de produção de TNFa (156, 157).

O papel dos DD FXIIla+ nas doenças infecciosas cutâneas tem sido pouco estudado. Foi demonstrado que na paracoccidioidomicose os DD FXIlla+ mostram-se aumentados em número, participam da resposta granulomatosa cutânea e incorporam células fúngicas. Desse modo, 
poderiam atuar tanto como células alvo e/ou como prováveis APC nesta doença (70). Além disso, estão aumentadas em número na resposta tecidual cutânea de tipo misto (ou seja, com granulomas epitelióides organizados e pouco organizados na mesma lesão) que também exibe número de $\mathrm{CL}$ epidérmicas conservadas em relação à pele controle normal (71). $\mathrm{Na}$ resposta tecidual cutânea da cromoblastomicose e da leishmaniose tegumentar americana essa população celular está aumentada em número e também exibe material antigênico fúngico e do protozoário no seu citoplasma $(22,72)$.

Enquanto a infecção por promastigotas pode induzir CD dérmicas e mieloides à maturação, estas células ativadas produzem citocinas próinflamatórias apenas transitoriamente e em pequenas quantidades. Estudos "in vitro" sugeriram que CD infectadas por promastigotas retêm a responsividade a estímulos exógenos, produzindo quantidades significativas de IL-1, TNFa, IL-12p70 e IL-10, na dependência da natureza e combinação de estímulos. A infecção por amastigotas, no entanto, frequentemente falha em induzir a ativação de $C D$, presumivelmente pela falta geral de LPG e pelo efeito direto das proteinases e oligopeptidases das amastigotas nas vias de sinalização intracelular do hospedeiro. Há cada vez maior conscientização da diferença de responsividade das CD aos parasitas dependendo da espécie envolvida, e também há importantes diferenças nos papéis biológicos desempenhados pelos diferentes subtipos de CD. A base molecular destas diferenças permanece enigmática, apesar dos estudos envolvendo CD já terem proporcionado informações valorosas (158). 
O envolvimento das CDP na leishmaniose é pouco conhecido. $\mathrm{Na}$ literatura indexada encontramos apenas três trabalhos, dois deles em modelos murinos com infecção por Leishmania major (159, 160); o primeiro aborda essa população celular nos modelos de maior e menor suscetibilidade à doença, e demonstrou que tanto as CD de origem mielóide como as CDP podem ser infectadas pela Leishmania, também sugerindo que as CDP poderiam afetar a qualidade da resposta imune na leishmaniose experimental, por controlar o balanço entre as respostas Th1 e Th2. O segundo trabalho mostra que a vacinação com CDP induz proteção contra a infecção por Leishmania major em camundongos. Um terceiro trabalho sobre a resposta imune inata contra Leishmania (161) demonstrou que, "in vitro", as CDP secretavam grande quantidade de IFN-I após exposição a $L$. major, L. braziliensis ou L. infantum, sem endocitose do parasito, e concluíram que as CDP são uma fonte mais potente de IFN-I que macrófagos e CD mieloides, e que a secreção de IFN-I pela CDP depende de sinalização do TLR-9, no entanto a verdadeira contribuição das CDP e sua secreção de IFN-I dependente de TLR-9 "in vivo" necessitaria de investigação mais aprofundada.

Em suma, as células dendríticas pertencem à família de células apresentadoras de antígeno (APC), que se localizam nos sítios de entrada de antígenos estranhos ao corpo humano. Essas células estão relacionadas à função de imunovigilância, e podem desempenhar esta função imunológica por serem células com motilidade e exibirem em sua superfície moléculas do complexo principal de histocompatibilidade (MHC-II). As 
células dendríticas presentes na pele humana normal compreendem as células de Langerhans $(C L)$ e os dendrócitos dérmicos (fator XIIla+ e CD34+). As células dendríticas melhor estudadas na leishmaniose tegumentar são as CL. Estas células têm sido exaustivamente estudadas na leishmaniose cutânea experimental e humana (146, 147, 162, 163).

A resposta tecidual da LTA caracteriza-se por resposta inflamatória crônica não específica, ou com formação de granulomas, com expressiva plasmocitose tecidual (164). Indagamos se muitas das células plasmocitoides observadas no processo inflamatório frente ao parasita, não seriam CDP.

Trabalhos de pesquisa com enfoque na atuação da população de dendrócitos dérmicos nos processos infecciosos cutâneos são escassos. $\mathrm{Na}$ tentativa de preencher essa lacuna e contribuir para o melhor entendimento da reatividade dessas células, o nosso grupo tem desenvolvido projetos para demonstrar o papel dessa população nos mecanismos patogenéticos de doenças infecciosas cutâneas $(22,70-72)$. O presente estudo faz parte da linha de pesquisa sobre a caracterização da resposta tecidual cutânea em processos infecciosos. 
4. MÉTODOS 


\subsection{CASUÍSTICA}

Foram selecionados do arquivo do Laboratório de Dermatopatologia da Divisão de Clínica Dermatológica do Hospital das Clínicas da Faculdade de Medicina da Universidade de São Paulo, espécimes de pele de lesões cutâneas de 52 doentes com diagnóstico de leishmaniose tegumentar americana, realizadas antes da introdução do tratamento específico. A diagnose de LTA foi embasada no quadro clínico dos pacientes, reação intradérmica de Montenegro positiva, e/ou demonstração de formas amastigotas e/ou antígeno de Leishmania nas lesões.

Foram critérios de exclusão pacientes apresentando a forma mucocutânea da doença e biópsias de tamanho insuficiente para a realização dos procedimentos técnicos do estudo.

Os dados clínicos quanto a idade, sexo, local e tipo de lesão, e resultados da reação intradérmica de Montenegro estão apresentados no Quadro 1. 
QUADRO 1 - Casos de leishmaniose tegumentar americana: idade, sexo, localização e tipo de lesão e resultado da reação intradérmica de Montenegro

\begin{tabular}{|c|c|c|c|c|c|}
\hline CASO & IDADE & SEXO & LOCALIZAÇÃO & TIPO DE LESÃO & $\begin{array}{l}\text { REAÇÃO DE } \\
\text { MONTENEGRO }\end{array}$ \\
\hline 1 & 70 & $M$ & TRONCO & ÚLCERA & NC \\
\hline 2 & 27 & $\mathrm{~F}$ & COXA D & ÚLCERA & $15 \times 18 \mathrm{~mm}$ \\
\hline 3 & 26 & M & JOELHO E & ÚLCERA & $5 \times 5 \mathrm{~mm}$ \\
\hline 4 & 12 & $M$ & COXA E & ÚLCERA & $15 \times 18 \mathrm{~mm}$ \\
\hline 5 & 32 & $\mathrm{~F}$ & ANTEBRAÇO E & ÚLCERA & $20 \times 20 \mathrm{~mm}$ \\
\hline 6 & 14 & $\mathrm{~F}$ & COXA D & ÚLCERA & $25 \times 20 \mathrm{~mm}$ \\
\hline 7 & 15 & M & PERNA D & ÚLCERA & $10 \times 10 \mathrm{~mm}$ \\
\hline 8 & 20 & $\mathrm{~F}$ & PERNA D & ÚLCERA & $12 \times 12 \mathrm{~mm}$ \\
\hline 9 & 53 & M & MALAR E & ÚLCERA & $16 \times 13 \mathrm{~mm}$ \\
\hline 10 & 71 & $\mathrm{M}$ & MSD & VERRUCOSA & $15 \times 12 \mathrm{~mm}$ \\
\hline 11 & 29 & M & MID & ÚLCERA & $10 \times 10 \mathrm{~mm}$ \\
\hline 12 & 67 & M & INDICADOR E & VERRUCOSA & $20 \times 20 \mathrm{~mm}$ \\
\hline 13 & 40 & M & JOELHO E & VERRUCOSA & $20 \times 20 \mathrm{~mm}$ \\
\hline 14 & 32 & M & COXA D & ÚLCERA & $13 \times 7 \mathrm{~mm}$ \\
\hline 15 & 39 & M & LÁBIO SUPERIOR & ÚLCERA & $\mathrm{NC}$ \\
\hline 16 & 44 & $\mathrm{~F}$ & COXA D & ÚLCERA & $\mathrm{NC}$ \\
\hline 17 & 49 & M & BRAÇO & ÚLCERA & NC \\
\hline 18 & 23 & M & MÃO E & ÚLCERA & NC \\
\hline 19 & 40 & M & MIE & ÚLCERA & $10 \times 10 \mathrm{~mm}$ \\
\hline 20 & 63 & $\mathrm{~F}$ & PUNHO D & ÚLCERA & NC \\
\hline 21 & 23 & M & MALÉOLO & ÚLCERA & $12 \times 12 \mathrm{~mm}$ \\
\hline 22 & 96 & $\mathrm{~F}$ & BRAÇO E & ÚLCERA & NEGATIVA \\
\hline 23 & 3 & M & PERNA E & ÚLCERA & $10 \times 10 \mathrm{~mm}$ \\
\hline 24 & 24 & $\mathrm{~F}$ & PERNA E & ÚLCERA & $10 \times 10 \mathrm{~mm}$ \\
\hline 25 & 66 & M & PERNA E & ÚLCERA & $8 \times 8 \mathrm{~mm}$ \\
\hline 26 & 7 & M & CALCANHAR & ÚLCERA & $8 \times 8 \mathrm{~mm}$ \\
\hline 27 & 61 & M & ORELHA & ÚLCERA & NEGATIVA \\
\hline 28 & 39 & $\mathrm{~F}$ & BRAÇO E & ÚLCERA & $3 \mathrm{~mm}$ \\
\hline 29 & 73 & M & FRONTE & ÚLCERA & NC \\
\hline 30 & 23 & $\mathrm{~F}$ & MIE & ÚLCERA & $\mathrm{NC}$ \\
\hline 31 & 28 & M & MANDIBULAR D & ÚLCERA & $12 \times 15 \mathrm{~mm}$ \\
\hline 32 & 44 & M & COXA E & ÚLCERA & SEM LEITURA \\
\hline 33 & 23 & M & PERNA E & ÚLCERA & $\mathrm{NC}$ \\
\hline 34 & 54 & $\mathrm{~F}$ & PERNA D & ÚLCERA & $8 \times 9 \mathrm{~mm}$ \\
\hline 35 & 54 & M & HIPOCÔNDRIO E & NC & NC \\
\hline 36 & 52 & M & PUNHO D & NC & NC \\
\hline 37 & 75 & M & MALAR E & NC & NC \\
\hline 38 & NC & $M$ & DORSO & $\mathrm{NC}$ & $0,2 \mathrm{~mm}$ \\
\hline
\end{tabular}




\begin{tabular}{|rrllll|}
\hline 39 & 34 & $\mathrm{~F}$ & ANTEBRAÇO & NC & POSITIVA \\
\hline 40 & 1 & $\mathrm{~F}$ & $\begin{array}{l}\text { PRÉ-AURICULAR } \\
\mathrm{E}\end{array}$ & NC & NC \\
\hline 41 & $\mathrm{NC}$ & $\mathrm{F}$ & NC & NC & POSITIVA \\
\hline 42 & 42 & $\mathrm{~F}$ & NÁDEGAS & $\begin{array}{l}\text { NÓDULOS } \\
\text { SARCOÍDEOS }\end{array}$ & $7 \mathrm{~mm}$ \\
\hline 43 & 63 & $\mathrm{M}$ & ANTEBRAÇO D & VERRUCOSA & $15 \mathrm{~mm}$ \\
\hline 44 & 33 & $\mathrm{~F}$ & MIE & NC & NEGATIVA \\
\hline 45 & 70 & $\mathrm{M}$ & ANTEBRAÇO E & NC & NR \\
\hline 46 & 22 & $\mathrm{M}$ & DORSO & ÚLCERA & $12 \mathrm{~mm}$ \\
\hline 47 & 44 & $\mathrm{M}$ & AXILA D & ÚLCERA & $7 \mathrm{~mm}$ \\
\hline 48 & 49 & $\mathrm{M}$ & PERNA E & ÚLCERA & $5 \mathrm{~mm}$ \\
\hline 49 & 65 & $\mathrm{M}$ & SUBMENTONIANA & ÚLCERA & $9 \mathrm{~mm}$ \\
\hline 50 & 25 & $\mathrm{M}$ & PERNA D & ÚLCERA & $8 \mathrm{~mm}$ \\
\hline 51 & 50 & $\mathrm{~F}$ & MIE & NC & $8 \mathrm{~mm}$ \\
\hline 52 & 44 & $\mathrm{~F}$ & MALAR E & ÚLCERA & NEGATIVA \\
\hline
\end{tabular}

$\mathrm{M}$ - masculino; F - feminino; NC - não consta; D - direito(a); E esquerdo(a); MI - membro inferior; MS - membro superior; NR - não realizada

Os casos foram classificados de acordo com o tipo de resposta tecidual ao exame anatomopatológico: se reação inflamatória crônica não específica, ou se reação inflamatória crônica granulomatosa (Quadro 2). Os casos com resposta inflamatória crônica não específica foram aqueles caracterizados por infiltrado inflamatório composto por linfócitos, histiócitos e numerosos plasmócitos, por vezes com fibrose, focos de necrose dérmica e ulceração da epiderme (Figura 1). Os casos com resposta inflamatória crônica granulomatosa apresentavam infiltrado inflamatório geralmente difuso, por vezes nodular, composto por linfócitos, histiócitos, agrupamentos epitelioides, células gigantes multinucleadas em número variável e numerosos plasmócitos. Alguns casos exibiam necrose dérmica e ulceração (Figura 2). 

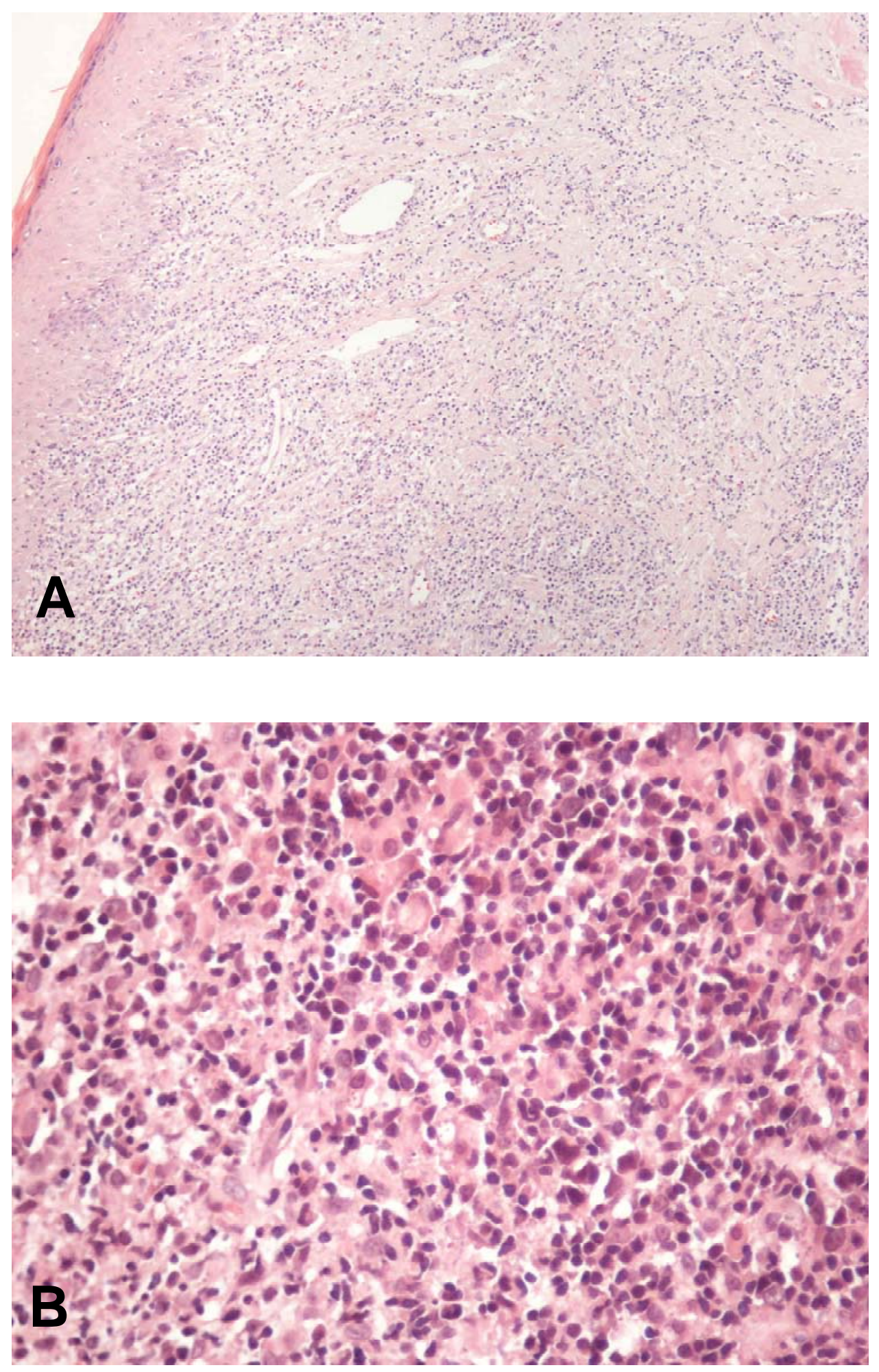

Figura 1. Leishmaniose tegumentar americana. Coloração pela hematoxilinaeosina. Padrão de resposta tecidual inflamatória crônica não específica (caso 27). A. Aumento original x100. B. Aumento original x400 

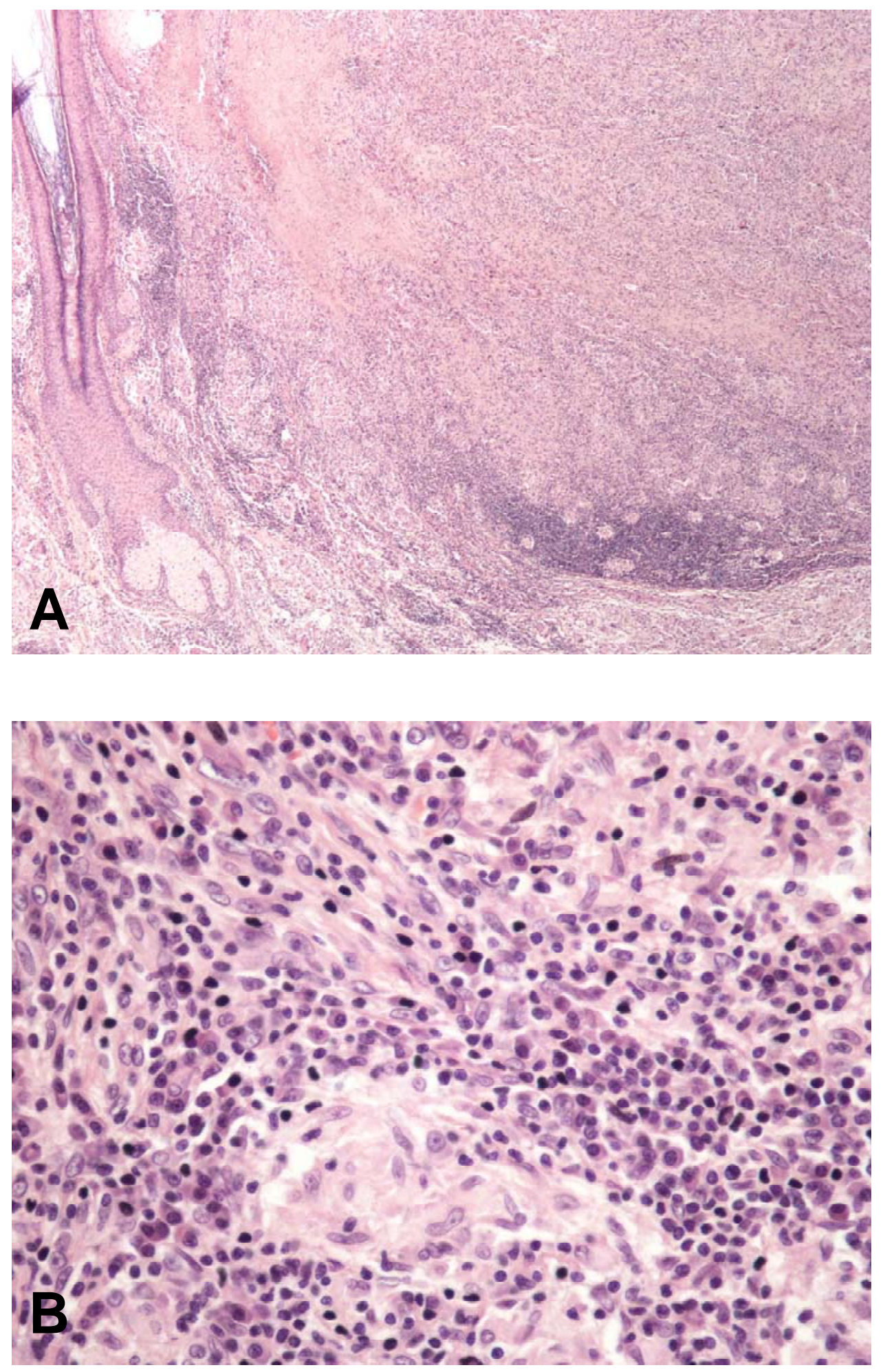

Figura 2. Leishmaniose tegumentar americana. Coloração pela hematoxilinaeosina. Padrão de resposta tecidual inflamatória crônica granulomatosa (caso 37). A. Aumento original x40. B. Aumento original $x 400$ 
O Quadro 2 demonstra também os dados sobre presença ou não de amastigotas nas lesões à coloração de hematoxilina-eosina (Figura 3) e os dados de semiquantificação de antígenos de Leishmania à imunohistoquímica (Figura 4).

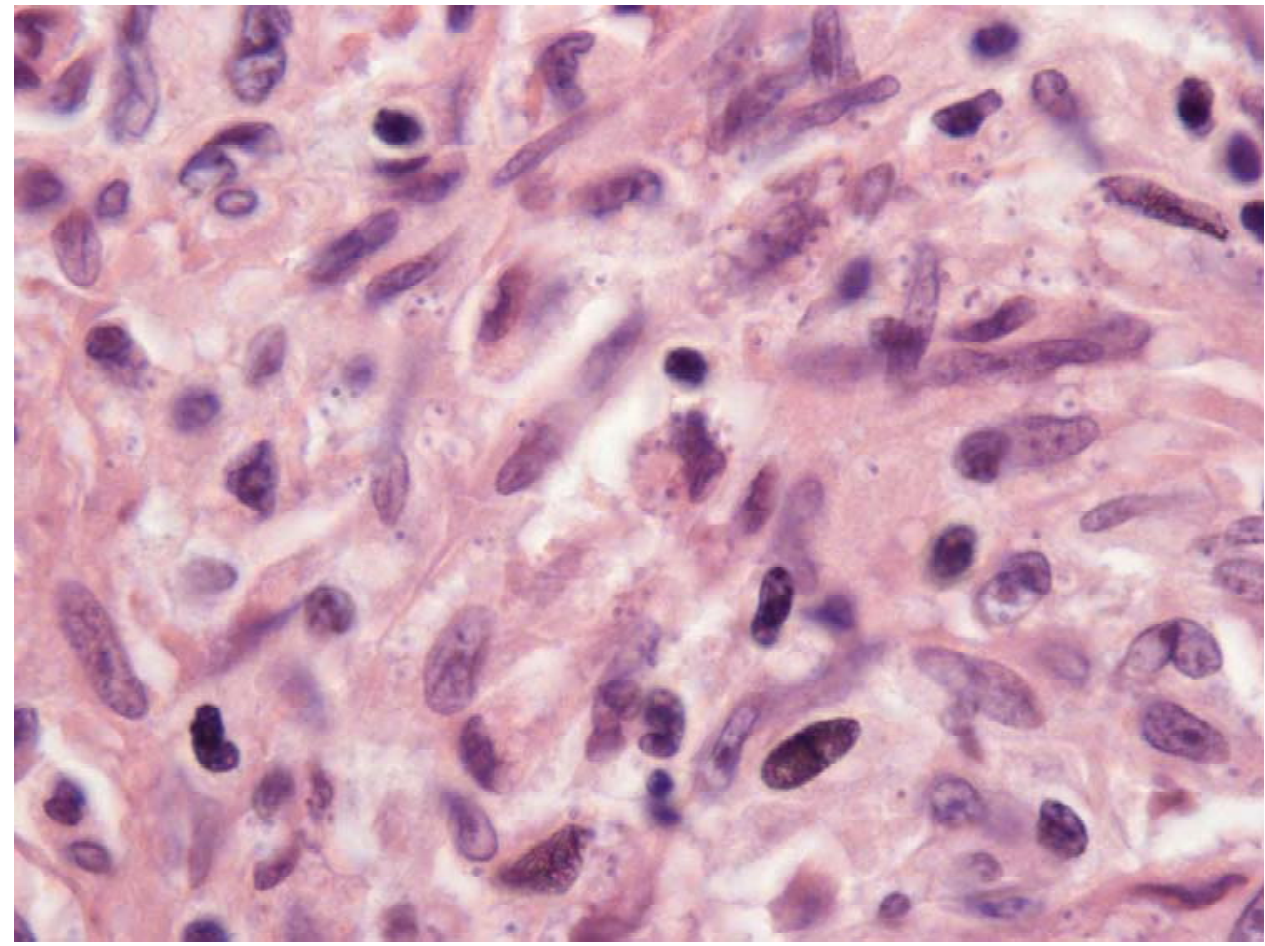

Figura 3. Leishmaniose tegumentar americana. Coloração pela hematoxilinaeosina. Presença de numerosas formas amastigotas no citoplasma de macrófagos (caso 37 - aumento original $\times 1000$ ) 


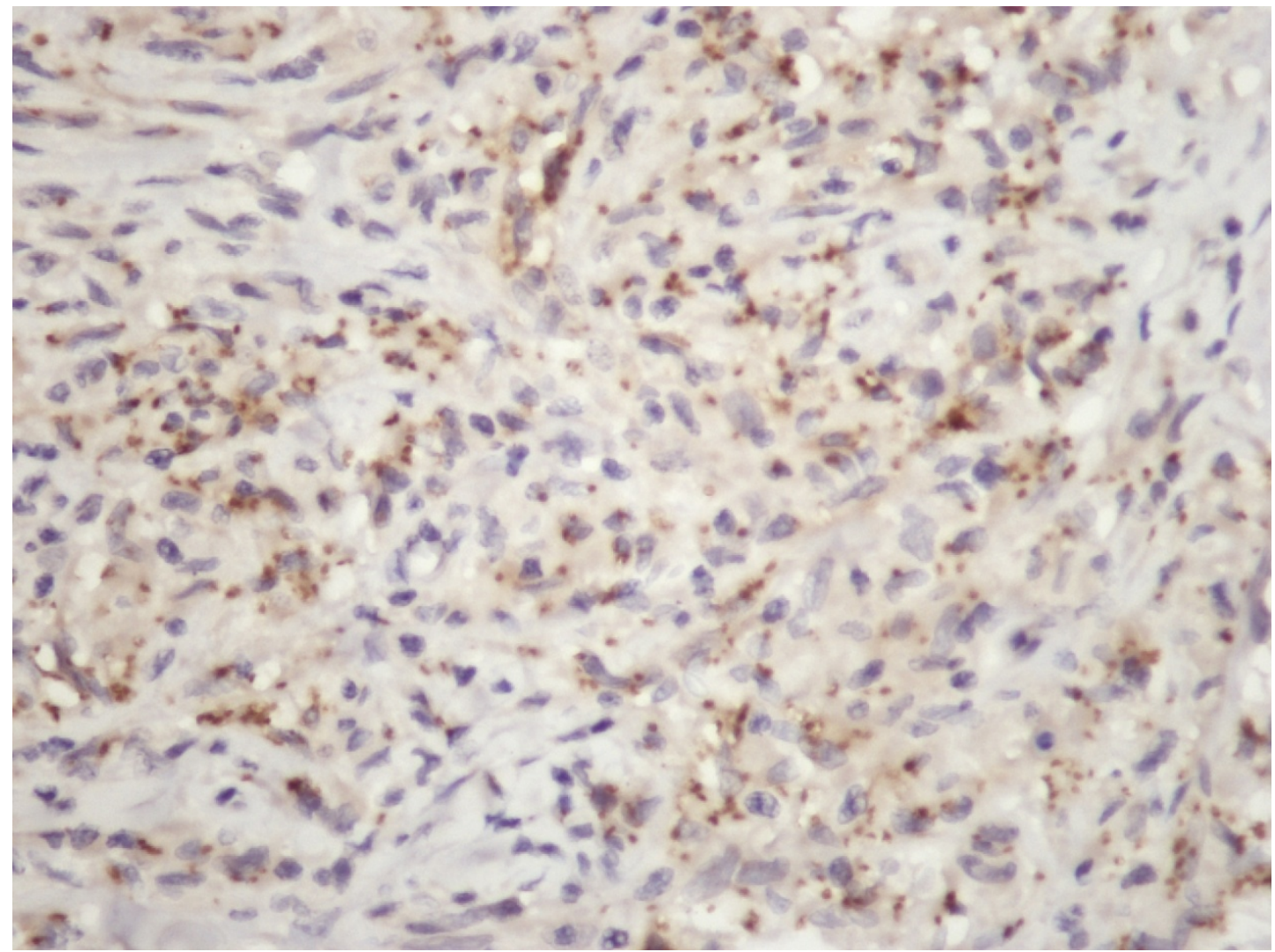

Figura 4. Leishmaniose tegumentar americana. Reação imuno-histoquímica - sistema EnVision peroxidase/diaminobenzidina. Presença de numerosas formas amastigotas $(3+/ 3+)$ no citoplasma de macrófagos, coradas em marrom (caso 37 - aumento original $x 400$ ) 
QUADRO 2 - Leishmaniose tegumentar americana. Tipo de resposta inflamatória e pesquisa de Leishmania nos preparados de biópsia corados pela hematoxilina-eosina e pela técnica imuno-histoquímica para pesquisa de antígeno parasitário

\begin{tabular}{rlll}
\hline CASO & TIPO DE RESPOSTA & PARASITAS (HE) & ANTIGENOS $($ IH) \\
\hline 1 & INFLAMATORIA & AUSENTES & POSITIVA +/3+ \\
\hline 2 & GRANULOMATOSA & AUSENTES & POSITIVA 2+/3+ \\
\hline 3 & INESPECÍFICA & PRESENTES & NEGATIVA \\
\hline 4 & GRANULOMATOSA & AUSENTES & POSITIVA +/3+ \\
\hline 5 & INESPECIIFICA & AUSENTES & POSITIVA +/3+ \\
\hline 6 & GRANULOMATOSA & AUSENTES & NEGATIVA \\
\hline 7 & GRANULOMATOSA & AUSENTES & NEGATIVA \\
\hline 8 & INESPECÍFICA & PRESENTES & POSITIVA 3+/3+ \\
\hline 9 & GRANULOMATOSA & AUSENTES & POSITIVA +/3+ \\
\hline 10 & GRANULOMATOSA & AUSENTES & NEGATIVA \\
\hline 11 & GRANULOMATOSA & AUSENTES & NEGATIVA \\
\hline 12 & GRANULOMATOSA & AUSENTES & NEGATIVA \\
\hline 13 & GRANULOMATOSA & AUSENTES & NEGATIVA \\
\hline 14 & GRANULOMATOSA & AUSENTES & NEGATIVA \\
\hline 15 & INESPECIFICA & PRESENTES & POSITIVA 2+/3+ \\
\hline 16 & GRANULOMATOSA & PRESENTES & POSITIVA 2+/3+ \\
\hline 17 & INESPECÍFICA & PRESENTES & POSITIVA 2+/3+ \\
\hline 18 & GRANULOMATOSA & PRESENTES & POSITIVA 2+/3+ \\
\hline 19 & GRANULOMATOSA & AUSENTES & NEGATIVA \\
\hline 20 & GRANULOMATOSA & PRESENTES & NR \\
\hline 21 & GRANULOMATOSA & AUSENTES & POSITIVA +/3+ \\
\hline 22 & GRANULOMATOSA & AUSENTES & POSITIVA 2+/3+ \\
\hline 23 & GRANULOMATOSA & AUSENTES & NEGATIVA \\
\hline 24 & GRANULOMATOSA & AUSENTES & NEGATIVA \\
\hline 25 & GRANULOMATOSA & AUSENTES & POSITIVA +/3+ \\
\hline 26 & GRANULOMATOSA & AUSENTES & POSITIVA +/3+ \\
\hline 27 & INESPECÍFICA & PRESENTES & POSITIVA +/3+ \\
\hline 28 & GRANULOMATOSA & PRESENTES & NR \\
\hline 29 & INESPECÍFICA & PRESENTES & POSITIVA 2+/3+ \\
\hline 30 & GRANULOMATOSA & PRESENTES & POSITIVA 2+/3+ \\
\hline 31 & GRANULOMATOSA & PRESENTES & POSITIVA 2+/3+ \\
\hline 32 & INESPECÍFICA & PRESENTES & POSITIVA 2+/3+ \\
\hline 33 & GRANULOMATOSA & PRESENTES & POSITIVA 2+/3+ \\
\hline 34 & GRANULOMATOSA & AUSENTES & POSITIVA +/3+ \\
\hline & GRANULOMATOSA & PRESENTES & POSITIVA +/3+ \\
\hline
\end{tabular}




\begin{tabular}{|llll}
\hline 37 & GRANULOMATOSA & PRESENTES & POSITIVA 3+/3+ \\
\hline 38 & GRANULOMATOSA & PRESENTES & NR \\
\hline 39 & GRANULOMATOSA & AUSENTES & POSITIVA +/3+ \\
\hline 40 & GRANULOMATOSA & PRESENTES & POSITIVA $2+/ 3+$ \\
\hline 41 & INESPECÍFICA & PRESENTES & POSITIVA 3+/3+ \\
\hline 42 & GRANULOMATOSA & AUSENTES & NEGATIVA \\
\hline 43 & GRANULOMATOSA & AUSENTES & NEGATIVA \\
\hline 44 & GRANULOMATOSA & AUSENTES & POSITIVA +/3+ \\
\hline 45 & INESPECÍFICA & PRESENTES & POSITIVA 2+/3+ \\
\hline 46 & GRANULOMATOSA & PRESENTES & POSITIVA +/3+ \\
\hline 47 & GRANULOMATOSA & PRESENTES & POSITIVA 3+/3+ \\
\hline 48 & GRANULOMATOSA & PRESENTES & POSITIVA +/3+ \\
\hline 49 & GRANULOMATOSA & AUSENTES & NEGATIVA \\
\hline 50 & GRANULOMATOSA & PRESENTES & POSITIVA 3+/3+ \\
\hline 51 & GRANULOMATOSA & PRESENTES & POSITIVA +/3+ \\
\hline 52 & GRANULOMATOSA & PRESENTES & POSITIVA 2+/3+ \\
\hline
\end{tabular}

$\mathrm{HE}$ - material corado pela hematoxilina-eosina; $\mathrm{IH}$ - material submetido à pesquisa de antígeno de Leishmania por técnica imuno-histoquímica (modificada de Sotto ET al. 1989) (165); NR - não realizado.

A realização deste trabalho foi aprovada pela Comissão de Ética para Análise de Projetos de Pesquisa - CAPPesq da Diretoria Clínica do Hospital das Clínicas da Faculdade de Medicina da Universidade de São Paulo sob o número 0133/08. 


\subsection{DEMONSTRAÇÃO DE CÉLULAS DENDRÍTICAS PLASMOCITOIDES}

Em biópsias provenientes de 36 pacientes, o material embebido em parafina foi submetido à microtomia com obtenção de cortes histológicos de quatro $\mu \mathrm{m}$ de espessura, colhidos em lâminas de vidro previamente preparadas com solução adesiva de 3 amino-propyltrietoxy-silane (Sigma Chemical Co, St. Louis, MO/USA, cód A3648). A seguir, foram desparafinizados em três banhos de xilol, sendo um a $65^{\circ} \mathrm{C}$ durante 30 minutos e os outros dois à temperatura ambiente por cinco minutos cada; posteriormente foram hidratados em cadeia decrescente de etanol (absoluto - duas passagens e 95\% - três passagens) durante um minuto, cada banho com posterior lavagem em água corrente e destilada. Foi feita a exposição antigênica com a solução Target Retrieval Solution (Dako, S170084) em panela a vapor por uma hora. O bloqueio da peroxidase endógena foi feito em câmara escura com duas incubações em peróxido de hidrogênio 3\% por 10 minutos cada vez e, em seguida, o material foi novamente lavado em água corrente, água destilada e solução salina tamponada com fosfatos $\mathrm{pH}$ 7,4 (PBS) por 10 minutos. A seguir foi feito bloqueio com leite desnatado $6 \%$ (Molico®, Nestlé ${ }^{\circledR}$ ) a $37^{\circ} \mathrm{C}$ por 30 minutos para evitar marcações inespecíficas. A demonstração das CDP (108) foi feita com o anticorpo monoclonal anti-CD123 (receptor $\alpha$ de interleucina-3) (eBioscience, USA clone $6 \mathrm{H} 6$ ), diluído 1:50 em PBS e 1\% de soroalbumina bovina (BSA) de um dia para o outro, a $4^{\circ} \mathrm{C}$. Após a incubação com o anticorpo primário o 
material foi submetido a três lavagens com PBS por cinco minutos cada; procedeu-se à incubação com o anticorpo secundário Advance Link de coelho e camundongo produzido em cabra (DAKO K 4068, Carpinteria, CA, USA), durante 40 minutos à temperatura ambiente. Os cortes histológicos foram novamente lavados em PBS e incubados com Advance Enzime (DAKO K 4068, Carpinteria, CA, USA), durante 40 minutos à temperatura ambiente. Após a nova lavagem em PBS, a reação foi revelada com solução cromógena de diaminobenzidina (3,3' - diaminobenzidine, SIGMA Chemical Co. St. Louis, MO, USA, cód. D5637), 60 mg diluídos em 100 ml de PBS, acrescida de um $\mathrm{mL}$ de peróxido de hidrogênio $6 \%$ ou $2 \mathrm{~mL}$ de peróxido de hidrogênio $3 \%$ por cinco minutos.

Os cortes histológicos foram a seguir lavados três vezes em água corrente, água destilada e PBS, sendo cada lavagem feita em 10 minutos, e então contracorados com hematoxilina de Carazzi por cinco minutos, lavados em água corrente, desidratados em etanol e diafanizados em xilol. Fez-se a montagem das lâminas com resina Permount (FISHER Scientific, Fair Lawn, NJ, USA, cód. SP15-100).

Cortes histológicos de pele com líquen plano foram utilizados como controles positivos para a reação. Como o anticorpo anti-CD123 marca também células endoteliais, este parâmetro foi utilizado como controle positivo interno. O controle negativo foi obtido pela omissão do anticorpo primário, que foi substituído por PBS. 


\subsection{QUANTIFICAÇÃO DE CÉLULAS DENDRÍTICAS PLASMOCITOIDES}

De cada um dos casos foram tomadas imagens digitais de seis campos "hot spot", com objetiva de $20 \times$ e ocular de 10×. Para a digitalização das imagens utilizou-se a câmera digital Zeiss AxioCam MRc5 montada em microscópio óptico Leica DMR, com o software para digitalização de imagens AxioVision Release 4.6.

Com o auxílio do programa de análise de imagens Image - Pro Plus 4.5.0.29 foi feita a quantificação manual do número de CDP, em monitor de computador, de cada uma das imagens obtidas. Para facilitar o reconhecimento das células marcadas ampliou-se cada uma das imagens com "zoom" digital. Áreas com artefatos de processamento, epiderme e epitélio anexial foram excluídas, obtendo-se de cada caso a média de células/unidade de área de derme, expressa em células $/ \mathrm{mm}^{2}$. 


\subsection{DEMONSTRAÇÃO DE EXPRESSÃO DE INOS POR DENDRÓCITOS DÉRMICOS FATOR XIIIa+ (REAÇÃO IMUNO-HISTOQUÍMICA DE DUPLA MARCAÇÃO)}

Cortes histológicos de quatro $\mu \mathrm{m}$ de espessura de biópsias provenientes de lesões de 34 pacientes foram inicialmente processados até a desparafinização, como anteriormente descrito. Fez-se a exposição antigênica com tripsina bovina $(20 \mathrm{mg}$ de tripsina diluídos em $100 \mathrm{~mL}$ de PBS) por 15 minutos. A seguir fez-se o bloqueio da peroxidase endógena e de ligações inespecíficas como o descrito anteriormente. Procedeu-se a três lavagens de cinco minutos cada com PBS, e realizada então a técnica de dupla marcação, com o anticorpo primário policlonal de coelho anti-fator XIIla (Biogenex Laboratories Inc., código PU337-UP, San Ramon, CA, USA) e o anticorpo policlonal de coelho anti-iNOS (iNOS Rabbit, código sc-651, Santa Cruz Biotechnology, Santa Cruz, California, USA).

Os cortes histológicos foram incubados com o anticorpo primário anti-fator XIlla na diluição de 1:200 em PBS com 0,01\% de BSA durante uma hora a $37^{\circ} \mathrm{C}$. A seguir, foram lavados em PBS por cinco minutos, três vezes, e incubados com o anticorpo secundário EnVision TM System/AP, Rabbit/Mouse (Dako, código K1396, Carpinteria, CA, USA) por 30 minutos em temperatura ambiente. Após três novas lavagens em PBS, fez-se a revelação da reação com solução cromógena "liquid permanent red", controlando-a ao microscópio óptico. 
A seguir, procedeu-se às lavagens consecutivas em água destilada e PBS por 5 minutos. Fez-se o bloqueio da primeira reação com solução bloqueadora de dupla marcação (Dual endogenous enzime block, Dako, código S2003, Carpinteria, CA, USA) durante 15 minutos em temperatura ambiente, seguida de lavagem em PBS por cinco minutos. A seguir, foi realizada incubação com anticorpo primário anti-iNOS diluído 1:500 em PBS, com $0,01 \%$ de BSA, de um dia para o outro em geladeira, seguida de três lavagens em PBS, cinco minutos cada, e incubação com anticorpo secundário EnVision HPR EnVisionTM System/HRP, Rabbit/Mouse (Dako, código K1491, Carpinteria, CA, USA) por 30 minutos em temperatura ambiente. A revelação desta etapa da reação foi feita com solução cromógena de diaminobenzidina com cloreto de níquel (3, 3' diaminobenzidine, SIGMA Chemical Co., St. Louis, MO/USA, cód. D5637), diluída em PBS, por dois minutos. A seguir, foram realizadas lavagens consecutivas em água destilada, aguardou-se a secagem e procedeu-se à montagem das lâminas com resina Permount (FISHER Scientific, Fair Lawn, NJ, USA, cód. SP15-100) e lamínulas de vidro.

A revelação das reações foi feita com os cromógenos diaminobenzidina com cloreto de níquel (negro), para o iNOS, e o "liquid permanent red" (vermelho), para o fator XIIla, uma vez que tanto o fator XIIla como a iNOS são expressos no citoplasma celular. Lembramos ainda que a iNOS é também expressa no núcleo celular (166). 
Cortes histológicos de dermatofibroma foram utilizados como controle positivo para o fator XIIla, e de tonsila palatina para a iNOS. O controle negativo foi obtido pela omissão do anticorpo primário, que foi substituído por PBS. 


\subsection{QUANTIFICAÇÃO DE DENDRÓCITOS DÉRMICOS FATOR XIIIa+}

Imagens digitais de cada um dos casos foram obtidas como o descrito para o material imunomarcado para CDP.

Com o auxílio do mesmo programa de análise de imagens foi feita a quantificação manual do número de DDFXIIla+, em monitor de computador, de cada uma das imagens obtidas, distinguindo-se os que coexpressaram iNOS, daqueles que não. Para facilitar o reconhecimento das células marcadas ampliou-se cada uma das imagens com "zoom" digital. Áreas com artefatos de processamento, epiderme e epitélio anexial foram excluídas, obtendo-se de cada caso a média de células/unidade de área de derme, expressa em células $/ \mathrm{mm}^{2}$. 


\subsection{DEMONSTRAÇÃO DE EXPRESSÃO DE INOS POR MACRÓFAGOS CD68+ (REAÇÃO IMUNO-HISTOQUÍMICA DE DUPLA MARCAÇÃO)}

Cortes histológicos de biópsias de lesões provenientes de 43 pacientes foram inicialmente processados até a desparafinização, como anteriormente descrito. Fez-se a exposição antigênica com tampão de ácido cítrico $0,01 \mathrm{M}$ em ph 6,0, em forno de microondas, por 18 minutos, sendo uma etapa de oito minutos, seguida de mais duas etapas de cinco minutos. A seguir fez-se o bloqueio da peroxidase endógena e de ligações inespecíficas como o descrito anteriormente. Procedeu-se a três lavagens de cinco minutos cada com PBS, e realizada então a técnica de dupla marcação, inicialmente com o anticorpo primário monoclonal anti-CD 68 (Dako, Clone KP1, código M0814, Carpinteria, CA, USA) diluído em PBS (1:300) com $0,01 \%$ de BSA por uma hora, na estufa a $37^{\circ} \mathrm{C}$.

A seguir, os cortes histológicos foram lavados em PBS por cinco minutos, três vezes, e incubados com o anticorpo secundário EnVision TM System/AP, Rabbit/Mouse (Dako, código K1396, Carpinteria, CA, USA) por 30 minutos em temperatura ambiente. Após três novas lavagens em PBS, fez-se a revelação da reação com solução cromógena de "liquid permanent red", sob controle ao microscópio de luz. A seguir, procedeu-se às lavagens consecutivas em água destilada e PBS por cinco minutos. Fez-se o bloqueio da primeira reação com solução bloqueadora de dupla marcação (Dual endogenous enzime block, Dako, código S2003, Carpinteria, CA, USA) 
durante 15 minutos em temperatura ambiente, seguida de lavagem em PBS por cinco minutos. A seguir, foi realizada incubação com anticorpo primário policlonal de coelho anti-iNOS (iNOS Rabbit, código sc-651, Santa Cruz Biotechnology, Santa Cruz, California, USA) diluído 1:500 em PBS, com 0,01\% de BSA, de um dia para o outro em geladeira, seguida de três lavagens em PBS, de cinco minutos cada, e incubação com anticorpo secundário EnVision HPR EnVisionTM System/HRP, Rabbit/Mouse (Dako, código K1491, Carpinteria, CA, USA) por 30 minutos em temperatura ambiente. A revelação desta etapa da reação foi feita com solução cromógena de diaminobenzidina com cloreto de níquel (3, 3’ diaminobenzidine, SIGMA Chemical Co., St. Louis, MO/USA, cód. D5637), diluída em PBS, por dois minutos. A seguir, foram realizadas lavagens consecutivas em água destilada, aguardou-se a secagem e procedeu-se à montagem das lâminas com resina Permount (FISHER Scientific, Fair Lawn, NJ, USA, cód. SP15-100) e lamínulas de vidro.

A revelação das reações foi feita com os cromógenos diaminobenzidina com cloreto de níquel (negro), para o iNOS, e o "liquid permanent red" (vermelho), para o fator CD68, uma vez que tanto o CD68 como a iNOS são expressos no citoplasma celular.

Cortes histológicos de tonsila palatina foram utilizados como controles positivos para CD68 e iNOS. O controle negativo foi obtido pela omissão do anticorpo primário, que foi substituído por PBS. 


\subsection{QUANTIFICAÇÃO DE MACRÓFAGOS CD68+}

De cada um dos preparados submetidos à dupla marcação iNOS/CD68 foram tomadas imagens digitais do mesmo modo que para o material submetido à imunomarcação de CDP e dupla marcação iNOS/Fator XIIIa.

Com o auxílio do mesmo programa de análise de imagens foi feita a quantificação manual do número de macrófagos CD68+, em monitor de computador, de cada uma das imagens obtidas, distinguindo-se os que coexpressaram iNOS, daqueles que não. Obteve-se de cada caso a média de células/unidade de área de derme, expressa em células $/ \mathrm{mm}^{2}$. 


\subsection{ANÁLISE ESTATÍSTICA DOS RESULTADOS}

Fez-se a comparação do número de células CD123+/mm², DD FXIIla+/mm², células com coexpressão de Fator XIIla/iNOS $/ \mathrm{mm}^{2}$, macrófagos CD68+/mm² e células com coexpressão de CD68/iNOS/mm², nos dois grupos de resposta tecidual: resposta inflamatória crônica granulomatosa (GR) e resposta inflamatória crônica não específica (NE). Fez-se também a comparação do número de células Fator XIIla/iNOS+ e CD68/iNOS+ entre os espécimes de LTA. A análise estatística foi realizada com o teste não paramétrico de Mann-Whitney, utilizando-se o programa Graph Pad Prisma (Sigma). Estabeleceu-se o nível de significância em 95\% $(p \leq 0,05)$. 
5.1. DEMONSTRAÇÃO E QUANTIFICAÇÃO DE CÉLULAS DENDRÍTICAS PLASMOCITOIDES NAS LESÕES CUTÂNEAS DE LEISHMANIOSE TEGUMENTAR AMERICANA

Demonstramos a presença das CDP em todos os 36 espécimes de lesões cutâneas de LTA que foram submetidos ao estudo imunohistoquímico com anticorpo monoclonal anti-CD123. As células endoteliais dos vasos dérmicos também demonstraram positividade para o anticorpo anti-CD123, tendo sido utilizadas como controle interno positivo para as reações (Figura 5).

$75 \%$ das amostras exibiam padrão de resposta tecidual granulomatoso (27 casos), e $25 \%$ das amostras apresentavam padrão de resposta tecidual não específico, rico em plasmócitos (nove casos).

Observamos as CDP distribuídas como células isoladas entre outras células inflamatórias em 22 amostras (61\%). Em 14 das biópsias (39\%), as CDP formaram agrupamentos celulares. Este aspecto foi mais frequentemente observado no grupo com resposta inflamatória granulomatosa (13 amostras), e em apenas um dos casos com resposta não específica (Figura 6A). 


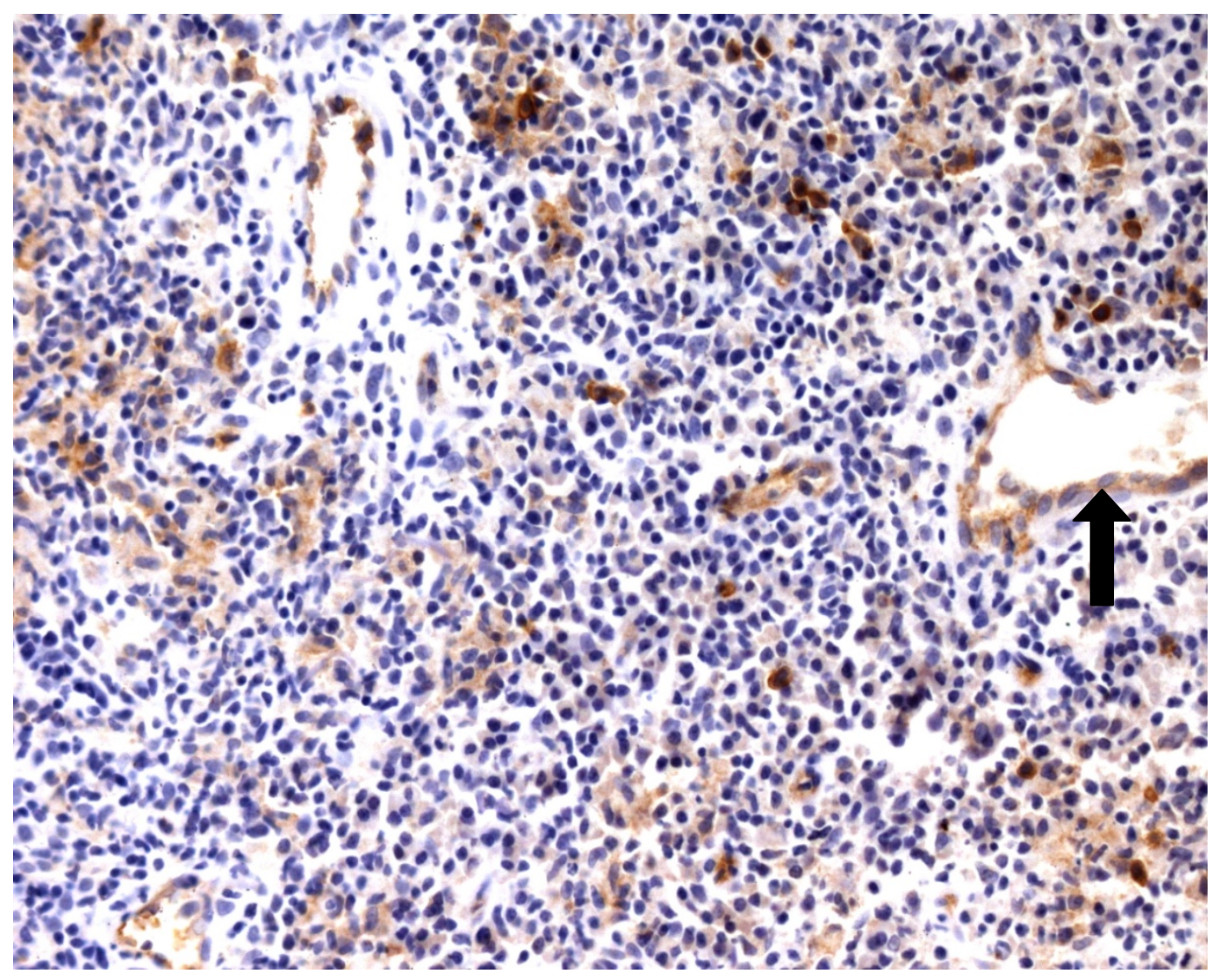

Figura 5. Leishmaniose tegumentar americana - Resposta inflamatória crônica não específica (caso 32). Células dendríticas plasmocitóides e células endoteliais (seta) evidenciadas pelo anticorpo anti-CD123. Reação imuno-histoquímica com o sistema Advance peroxidase/diaminobenzidina (aumento original $\mathrm{x} 200$ )

As CDP mostraram-se alinhadas na junção dermoepidérmica, por vezes permeando a epiderme, em 10 amostras (36\%), sendo oito no grupo de resposta inflamatória granulomatosa e duas no grupo com resposta não específica (Figura 6B). 


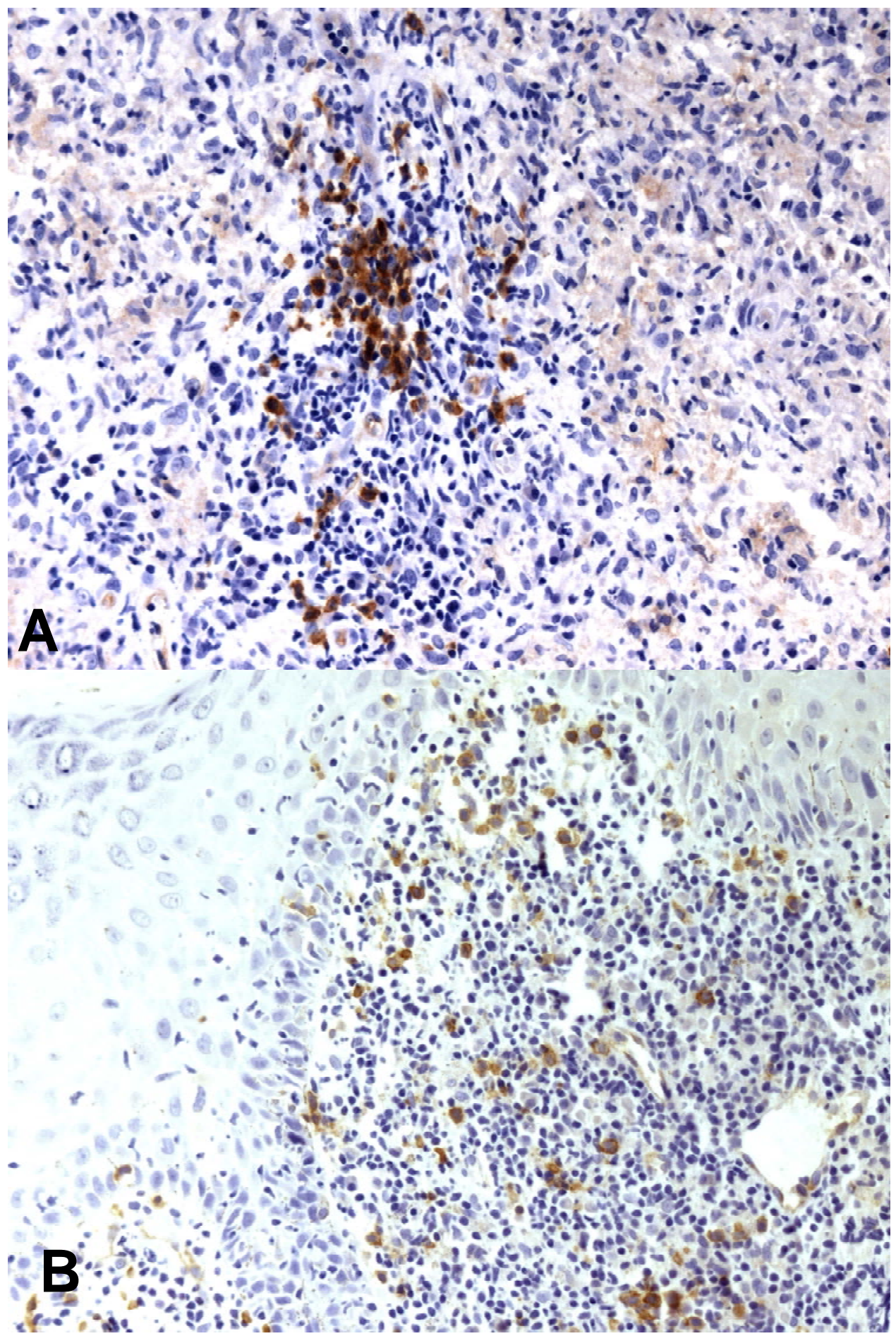

Figura 6. Leishmaniose tegumentar americana. A (caso 30) - Células CD123+ em agrupamentos celulares. B (caso 36) - Células CD123+ alinhadas na junção dermoepidérmica e permeando a epiderme. Reação imuno-histoquímica - sistema Advance peroxidase/diaminobenzidina ( $\mathrm{A}$ e B - aumento original $\times 200$ ) 
Um achado interessante foi a observação de células CD123+ com morfologia dendrítica, presentes ao redor de granulomas em alguns casos do grupo GR (Figura 7).

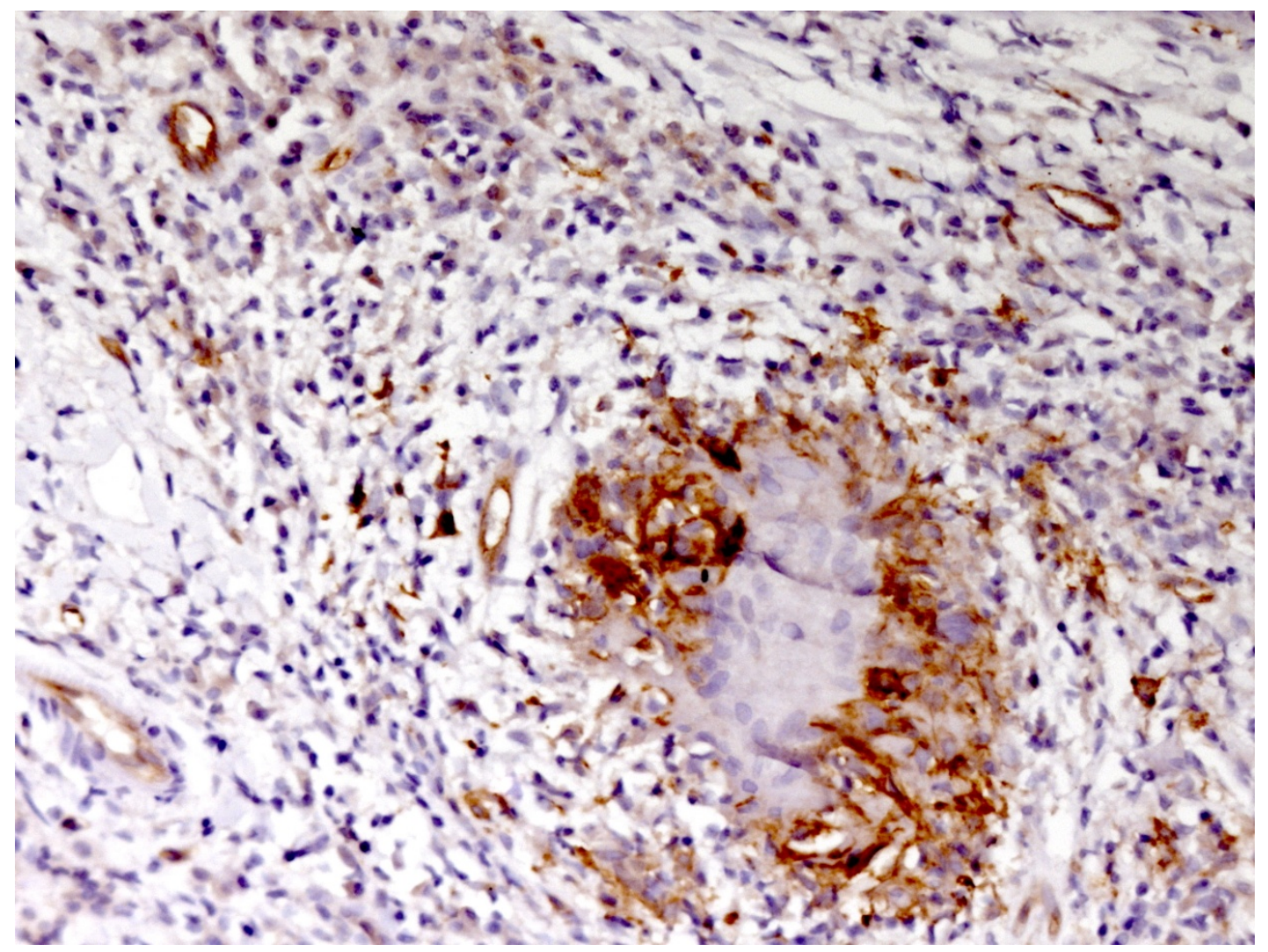

Figura 7. Leishmaniose tegumentar americana (caso 49). Células CD123+ com morfologia dendrítica ao redor de granuloma. Reação imunohistoquímica - sistema Advance peroxidase/diaminobenzidina (aumento original $\times 200$ )

Não houve diferença estatisticamente significativa no número de células CD123+/mm² entre os dois grupos de resposta tecidual (Gráfico 1 e Tabela 1). 


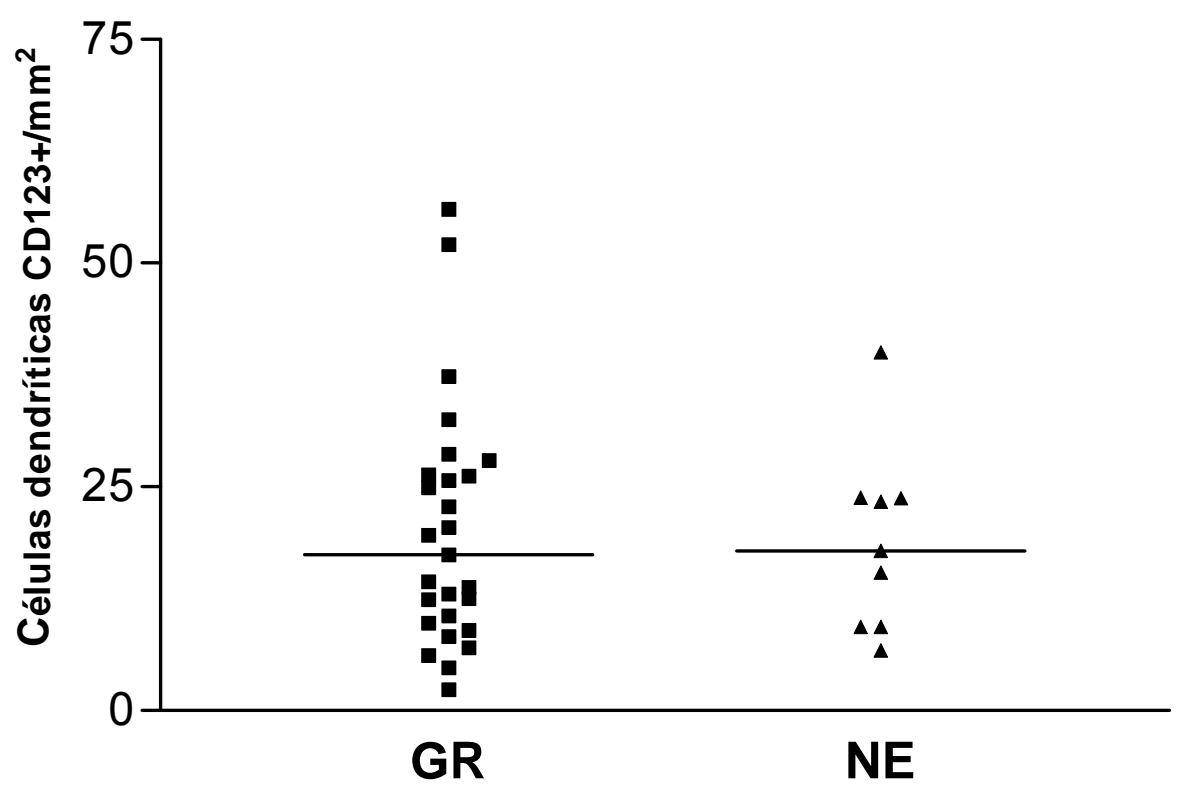

Gráfico 1. Leishmaniose tegumentar americana. Comparação do número de células dendríticas plasmocitoides (CD123+) nas lesões cutâneas com resposta inflamatória crônica granulomatosa (GR) e crônica não específica (NE). Barra - mediana. Teste de Mann-Whitney $(p>0,05)$

Tabela 1. Leishmaniose tegumentar americana. Comparação do número de células dendríticas plasmocitoides (CD123+) nas lesões cutâneas com resposta inflamatória crônica granulomatosa e crônica não específica

Tipo de resposta inflamatória

\begin{tabular}{lccc} 
Tipo de resposta inflamatória & & & Valor de $p$ \\
\hline Granulomatosa $(n=27)$ & Média \pm DP & $20,08 \pm 13,39$ & \\
& Variância & $2,34-56,04$ & $\mathrm{p}>0,05$ \\
Não específica $(\mathrm{n}=9)$ & Mediana & 17,42 & \\
& Média \pm DP & $18,83 \pm 10,35$ & \\
& Variância & $6,73-40,02$ & \\
& Mediana & 17,83 & \\
\hline
\end{tabular}

DP - desvio padrão; Teste de Mann-Whitney 


\subsection{DEMONSTRAÇÃO E QUANTIFICAÇÃO DE EXPRESSÃO DE INOS} POR DENDRÓCITOS DÉRMICOS FATOR XIIIa+

Através da reação imuno-histoquímica de dupla marcação demonstramos que os DD FXlla+ expressaram iNOS nas lesões cutâneas da LTA (Figura 8A). Os queratinócitos, na epiderme, também demonstraram positividade para o anticorpo anti-iNOS, tendo sido utilizados como controle interno positivo para as reações (Figura 8B).

Vinte e sete dos espécimes submetidos à dupla marcação DDFXIIIa/iNOS exibiam padrão de resposta tecidual granulomatoso (79\%) e sete a resposta inflamatória crônica não específica $(21 \%)$ (Figuras $9 \mathrm{~A}$ e B). 


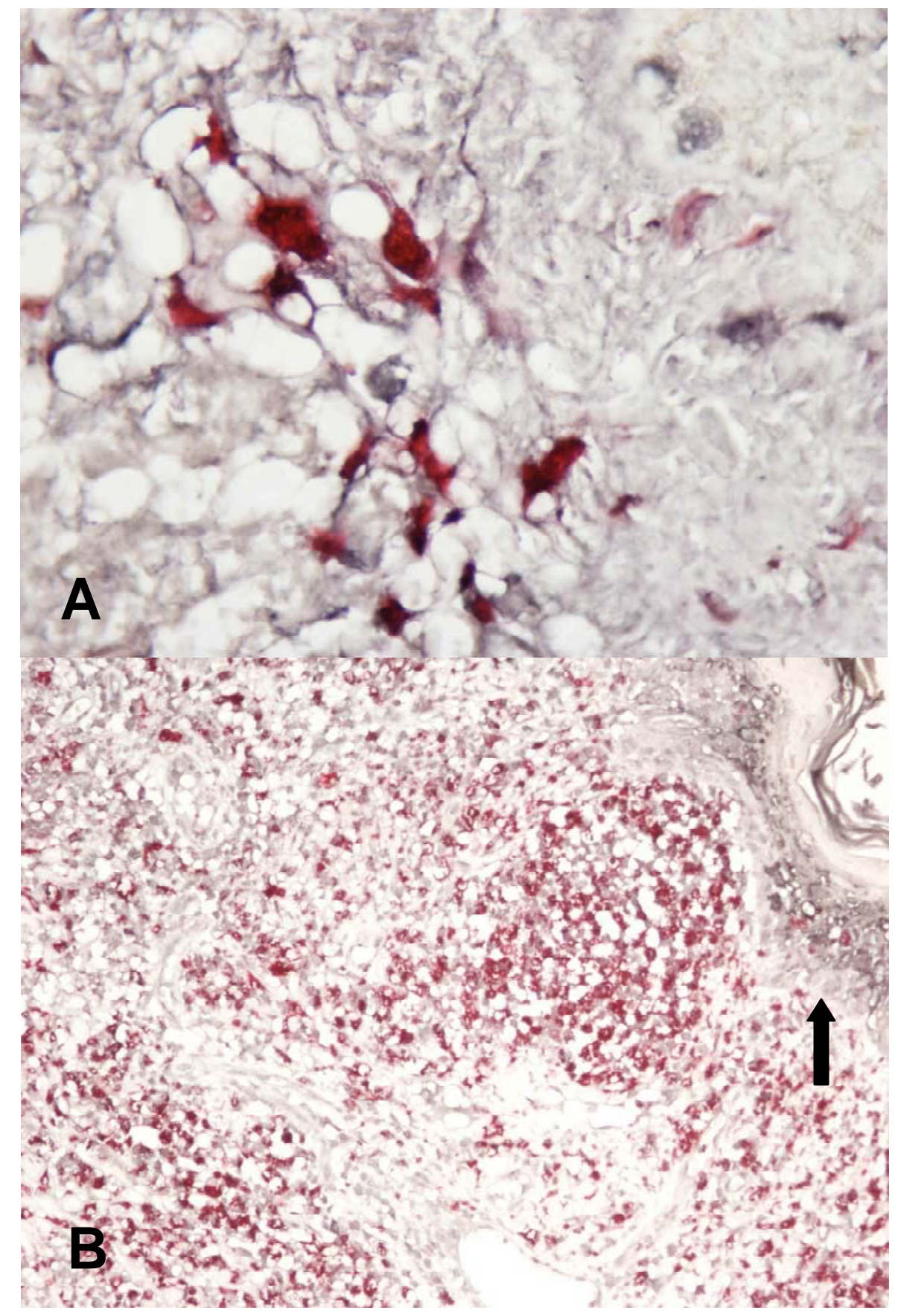

Figura 8. Leishmaniose tegumentar americana. A (caso 26) - Dendrócitos dérmicos fator XIIla+ corados pelo cromógeno vermelho, apresentando coexpressão citoplasmática de iNOS, evidenciada pelo cromógeno negro. B (caso 38) - Expressão epidérmica de iNOS (seta). Reação imunohistoquímica de dupla marcação - sistema EnVision peroxidase/ "permanent red" / diaminobenzidina com níquel (A - aumento original $\times 1000, B$ - aumento original $\mathrm{x} 200$ ) 

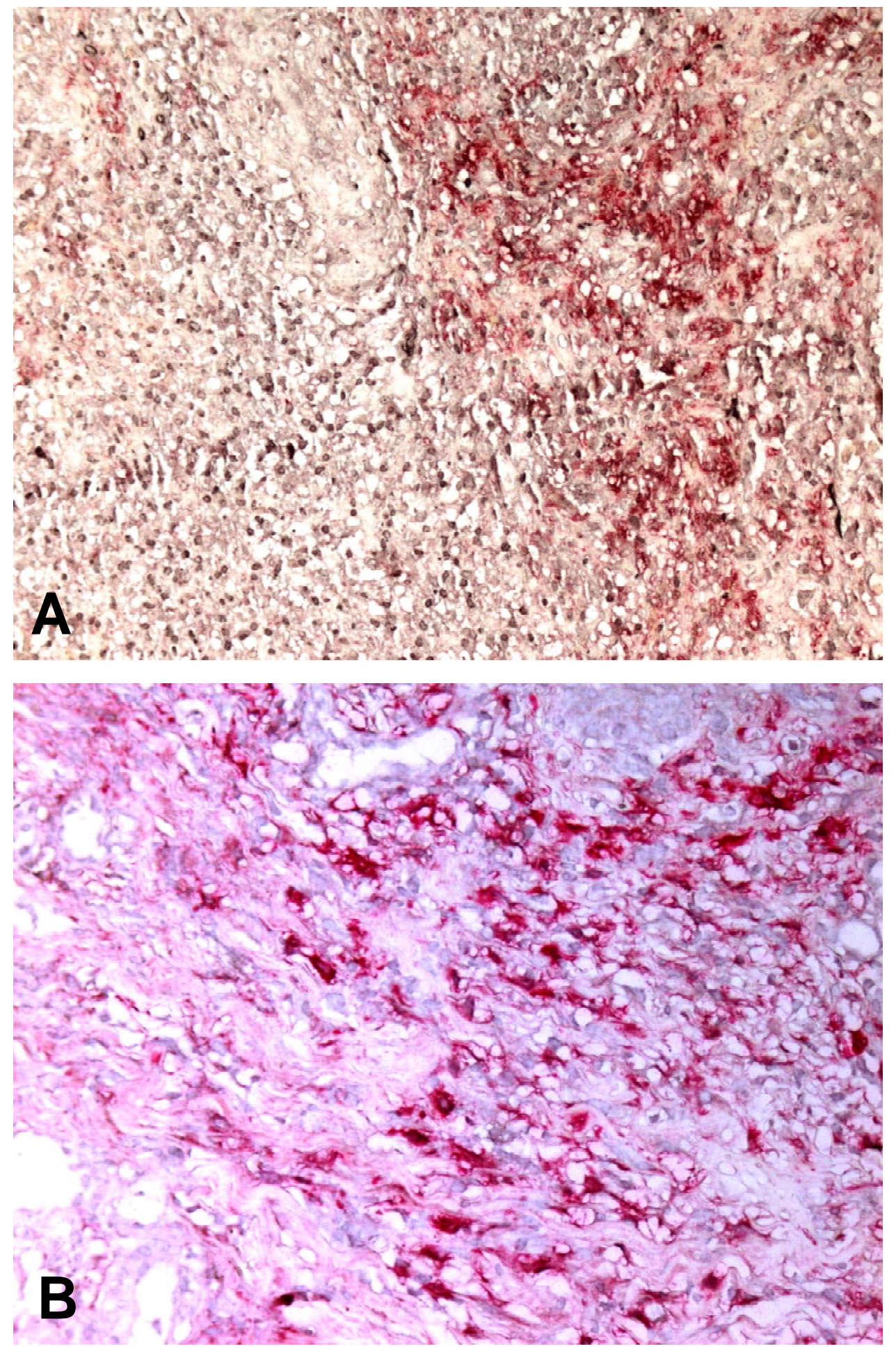

Figura 9. Leishmaniose tegumentar americana. A (caso 38) - Resposta tecidual granulomatosa. B (caso 5) - Resposta tecidual não específica. Notar dendrócitos dérmicos fator XIIla+ (marcados em vermelho) com coexpressão de iNOS (corados em negro). Reação imuno-histoquímica de dupla marcação - sistema EnVision peroxidase/"permanent red"/diaminobenzidina com níquel (A e B - aumento original $\times 200)$ 
Não houve diferença estatisticamente significativa entre número total de DD FXIIla+ presentes nos dois grupos, classificados de acordo com a resposta tecidual (Gráfico 2 e Tabela 2). Entretanto, o número de DDFXIIla+ com coexpressão de iNOS foi maior no grupo de resposta inflamatória granulomatosa (Gráfico 3 e Tabela 3).

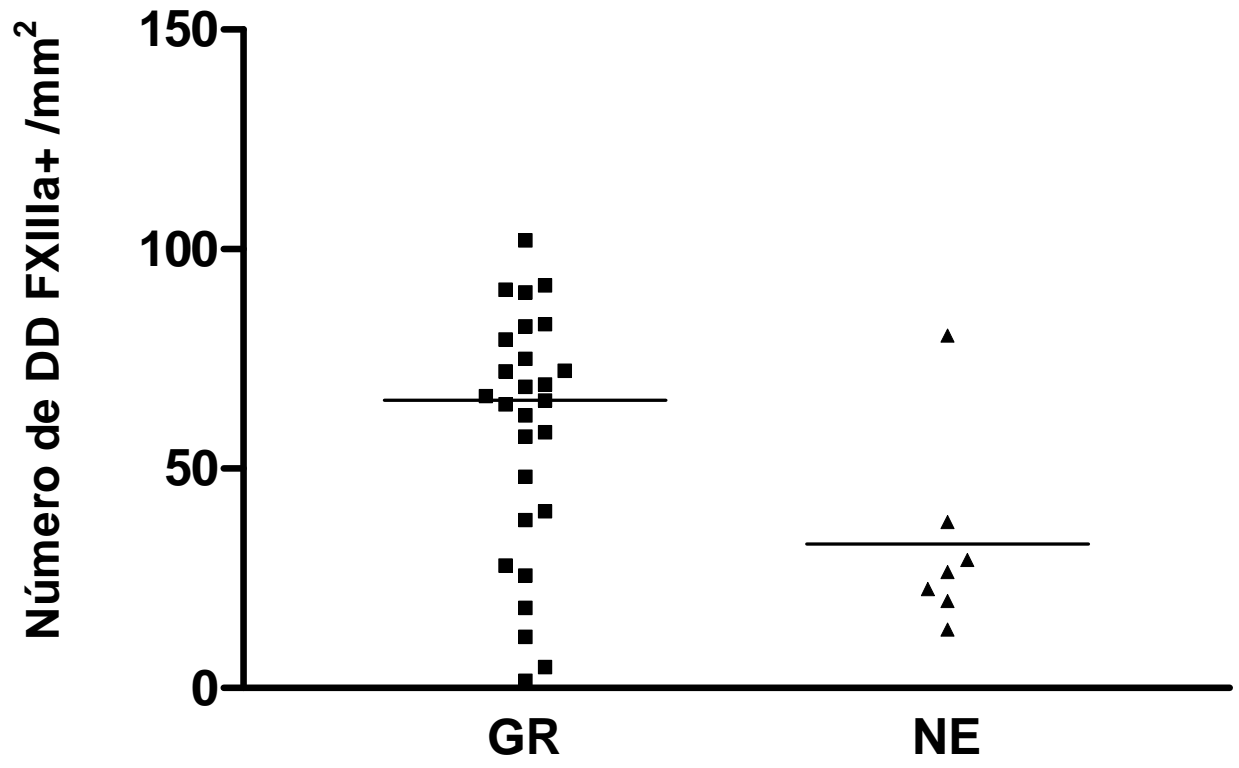

Gráfico 2. Leishmaniose tegumentar americana. Comparação do número de dendrócitos dérmicos Fator XIIla+/mm2 nas lesões cutâneas com resposta inflamatória crônica granulomatosa (GR) e crônica não específica (NE). Barra - mediana. Teste de Mann-Whitney $(p=0,055)$ 
Tabela 2. Leishmaniose tegumentar americana. Comparação do número de dendrócitos dérmicos fator XIIla+ nas lesões cutâneas com resposta inflamatória crônica granulomatosa e crônica não específica.

Tipo de resposta inflamatória

Valor de $p$

\begin{tabular}{|c|c|c|c|}
\hline Granulomatosa $(n=27)$ & Média $\pm D P$ & $58,10 \pm 28,06$ & $p=0,55$ \\
\hline & Variância & 1,63-102 & \\
\hline & Mediana & 65,51 & \\
\hline Não específica $(\mathrm{n}=7)$ & Média $\pm D P$ & $32,76 \pm 22,33$ & \\
\hline & Variância & $13,37-80,36$ & \\
\hline & Mediana & 26,38 & \\
\hline
\end{tabular}

DP - desvio padrão; Teste de Mann-Whitney

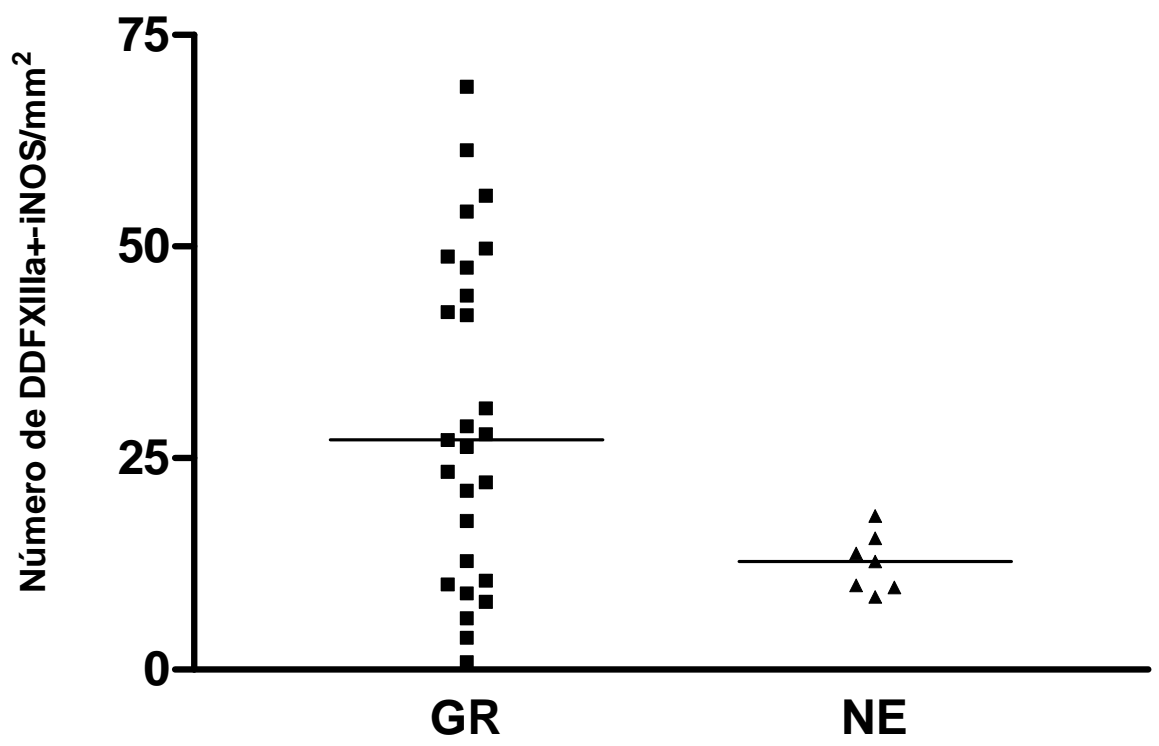

Gráfico 3. Leishmaniose tegumentar americana. Comparação do número de dendrócitos dérmicos Fator XIIla+ com coexpressão de iNOS, nas lesões cutâneas com resposta inflamatória crônica granulomatosa (GR) e crônica não específica (NE). Barra - mediana. Teste de Mann-Whitney $(p=0,04)$ 
Tabela 3. Leishmaniose tegumentar americana. Comparação do número de dendrócitos dérmicos fator XIIla+ que coexpressam iNOS nas lesões cutâneas com resposta inflamatória crônica granulomatosa e crônica não específica

Tipo de resposta inflamatória

Valor de $p$

$\begin{array}{lll}\text { Granulomatosa }(\mathrm{n}=27) & \text { Média } \pm \mathrm{DP} & 29,69 \pm 19,39 \\ & \text { Variância } & 0,89-68,9 \\ & \text { Mediana } & 27,18 \\ \text { Não específica }(\mathrm{n}=7) & \text { Média } \pm \mathrm{DP} & 29,69 \pm 12,36 \\ & \text { Variância } & 8,57-18,8 \\ & \text { Mediana } & 12,78\end{array}$

DP - desvio padrão; teste de Mann-Whitney 


\subsection{DEMONSTRAÇÃO E QUANTIFICAÇÃO DE EXPRESSÃO DE INOS} POR MACRÓFAGOS CD68+

Demonstramos, através de reação imuno-histoquímica de dupla marcação, que a maioria dos macrófagos CD68+ das lesões cutâneas estudadas expressa iNOS, (Figura 10). Das amostras selecionadas para este estudo, 33 exibiam padrão de resposta tecidual granulomatoso (77\%) (Figura 11A) e 10 apresentavam padrão inespecífico (23\%) (Figura 11B).

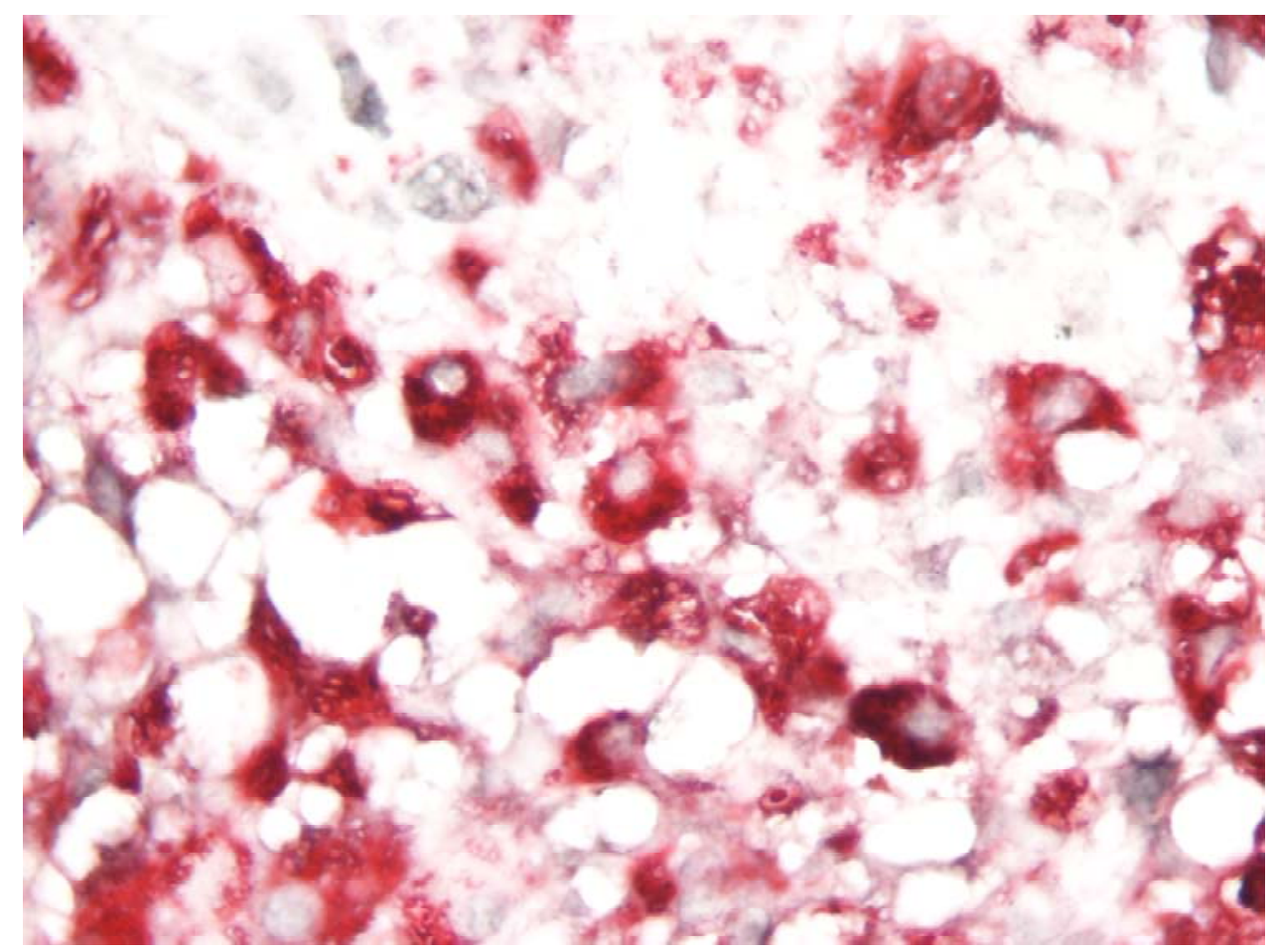

Figura 10. Leishmaniose tegumentar americana (caso 32). Macrófagos com coexpressão de CD68 (marcação em vermelho) e iNOS (negro) presentes no infiltrado inflamatório dérmico. Reação imuno-histoquímica de dupla marcação - sistema EnVision peroxidase/"permanent red"/diaminobenzidina com níquel (aumento original $\times 1000$ ) 


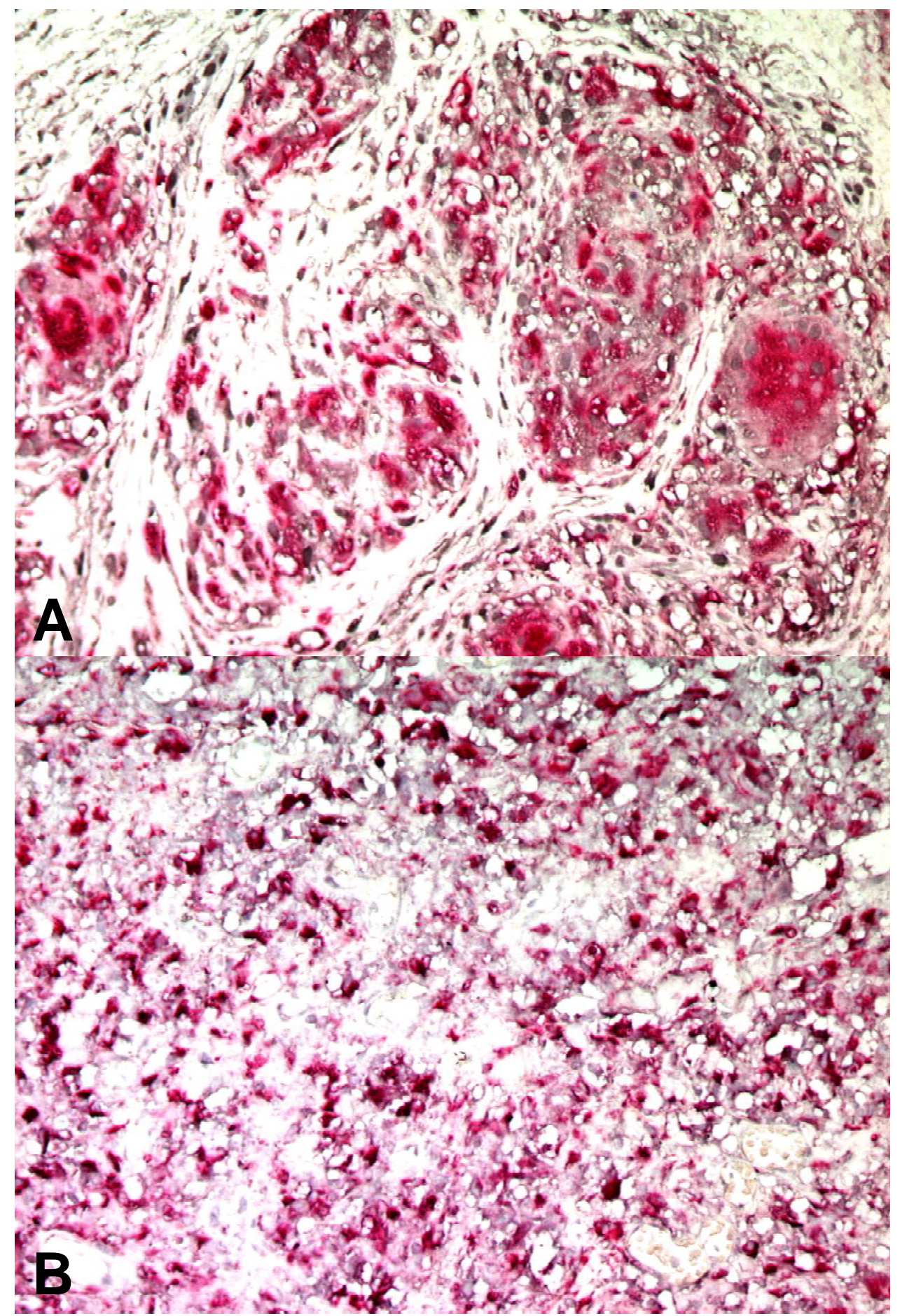

Figura 11. Leishmaniose tegumentar americana. A. Padrão de resposta tecidual granulomatoso (caso 4). B. Padrão de resposta tecidual não específico (caso 5). Ambos apresentam macrófagos (CD68+ imunomarcados em vermelho) com coexpressão de iNOS (marcação citoplasmática em negro). Reação imuno-histoquímica de dupla marcação sistema EnVision peroxidase/"permanent red"/diaminobenzidina com níquel. (A e B aumento original $\times 200$ ) 
Não houve diferença estatisticamente significativa em relação ao número total de macrófagos CD68+, assim como no número de macrófagos CD68+ coexpressando iNOS presentes nos dois grupos (Gráficos 4 e 5 e Tabelas 4 e 5).

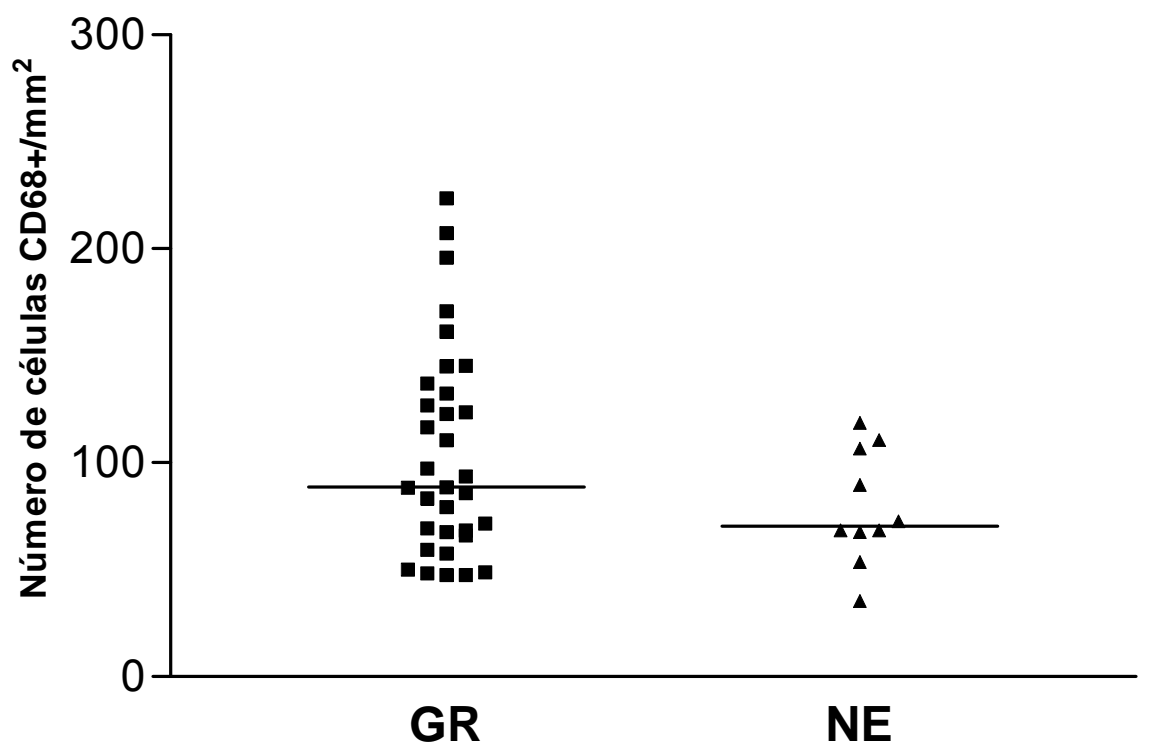

Gráfico 4. Leishmaniose tegumentar americana. Comparação do número de macrófagos (CD68+) nas lesões cutâneas com resposta inflamatória crônica granulomatosa (GR) e crônica não específica (NE). Barra - mediana. Teste de Mann-Whitney $(p>0,05)$ 
Tabela 4. Leishmaniose tegumentar americana. Comparação do número de macrófagos (CD68+) nas lesões cutâneas com resposta inflamatória crônica granulomatosa e crônica não específica

Tipo de resposta inflamatória

Valor de $p$

\begin{tabular}{|c|c|c|c|}
\hline \multirow[t]{3}{*}{ Granulomatosa $(n=33)$} & Média $\pm \mathrm{DP}$ & $104 \pm 48,67$ & $p>0,05$ \\
\hline & Variância & $47,61-223,6$ & \\
\hline & Mediana & 88,53 & \\
\hline \multirow[t]{3}{*}{ Não específica $(n=10)$} & Média $\pm D P$ & $79,16 \pm 26,64$ & \\
\hline & Variância & $35,42-118,6$ & \\
\hline & Mediana & 70,42 & \\
\hline
\end{tabular}

DP - desvio padrão; teste de Mann-Whitney

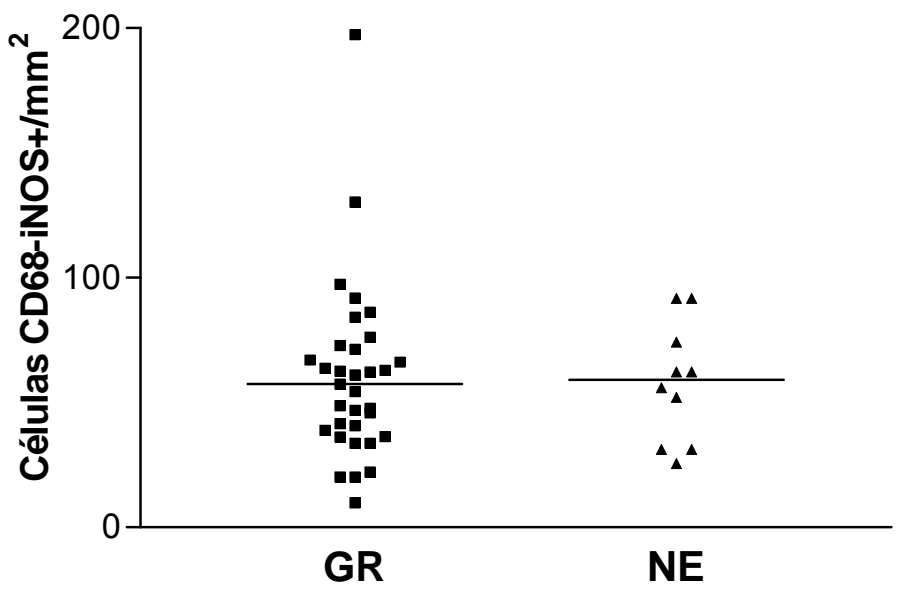

Gráfico 5. Leishmaniose tegumentar americana. Comparação do número de macrófagos (CD68+) com coexpressão de iNOS nas lesões cutâneas com resposta inflamatória crônica granulomatosa (GR) e crônica não específica (NE). Barra - mediana. Teste de Mann-Whitney $(p>0,05)$ 
Tabela 5. Leishmaniose tegumentar americana. Comparação do número de macrófagos (CD68+) que coexpressam iNOS nas lesões cutâneas com resposta inflamatória crônica granulomatosa e crônica não específica

Tipo de resposta inflamatória

Valor de $p$

\begin{tabular}{|c|c|c|c|}
\hline \multirow[t]{3}{*}{ Granulomatosa $(n=33)$} & Média $\pm \mathrm{DP}$ & $160,28 \pm 35,22$ & $p>0,05$ \\
\hline & Variância & $9,85-197,5$ & \\
\hline & Mediana & 57,35 & \\
\hline \multirow[t]{3}{*}{ Não específica $(n=10)$} & Média $\pm \mathrm{DP}$ & $25,53 \pm 91,78$ & \\
\hline & Variância & $35,42-118,6$ & \\
\hline & Mediana & 59,13 & \\
\hline
\end{tabular}

DP - desvio padrão; Teste de Mann-Whitney 
5.4. COMPARAÇÃO DO NÚMERO DE DENDRÓCITOS DÉRMICOS FATOR XIIIA+ E DE MACRÓFAGOS, SEM E COM COEXPRESSÃO DE iNOS NAS LESÕES CUTÂNEAS DA LEISHMANIOSE TEGUMENTAR AMERICANA.

A comparação de 34 biópsias submetidas à dupla marcação FXIIla/iNOS e CD68/iNOS revelou haver diferença na quantidade de DD FXIIla+ e macrófagos, assim como das células com coexpressão de iNOS, tanto na totalidade dos casos analisados, quanto quando estes foram analisados de acordo com seu padrão de resposta tecidual (gráficos 6 a 11 e tabelas 6 e 7).

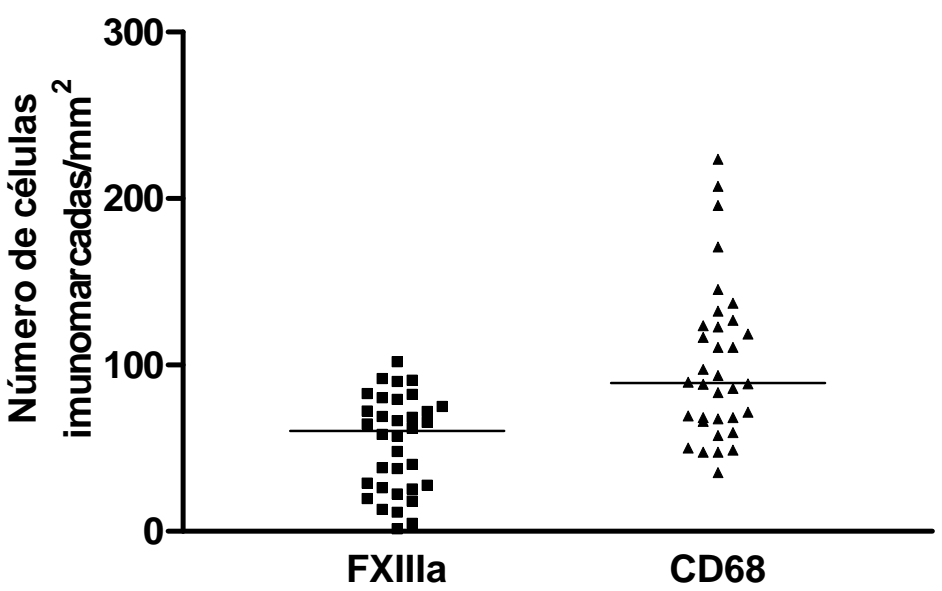

Gráfico 6. Leishmaniose tegumentar americana. Comparação do número de dendrócitos dérmicos fator XIIla+ e de macrófagos (CD68+) nas lesões cutâneas. Barra - mediana. Teste de Mann-Whitney $(p<0,0001)$ 


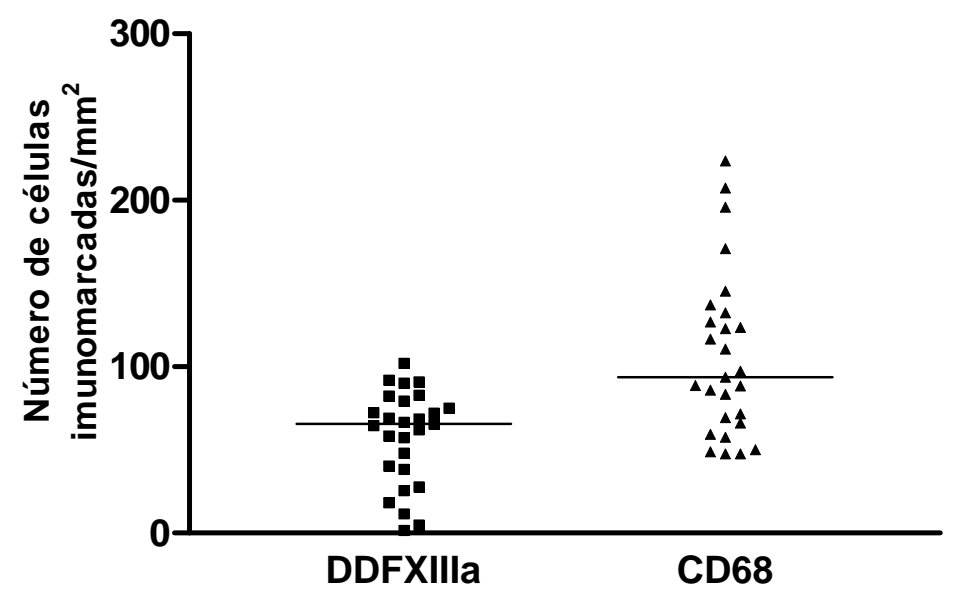

Gráfico 7. Leishmaniose tegumentar americana. Comparação do número de dendrócitos dérmicos fator XIIla+ e de macrófagos (CD68+) nas lesões cutâneas com resposta tecidual granulomatosa. Barra - mediana. Teste de Mann-Whitney $(p=0,0004)$

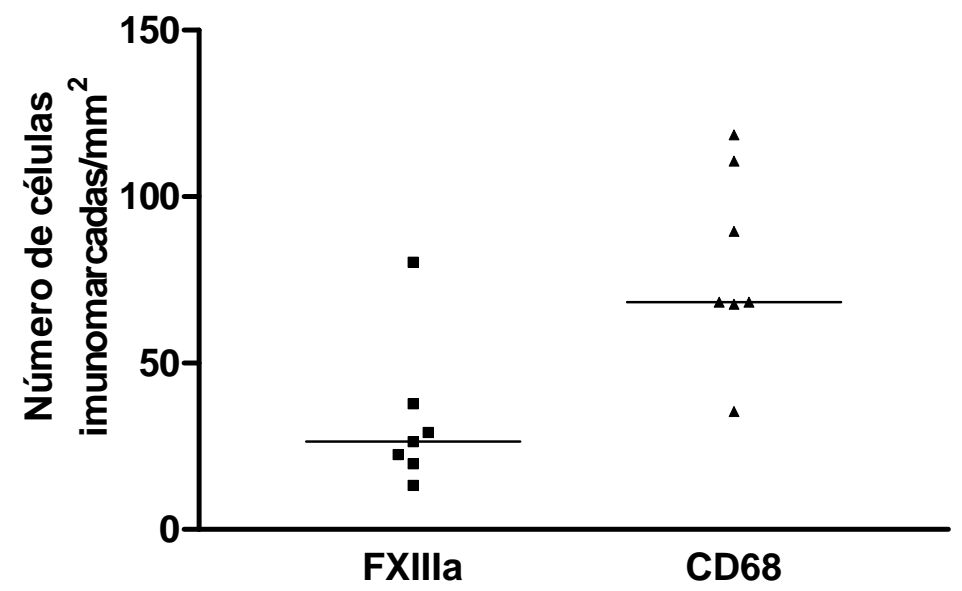

Gráfico 8. Leishmaniose tegumentar americana. Comparação do número de dendrócitos dérmicos fator XIIla+ e de macrófagos (CD68+) nas lesões cutâneas com resposta tecidual não específica. Barra - mediana. Teste de Mann-Whitney $(p=0,01)$ 


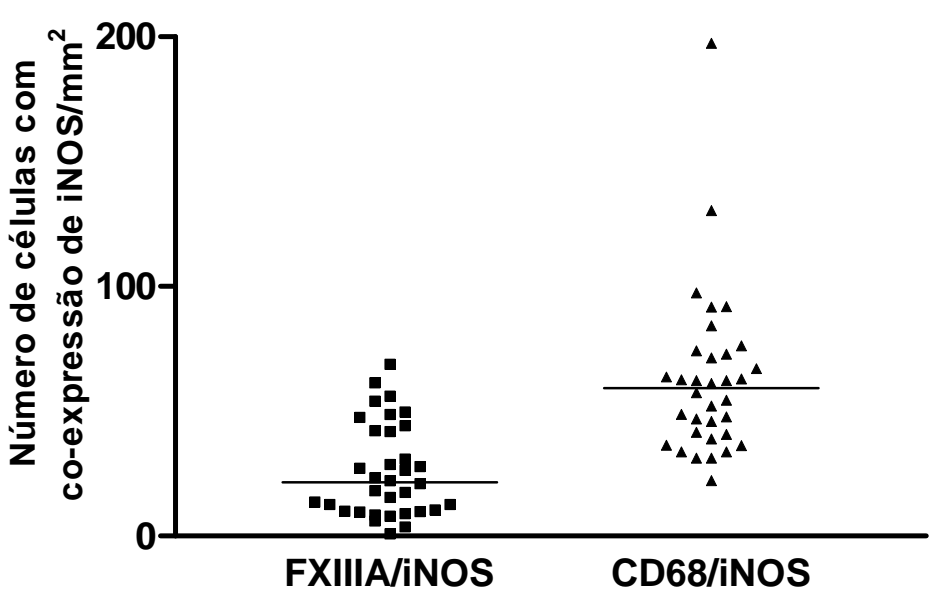

Gráfico 9. Leishmaniose tegumentar americana. Comparação do número de dendrócitos dérmicos fator XIIla+ e de macrófagos (CD68+) com coexpressão de iNOS. Barra - mediana. Teste de Mann-Whitney $(p<0,0001)$

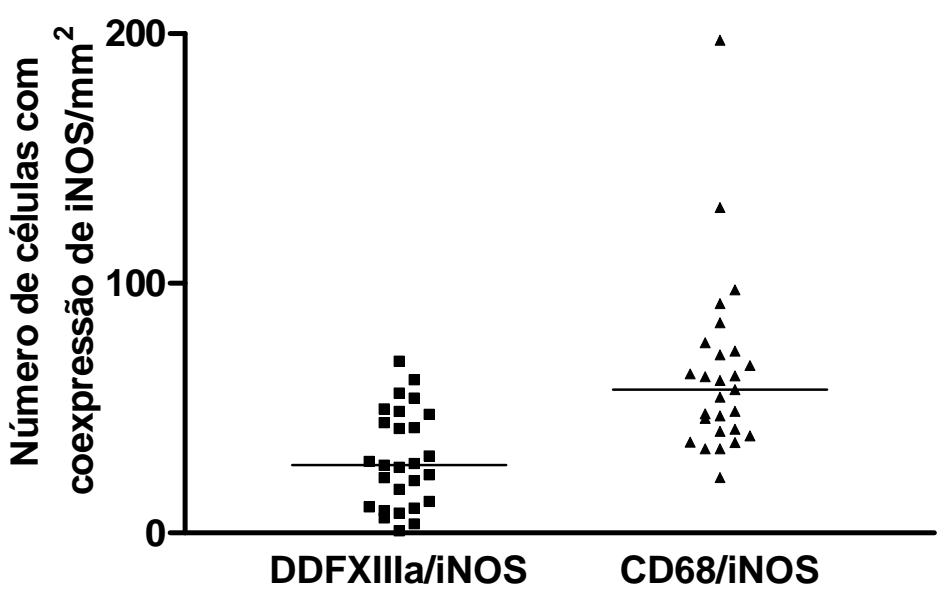

Gráfico 10. Leishmaniose tegumentar americana. Comparação do número de dendrócitos dérmicos fator XIIla+ e de macrófagos (CD68+) com coexpressão de iNOS nos casos de resposta granulomatosa. Barra mediana. Teste de Mann-Whitney $(p<0,0001)$ 


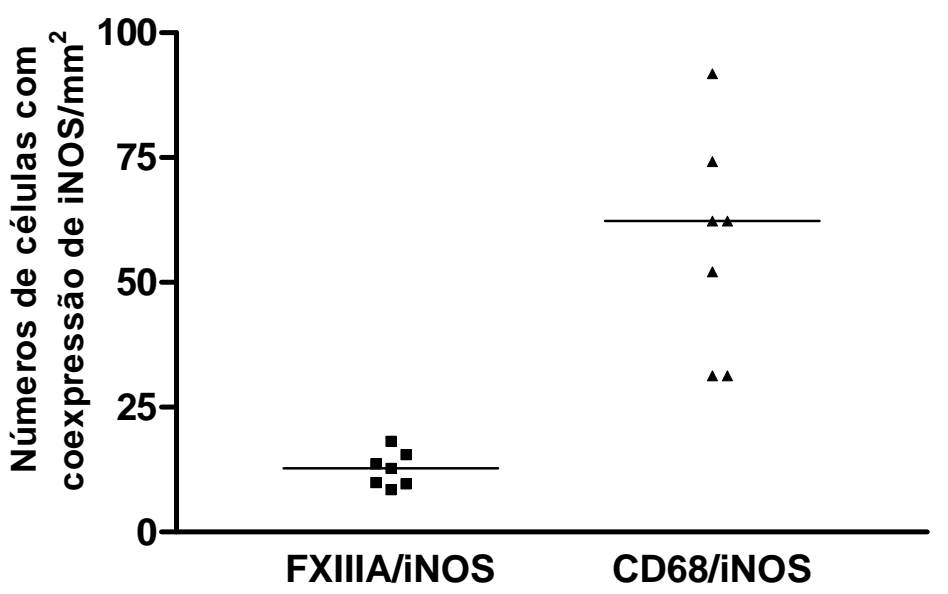

Gráfico 11. Leishmaniose tegumentar americana. Comparação do número de dendrócitos dérmicos fator XIlla+ e de macrófagos (CD68+) com coexpressão de iNOS nos casos de resposta não específica. Barra mediana. Teste de Mann-Whitney $(p=0,0006)$ 
Tabela 6. Leishmaniose tegumentar americana. Comparação do número de células dendríticas fator XIIla+ e de macrófagos (CD68+) em 34 biópsias de lesões cutâneas

Todos os casos $(n=34) \quad$ Resposta granulomatosa $(n=27) \quad$ Resposta inespecífica $(n=7)$

\begin{tabular}{lllllll}
\hline & DDFXIIla & CD68 & DDFXIIla & CD68 & DDFXIIIa & CD68 \\
Média $\pm D P$ & $52,88 \pm 28,62$ & $100,8 \pm 47,09$ & $58,1 \pm 28,06$ & $106,2 \pm 49,76$ & $32,76 \pm 22,33$ & $79,81 \pm 28,68$ \\
Variância & $1,63-102$ & $35,42-222,6$ & $1,63-102$ & $47,61-223,6$ & $13,37-80,36$ & $35,42 \pm 118,6$ \\
Mediana & 60,28 & $89,06^{a}$ & 65,51 & $93,68^{\text {b }}$ & 26,38 & $68,34^{c}$ \\
\hline
\end{tabular}

Teste de Mann-Whitney; $a-p<0,0001 ; b-p=0,0004 ; c-p=0,01$ 
Tabela 7. Leishmaniose tegumentar americana. Comparação do número de células dendríticas fator XIIla+ e de macrófagos $(\mathrm{CD68+})$ que expressam iNOS, em 34 biopsias de lesões cutâneas

\begin{tabular}{llllllc}
\multicolumn{2}{c}{ Todos os casos $(\mathrm{n}=34)$} & \multicolumn{2}{l}{ Resposta granulomatosa $(\mathrm{n}=27)$} & \multicolumn{2}{l}{ Resposta inespecífica $(\mathrm{n}=7)$} \\
\hline & DDFXIIIa/iNOS & CD68/iNOS & DDFXIIIa/iNOS & CD68/iNOS & DDFXIIIa/iNOS & CD68/iNOS \\
Média $\pm D P$ & $26,18 \pm 18,64$ & $62,63 \pm 33,02$ & $29,69 \pm 19,39$ & $63,86 \pm 35,57$ & $12,63 \pm 3,48$ & $57,91 \pm 21,98$ \\
Variância & $0,89-68,9$ & $22,25-197,5$ & $0,89-68,9$ & $41,10-197,5$ & $8,57-18,8$ & $31,32 \pm 91,78$ \\
Mediana & 21,66 & $59,21^{a}$ & 27,18 & $57,35^{\mathrm{b}}$ & 12,78 & $62,30^{\mathrm{c}}$ \\
\hline
\end{tabular}

Teste de Mann-Whitney; $a-p<0,0001 ; b-p<0,0001 ; c-p=0,0006$ 
5.5. COMPARAÇÃO DA PORCENTAGEM DE DENDRÓCITOS DÉRMICOS FATOR XIIIA+ E DE MACRÓFAGOS COM COEXPRESSÃO DE INOS NAS LESÕES CUTÂNEAS DA LEISHMANIOSE TEGUMENTAR AMERICANA.

A comparação de 34 biópsias submetidas à dupla marcação FXIIla/iNOS e CD68/iNOS revelou haver diferença na porcentagem de DD FXIlla+ e macrófagos com coexpressão de iNOS, apenas na totalidade dos casos analisados, não havendo diferença quando estes foram analisados de acordo com seu padrão de resposta tecidual (gráficos 12 a 14 e tabela 8).

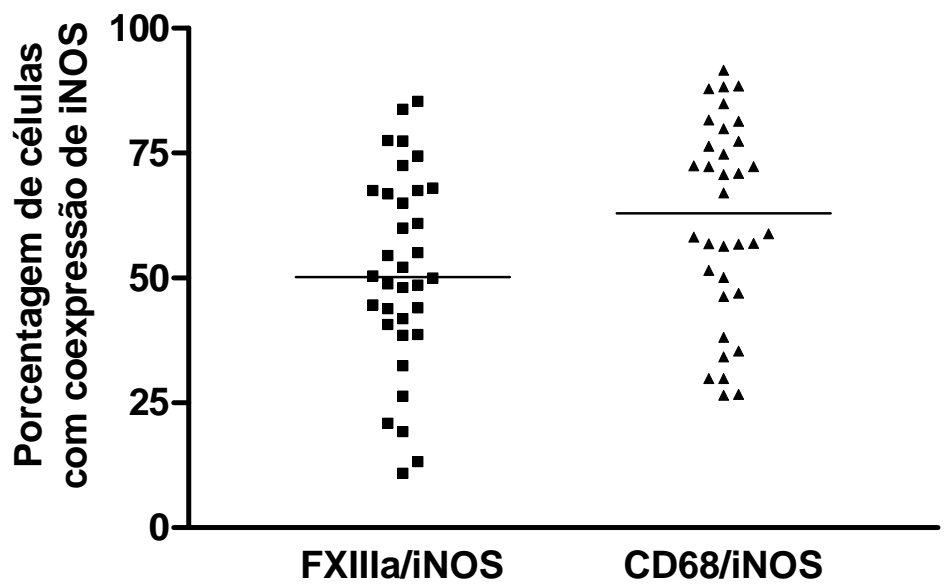

Gráfico 12. Leishmaniose tegumentar americana. Comparação da porcentagem de dendrócitos dérmicos fator Xllla+ e de macrófagos (CD68+) com coexpressão de iNOS. Barra - mediana. Teste de Mann-Whitney $(p=0,0412)$ 


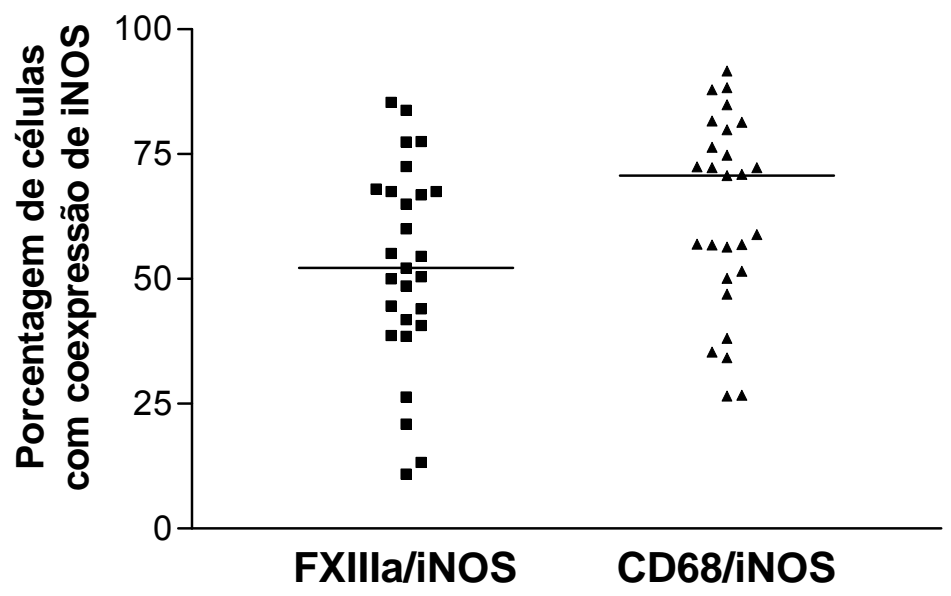

Gráfico 13. Leishmaniose tegumentar americana. Comparação da porcentagem de dendrócitos dérmicos fator XIIla+ e de macrófagos (CD68+) com coexpressão de iNOS nos casos de resposta granulomatosa. Barra - mediana. Teste de Mann-Whitney $(p=0,0618)$

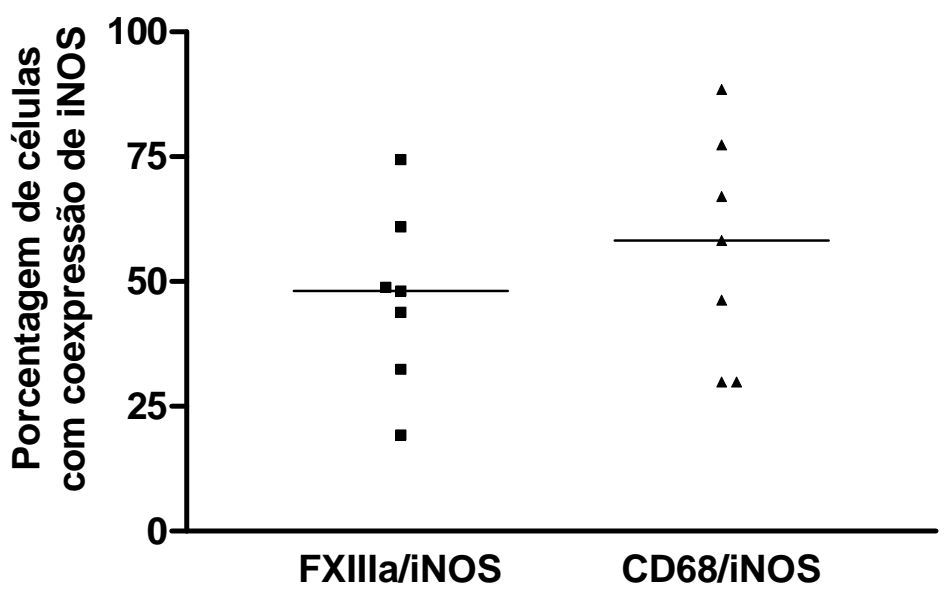

Gráfico 14. Leishmaniose tegumentar americana. Comparação da porcentagem de dendrócitos dérmicos fator XIIla+ e de macrófagos (CD68+) com coexpressão de iNOS nos casos de resposta não específica. Barra mediana.

Teste

de

Mann-Whitney

$(p=0,5350)$ 
Tabela 8. Leishmaniose tegumentar americana. Comparação da porcentagem de células dendríticas fator XIIla+ e de macrófagos (CD68+) que expressam iNOS, em 34 biopsias de lesões cutâneas

\begin{tabular}{lllllll} 
& \multicolumn{2}{l}{ Todos os casos $(n=34)$} & \multicolumn{2}{l}{ Resposta granulomatosa $(n=27)$} & \multicolumn{2}{l}{ Resposta inespecífica $(n=7)$} \\
\hline & DDFXIIla/iNOS & CD68/iNOS & DDFXIIIa/iNOS & CD68/iNOS & DDFXIIIa/iNOS & CD68/iNOS \\
Média \pm DP & $51,49 \pm 19,61$ & $61,71 \pm 19,95$ & $52,69 \pm 20,16$ & $63,00 \pm 19,43$ & $46,86 \pm 17,97$ & $56,72 \pm 22,70$ \\
Variância & $10,93-85,35$ & $26,57-91,63$ & $10,93-85,35$ & $26,57-91,63$ & $19,31-74,42$ & $29,87 \pm 88,43$ \\
Mediana & 50,25 & $62,98^{\text {a }}$ & 52,24 & $70,67^{\text {b }}$ & 48,15 & $58,17^{\mathrm{c}}$ \\
\hline
\end{tabular}

Teste de Mann-Whitney; $a-p=0,0412 ; b-p=0,0618 ; c-p=0,5350$ 
6. DISCUSSÃO 
O primeiro dos propósitos deste trabalho foi demonstrar a participação das CDP na resposta tecidual das lesões cutâneas da LTA. As CDP foram raramente demonstradas na pele humana normal (9). Demonstramos a presença destas células em todos os casos estudados, ora isoladas entre outras células inflamatórias, ora agrupadas e também na junção dermoepidérmica. Este padrão de distribuição é semelhante ao dos DD FXIIla+ que demonstramos nas lesões cutâneas da LTA (22).

A presença de CDP agrupadas, principalmente ao redor de granulomas, pode estar relacionada à sua capacidade de secretar IL-12, já que esta citocina está envolvida com a indução de resposta tipo Th1 e promoção da reação granulomatosa. (167) Entretanto, agrupamentos de CDP foram descritos ao redor de melanoma maligno metastático em linfonodos sentinela. (168)

As APC têm a capacidade de induzir tolerância ou imunidade (169), e as CDP parecem possuir a habilidade de induzir tolerância independente do seu estado de maturação (170).

No melanoma metastático as CDP expressam indoleamina (2,3)dioxigenase (IDO) que é enzima catabolizante do triptofano. As CDP, devido à sua capacidade de produzir IDO, têm sido consideradas agentes reguladores de promoção de tolerância. Essas células podem modular a intensidade da resposta imune por promover a geração de células T regulatórias $(169,171$, 172). Como nos processos neoplásicos, podemos sugerir que as CDP possam também exercer influência tolerogênica nas lesões cutâneas da LTA. 
Entretanto, nesta situação o seu papel tolerogênico deve ser interpretado como benéfico ao atenuar o dano tecidual induzido pela resposta imune local, ao contrário do observado nas neoplasias, onde representaria um mecanismo de evasão das células neoplásicas.

Observamos nos sítios de lesão da LTA a presença de CDP com morfologia dendrítica, não somente plasmocitoide. Dados da literatura afirmam que as CDP com morfologia dendrítica perderiam a capacidade de produzir IFN-I $(89,90)$, portanto especulamos que, como células maduras, as CDP sob estímulo do TLR-9 produzido por macrófagos, expressariam IDO. Esta especulação encontra embasamento nas observações relatadas em linfonodos sentinela de pacientes com câncer, onde foram observadas células CD123+/CCR6+ com atividade regulatória (127).

A presença de CDP na junção dermoepidérmica, pode ser interpretada, por outro lado, como provável fator de dano epitelial, com resultante necrose e ulceração da epiderme. A disposição de CDP alinhadas na junção dermoepidérmica foi relatada em lesões inflamatórias com atividade de interface, como o lúpus eritematoso, dermatite de contato alérgica, psoríase e líquen plano $(8,9,11,173-175)$. Nessas doenças as CDP localizadas na junção dermoepidérmica expressam granzima $B$, e estão associadas a linfócitos $T$ citotóxicos e a queratinócitos apoptóticos nos focos de dano epitelial. As CDP, portanto, seriam também potencializadoras da atividade citotóxica.

Considerando que as CDP participam tanto da imunidade inata quanto da adaptativa, essas células já estariam presentes precocemente no sítio de 
infecção produzindo IFN-I e citocinas pró-inflamatórias, com subsequente maturação e capacidade de função de APC. Desse modo exerceriam função na modulação da resposta imune adaptativa (94). Demonstramos em alguns casos do grupo GR a presença de células CD123+ com morfologia dendrítica dispostas ao redor dos granulomas. Esta observação sugere que as CDP maturaram nas lesões cutâneas de LTA e provavelmente estariam exercendo atividade de APC. Acreditamos que as CDP maduras também participariam do braço adaptativo da imunidade interagindo com macrófagos produtores de TLR-9 (123) presentes nos granulomas da resposta tecidual da LTA.

A presença das CDP isoladas, observadas mais frequentemente no padrão de resposta inespecífico, e agrupadas, mais frequente no padrão granulomatoso, poderia ser explicada pela capacidade das CDP de induzir secreção de anticorpos, como já demonstrado em cultura. Sob estímulo viral as CDP são capazes de induzir, via IFN-I e secreção de IL-6, os linfócitos B à diferenciação em plasmócitos, através da geração de plasmoblastos, com posterior diferenciação em plasmócitos (98). As lesões cutâneas na LTA caracterizam-se pela plasmocitose tecidual, apesar de representarem padrão de resposta Th1. Podemos especular se presença de plasmócitos nas lesões de LTA poderia ser explicada pelo estímulo proveniente das CDP ali presentes. Além disso, muitas das células com aspecto de plasmócitos observadas nas lesões poderiam ser as próprias CDP. Os plasmócitos mostram-se abundantes em ambos padrões de resposta tecidual, GR e NE. Entretanto, no padrão NE ocorre uma distribuição celular mais difusa, o que justificaria o predomínio de CDP isoladas por entre as células inflamatórias que ocupam a derme. No padrão de resposta GR o infiltrado celular dérmico é nodular e, desse modo, 
justifica-se o predomínio de CDP agrupadas nas biópsias desse grupo de resposta tecidual.

Apesar das diferenças observadas no arranjo e localização das CDP nos dois grupos de resposta tecidual das lesões cutâneas da LTA, sua distribuição numérica não diferiu quando comparados os dois grupos. Este resultado justifica-se pelo fato de que resposta tecidual diversa pode ser observada simultaneamente num mesmo doente, em diferentes lesões, ou até em diferentes áreas analisadas de uma única lesão de LTA (176).

O segundo propósito de nosso projeto de pesquisa foi o de demonstrar se os DD FXIlla+ teriam a capacidade de expressar iNOS, uma vez que os dados da literatura quanto à capacidade de produção de NO por células dendríticas são conflitantes (153-155). Demonstramos a expressão de iNOS pelos DD FXIIla+ em todos os espécimes de lesões cutâneas de LTA.

DD que produzem iNOS e TNF- $\alpha$ participam na resposta imune a infecções bacterianas e na psoríase $(80,81)$. Portanto, podemos agora sugerir que também na LTA os DD FXIIla+ participariam não somente como células alvos do parasita (22), mas também com capacidade leishmanicida.

Nas lesões cutâneas de LTA estudadas pudemos constatar também que, como esperado, a maioria dos macrófagos imunomarcados pelo anticorpo anti-CD68 coexpressa iNOS. Os macrófagos são o principal alvo de infecção na LTA, e sua atividade leishmanicida resulta de sua capacidade de produzir derivados de oxigênio e NO em resposta ao IFN-y e TNF-a. O NO é crítico para a eliminação do parasita (148). 
Como os DD FXIIla+ possuem a habilidade de fagocitar Leishmania (22) e de expressar iNOS, portanto capazes de atuar na lise dos parasitas na LTA, surge então a questão se os DD FXIIla+ não seriam, de fato, macrófagos.

No estudo dos processos patológicos os marcadores proteína S-100 A, FXIlla e ATPase ainda são rotineiramente empregados para identificar populações de CD, apesar destes marcadores serem também compartilhados por macrófagos (177). Expressão de FXIIla foi observada em DD CD1a+, DD CD14+ e em macrófagos, mas não em CL. A distinção entre DD e macrófagos dérmicos na pele humana tornou-se mais clara recentemente através de cuidadosos estudos imuno-histoquímicos $(63,64)$. Macrófagos e DD CD14+ compartilhariam vários marcadores em comum (CD11a, CD11b, CD14, CD18, CD32, CD45, CD68, CD206, CD209 e FXIIla) (177). Estudos por citometria de fluxo demonstraram expressão de FXIIla em células CD14+ isoladas por migração tecidual (6). Esse estudo supôs que essas células representariam as células dendríticas observadas "in situ". No entanto, Zaba et al. (63) demonstraram que FXIIla era principalmente expresso por macrófagos CD163+, como previamente argumentado (73). CD163 (receptor eliminador do complexo de ligação hemoglobina/haptoglobina) é um receptor expresso na maioria dos macrófagos teciduais (178) e é considerado critério fenotípico dos macrófagos da pele. A expressão de FXIlla é relacionada à ativação celular induzida por IL-4 em macrófagos ativados alternativamente (73). FXIIla também é expresso em DD migratórios $(6,179), C D$ derivadas de monócitos (180), DD derivados de células progenitoras hematopoiéticas (45), além dos DD dendríticos MHC II+ descritos por Cerio et al. (67). A expressão de FXIIla indicaria um estado de ativação celular alternativo, induzido pela exposição de 
CD e macrófagos a IL-4 $(73,180)$. Além disso, a expressão de FXIIla pode indicar um papel potencial na remodelação tecidual. Logo, a descrição original de DD FXIIla+ em vários estados patológicos (67) pode ter incluído tanto CD como macrófagos com morfologia dendrítica, residentes em um microambiente rico em uma citocina distinta, por exemplo, IL-4 (65).

Pelo acima exposto, parece haver uma grande plasticidade entre macrófagos e CD teciduais (181). Pelos achados de Zaba et al. (63), certos marcadores fenotípicos podem ser úteis na definição de subgrupos de células mononucleares em dois polos espectrais. Por exemplo, células BDCA-1+ identificam células com potentes propriedades aloestimulatórias, enquanto células CD163+ não têm capacidade aloestimulatória, mas possuem grande atividade fagocítica. Entre estes dois polos há subgrupos de células dérmicas mononucleares que expressam vários marcadores, os quais podem identificar tipos celulares funcionalmente flexíveis em relação à apresentação de antígenos e fagocitose. Está bem estabelecido que CD imaturas, incluindo DD, podem ter atividade fagocítica, uma função usualmente atribuída a macrófagos (22, 182, 183). Por outro lado, macrófagos podem ser potentes células apresentadoras de antígenos para células T CD8+ (184). DD que expressam CD1a possuem função potente de apresentação de antígenos, enquanto a expressão de CD14 indica papel precursor de CL (179). Portanto, as células mononucleares sentinelas da derme parecem existir em estado pluripotente e, na dependência de fatores microambientais, podem apresentar função de apresentação antigênica, migratória e função fagocítica (65).

Nosso estudo evidenciou que há maior número de células FXIIla+/iNOS+ no padrão de resposta tecidual granulomatoso. Uma vez que 
DD FXIIla+ são produtores de TNF- $\alpha(156,157)$ e esta citocina é importante na indução da resposta granulomatosa (185), acreditamos que os DD FXIlla+ participam da organização da resposta tecidual das lesões cutâneas da LTA. As citocinas associadas ao padrão de resposta Th1, IFN-ץ e TNF- $\alpha$, induzem a produção de iNOS. Como o microambiente da resposta granulomatosa é rico em IFN-y e TNF- $\alpha$, poderíamos a partir desses dados, explicar o maior número de células FXIIla+/iNOS+ no padrão de resposta tecidual granlomatoso. Ainda, a capacidade de produção de TNF-a pelas próprias células FXIIla+ $(156,157)$, seria também um fator de auto-estimulação. Ora, se os DD FXIlla+ são produtores de TNF- $\alpha$, e agora demonstramos que também expressam iNOS, poderíamos especular se estas células não seriam os DD inflamatórios ( $\mathrm{PTI})$, previamente descritos $(80,81)$. No entanto, Lowes et al. afirmam que os DD inflamatórios seriam populações celulares distintas dos outros DD (81).

A disposição dos DD FXIIla+, com ou sem coexpressão de iNOS, ao redor de granulomas nas lesões cutâneas de LTA é semelhante ao observado em outras doenças infecciosas $(22,70,72,186)$, onde se sugeriu também serem estas células, através de sua capacidade de secreção de TNF- $\alpha$, promotoras da formação de granulomas.

Quando comparadas as amostras submetidas à dupla marcação FXIIIa/iNOS e CD68/iNOS, notamos número total maior de macrófagos, com ou sem coexpressão de iNOS, em relação ao número de DD FXIlla+, com ou sem coexpressão de iNOS, tanto na totalidade dos casos analisados, como quando estes foram analisados de acordo com seu padrão de resposta tecidual. A porcentagem de macrófagos com coexpressão de iNOS foi maior do que a porcentagem de DD FXIIla+ iNOS+ na totalidade dos casos. Estes dados 
confirmam os macrófagos como principais células com capacidade leishmanicida, e os DD FXIIla+ como células auxiliares na resposta imune efetora. Além disso, esses resultados lançam dúvida quanto à possibilidade dos DD FXIIla+ serem macrófagos cutâneos como o proposto por alguns autores $(36,63)$.

Demonstramos pela primeira vez a participação das CDP nas lesões cutâneas da leishmaniose humana. Essa população de CD teria, como o proposto em outros processos de natureza inflamatória ou neoplásica, função imunomoduladora promovendo ou atenuando a resposta imune. Os DD FXIIla+ desempenhariam provável função acessória como APC, células alvo dos parasitas e teriam, como os macrófagos, função leishmanicida nos sítios de lesão da LTA.

As células dendríticas são reguladoras fundamentais das respostas imunes cutâneas, e são alvos atraentes para abordagens imunoterapêuticas. É importante entender a contribuição de cada subgrupo de célula dendrítica cutânea na resposta imune a diferentes patógenos, pois a compreensão de como o balanço entre efeitos protetores e patológicos é mantido, pode ser a chave para a manipulação terapêutica desse componente celular nas doenças, entre elas a LTA. 
7. CONCLUSÕES 
1. As células dendríticas plasmocitoides, que têm atividade próinflamatória e/ou tolerogênica, foram pela primeira vez demonstradas nas lesões cutâneas da leishmaniose tegumentar americana.

2. Não houve diferença significativa na quantidade de células dendríticas plasmocitoides entre os dois padrões de resposta tecidual, granulomatoso e não específico.

3. Dendrócitos dérmicos Fator XIIla+ com coexpressão de iNOS foram pela primeira vez observados em amostras de lesões cutâneas de leishmaniose tegumentar americana estudadas. Essas células teriam atividade semelhante à de macrófagos na destruição dos parasitas nos sítios de lesão.

4. O maior número de DD FXIlla+ com coexpressão de iNOS na resposta tecidual granulomatosa sugere sua participação na organização da resposta tecidual frente à Leishmania.

5. Nas lesões cutâneas de LTA, o número de macrófagos, com ou sem coexpressão de iNOS, assim como a porcentagem de macrófagos com coexpressão de iNOS, foram maiores que os de DD FXIIla+, com e sem expressão de iNOS. Esses resultados sugerem que, apesar dos DD FXIlla+ serem capazes de atuar como células leishmanicidas, essa função deve ser efetuada principalmente pelos macrófagos, que representam o principal alvo da infecção na LTA. 
8. ANEXOS 


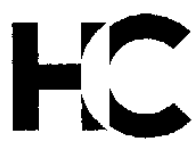

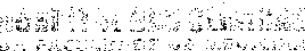

\section{APROVAÇĀO}

A Comissāo de Ética para Análise de Projetos de Pesquisa - CAPPesq da Diretoria Clínica do Hospital das Clínicas e da Faculdade de Medicina da Universidade de São Paulo, em sessāo de 23/04/2008, APROVOU o Protocoló de Pesquisa n 0133/08, intitulado: "CÉlULAS DENDRÍTICAS PLASMOCITÓIDES, DENDRÓCITOS DÉRMICOS FAIOR XIIIA POSITIVOS, MACRÓFAGOS E EXPRESSĀO DE INOS NA RESPOSTA TECIDUAL CUTÃNEA DA LEISHMANIOSE TEGUMENTAR AMERICANA." apresentado pelo Departamento de PATOLOGIA.

Cabe ao pesquisador elaborar e apresentar d̀ CAPPesq, os relatórios parciais e final sobre a pesquisa (Resoluçāo do Conselho Nacional de Saúde $n^{\circ} 196$, de 10/10/1996, inciso IX.2, letra "c").

Pesquisador (a) Responsável: Profa. Dra. Mírian Nacagami Sotto Pesquisador (a) Executante: llana Halpern Salomon

CAPPesq, 28 de Abril de 2008

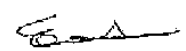

Prof. Dr. Eduardo Massad Presidente da Comissão de Éfica para Análise de Projetos de Pesquisa

Comissão de Ética para Anàlise de Projetos de Pesquisa do HCFMUSP e da FMUSP Diretoria Clinica co Hospital das Clínicas da Faculdade

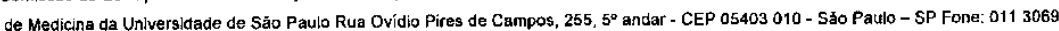
6442 Fax: 01130696492 e-mail: cappesq io: henet.usp.br/ secretariacappesq2@henet.usp.br 


\section{ANEXO B - INFORMAÇÕES ADICIONAIS SOBRE A CASUÍSTICA}

A casuística do estudo foi composta por 18 (35\%) doentes do gênero feminino e 34 (65\%) do gênero masculino (Gráfico 15).

Gráfico 15. LEISHMANIOSE TEGUMENTAR AMERICANA. DISTRIBUIÇÃO DOS DOENTES POR GÊNERO

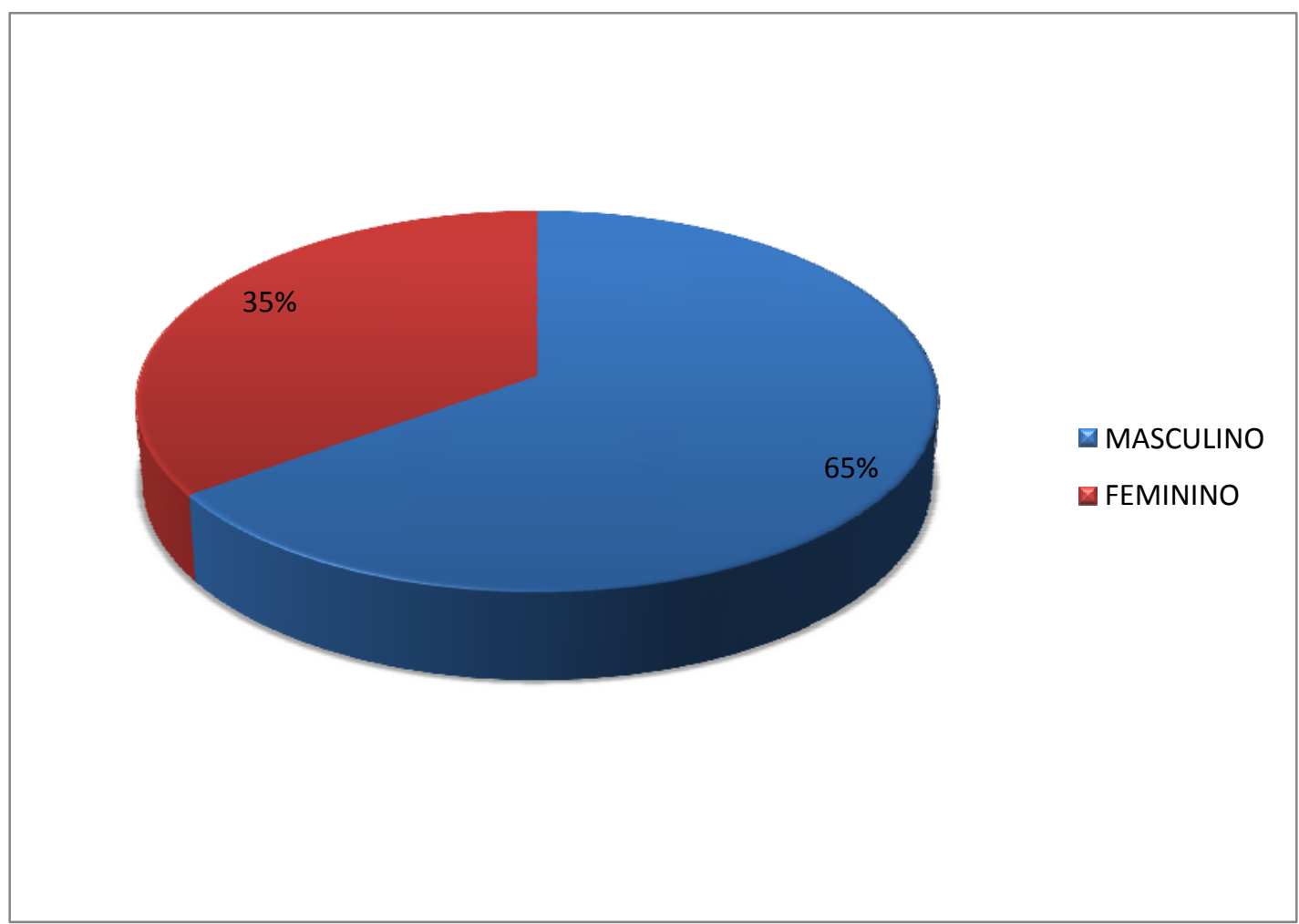

A idade dos pacientes variou de 1 a 96 anos, com idade média de 41 anos (dados obtidos de 50 casos que apresentavam esta informação clínica nos prontuários) (Gráfico 16). 
Gráfico 16. LEISHMANIOSE TEGUMENTAR AMERICANA. DISTRIBUIÇÃO DOS DOENTES POR FAIXA ETÁRIA

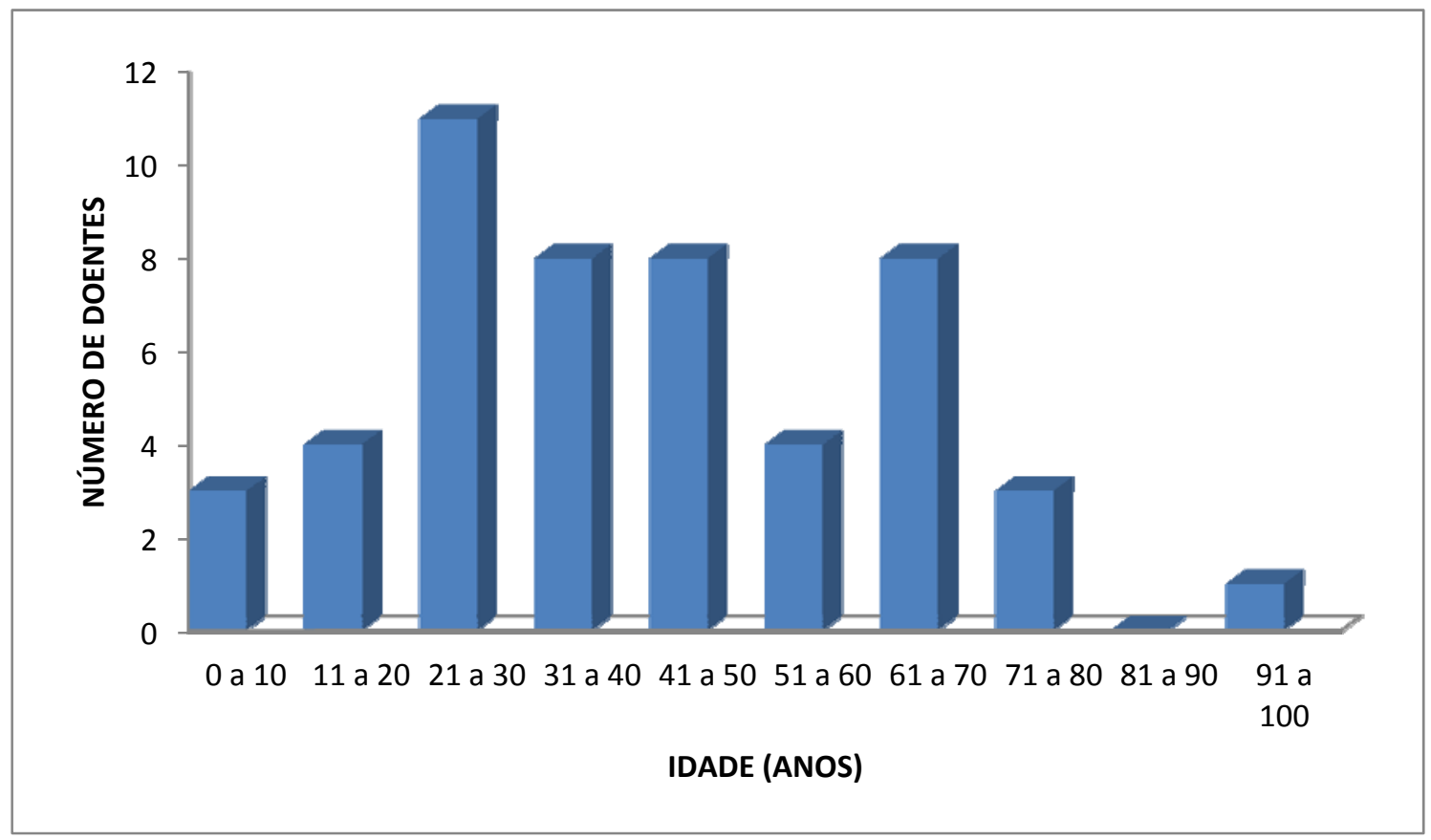

As lesões estavam presentes predominantemente nos membros, em 36 dos pacientes $(70 \%)$, mas também na região da face/cabeça em nove dos pacientes (18\%), e no tronco em seis pacientes (12\%). Esta informação estava disponível em 51 dos 52 prontuários consultados (Gráfico 17). 
Gráfico 17. LEISHMANIOSE TEGUMENTAR AMERICANA. DISTRIBUIÇÃO TOPOGRÁFICA DAS LESÕES CUTÂNEAS

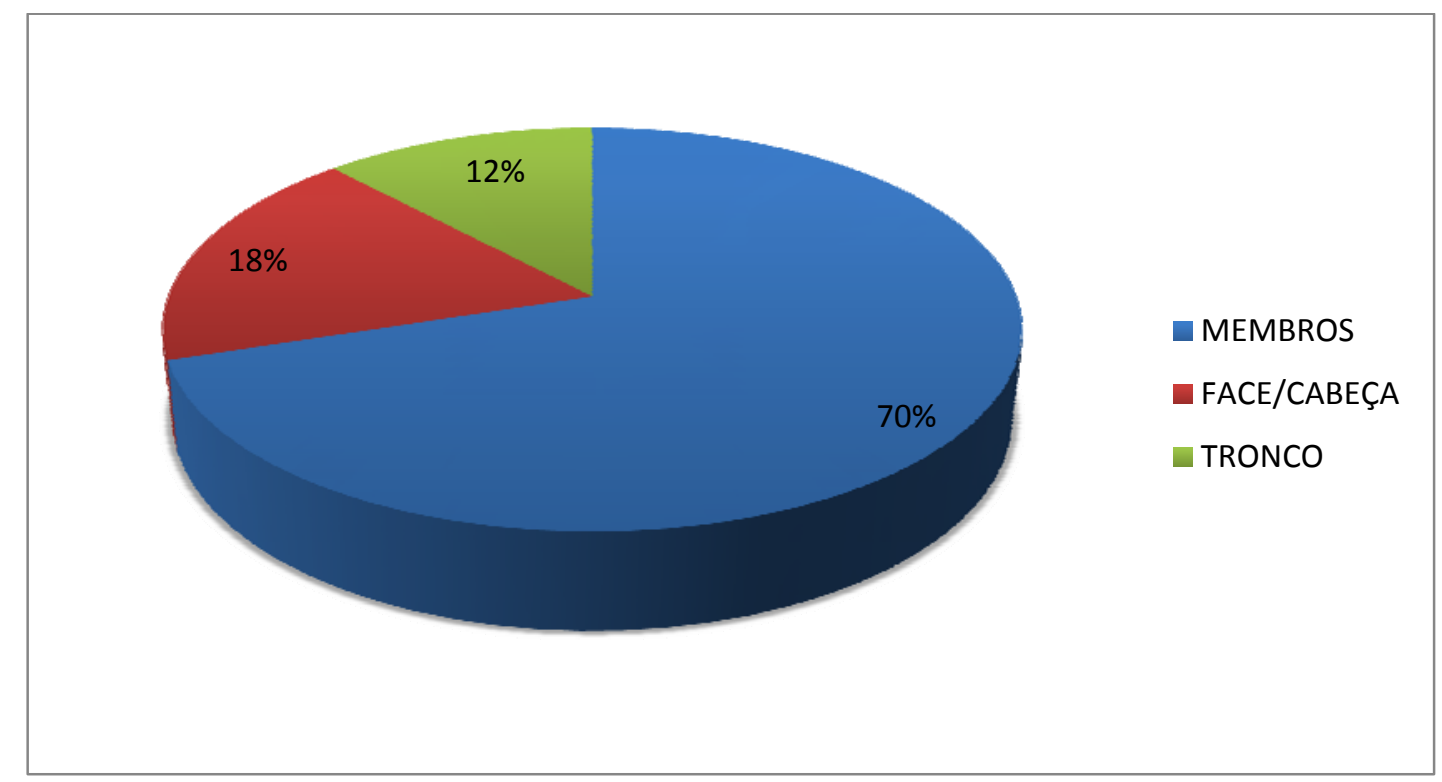

A descrição do tipo de lesão foi obtida para 42 pacientes. A forma ulcerada foi a observada em 37 dos pacientes (88\%), lesões verrucosas em quatro pacientes (10\%) e nódulos sarcoídeos em um deles (2\%) (Gráfico 18).

Gráfico 18. LEISHMANIOSE TEGUMENTAR AMERICANA. CARACTERÍSTICA DAS LESÕES

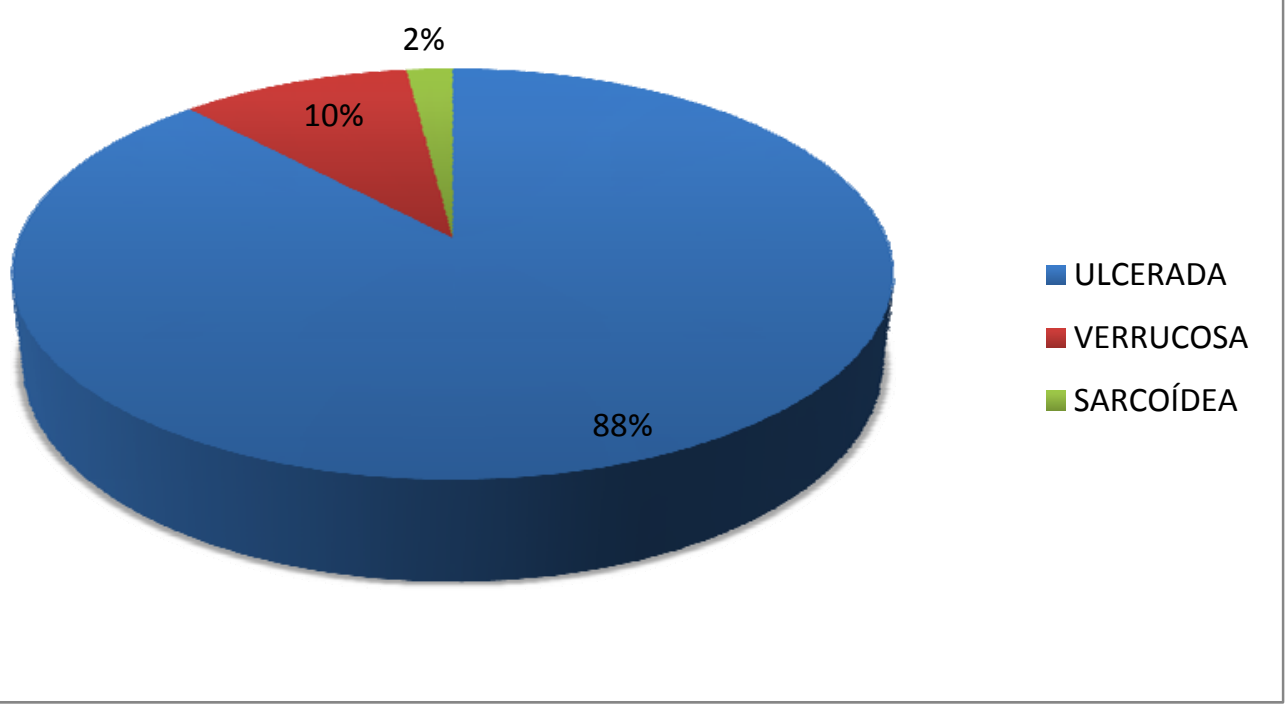


Dados relativos à intradermorreação de Montenegro estavam presentes em 39 prontuários. Reação positiva foi observada em 31 doentes (84\%) e negativa em seis (16\%). Um dos doentes não realizou o teste, e outro não compareceu à leitura (Gráfico 19).

Gráfico 19. LEISHMANIOSE TEGUMENTAR AMERICANA. RESULTADO DA REAÇÃO DE MONTENEGRO

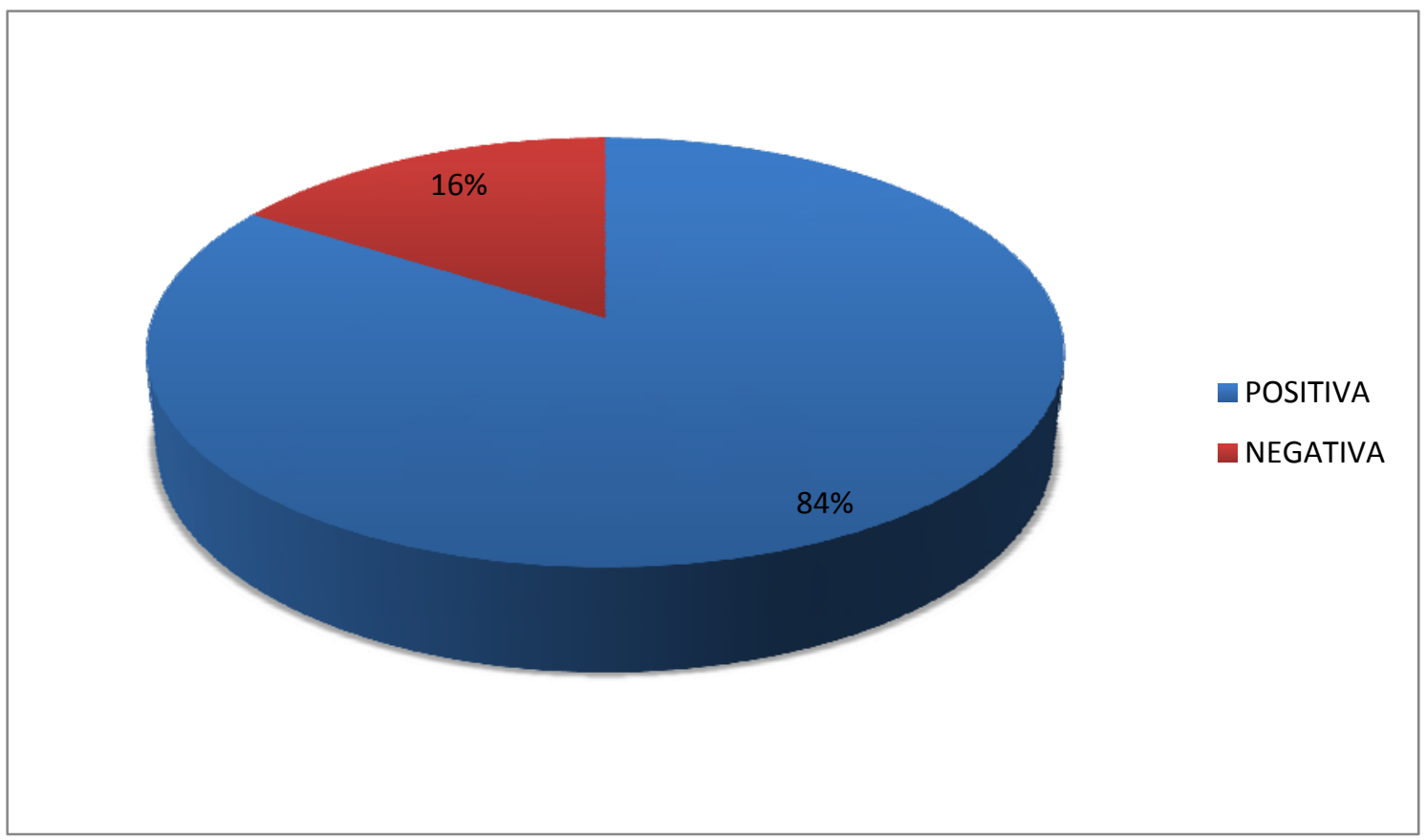

A análise histopatológica revelou que os espécimes de 11 doentes apresentavam reação inflamatória crônica não específica (21\%), e 41, reação inflamatória crônica granulomatosa (79\%). 
Gráfico 20. LEISHMANIOSE TEGUMENTAR AMERICANA. TIPO DE RESPOSTA TECIDUAL

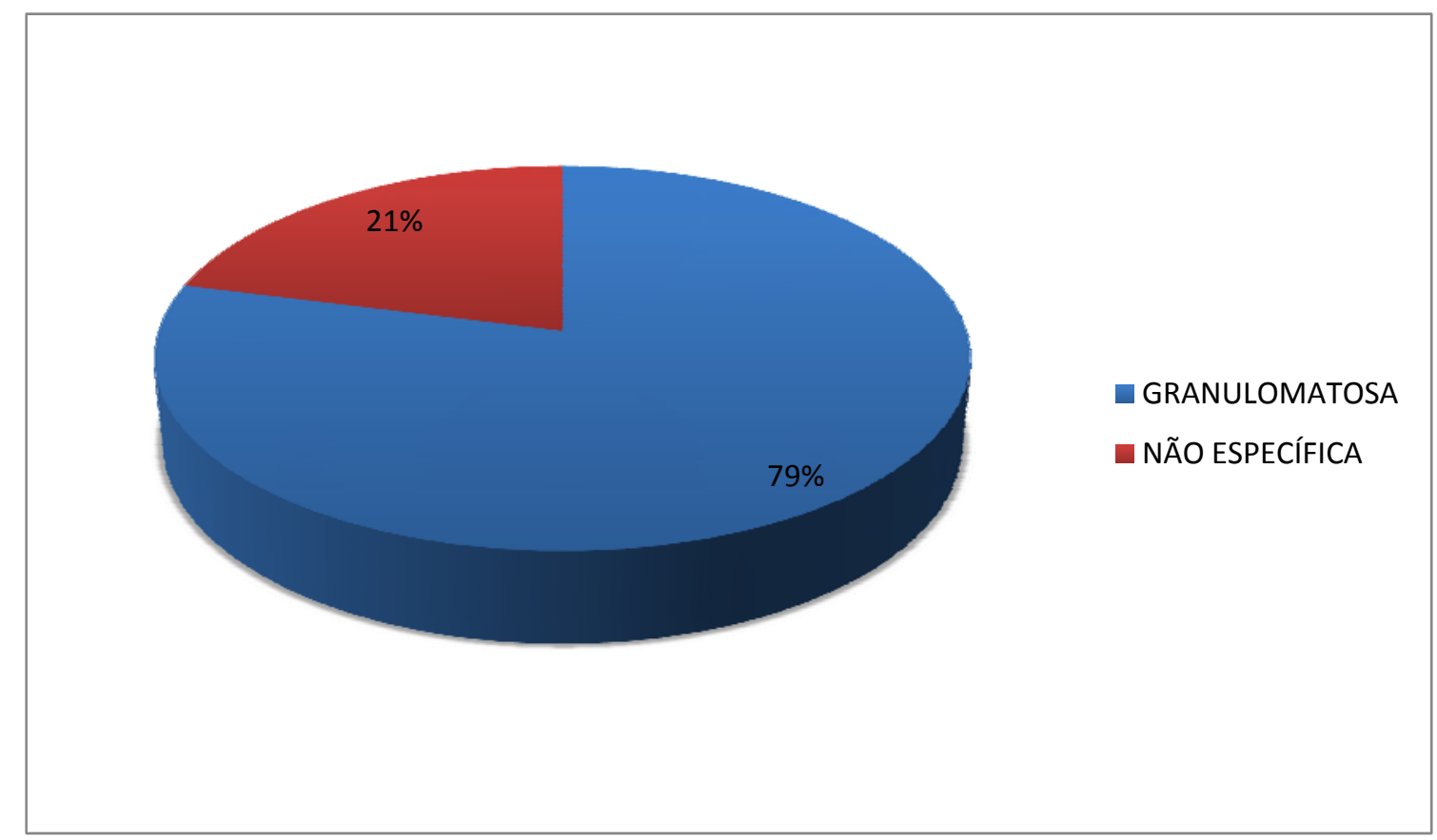

Formas amastigotas foram observadas em 27 biópsias à coloração de hematoxilina-eosina (52\%), e não foram detectadas em 25 das amostras (48\%). Formas amastigotas foram mais frequentes nos espécimes com padrão de resposta inflamatória crônica não específica (Gráfico 21). 
Gráfico 21. LEISHMANIOSE TEGUMENTAR AMERICANA. PRESENÇA OU AUSÊNCIA DE FORMAS AMASTIGOTAS ENTRE OS PADRÕES DE RESPOSTA TECIDUAL (HE)

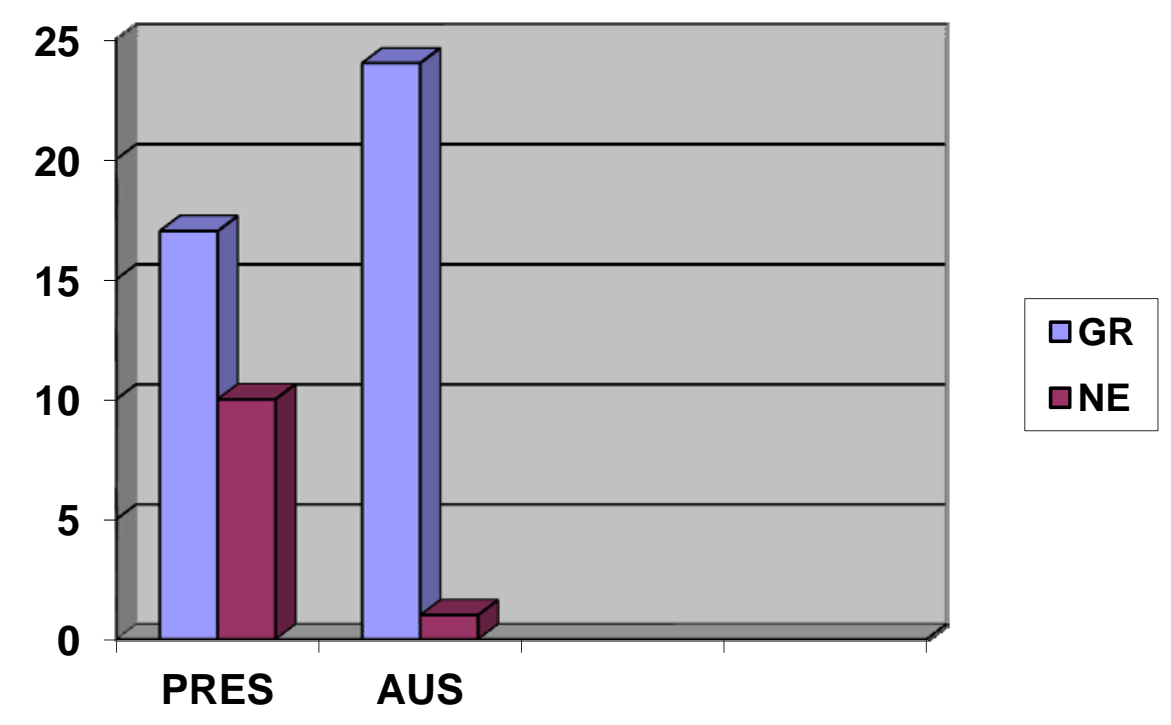

HE - hematoxilina-eosina; GR - granulomatoso; NE - não específico; PRES - presença de amastigotas à coloração hematoxilina-eosina; AUS ausência de amastigotas à coloração hematoxilina-eosina

Antígeno parasitário de Leishmania foi evidenciado, pela técnica imunohistoquímica (165), em 34 dos 48 (71\%) espécimes submetidos à reação. Antígeno de Leishmania não pode ser demonstrado em 14 das biópsias (29\%). Dentre os casos positivos, a semiquantificação revelou 15 casos (44\%) com presença de raras amastigotas $(+/ 3+), 14$ casos $(41 \%)$ com presença moderada de formas amastigotas $(2+/ 3+)$ e cinco casos $(15 \%)$ com numerosas amastigotas $\left(3^{+/ 3+)}\right.$. O padrão de distribuição do antígeno de Leishmania entre os padrões de resposta tecidual demonstrou que na resposta inflamatória crônica granulomatosa a quantidade de antígeno observada é menor que nos casos com resposta inflamatória crônica não específica (Gráfico 22). 
Gráfico 22. LEISHMANIOSE TEGUMENTAR AMERICANA. DISTRIBUIÇÃO DA QUANTIDADE DE ANTÍGENO DE Leishmania (IH) ENTRE OS PADRỖES DE RESPOSTA TECIDUAL

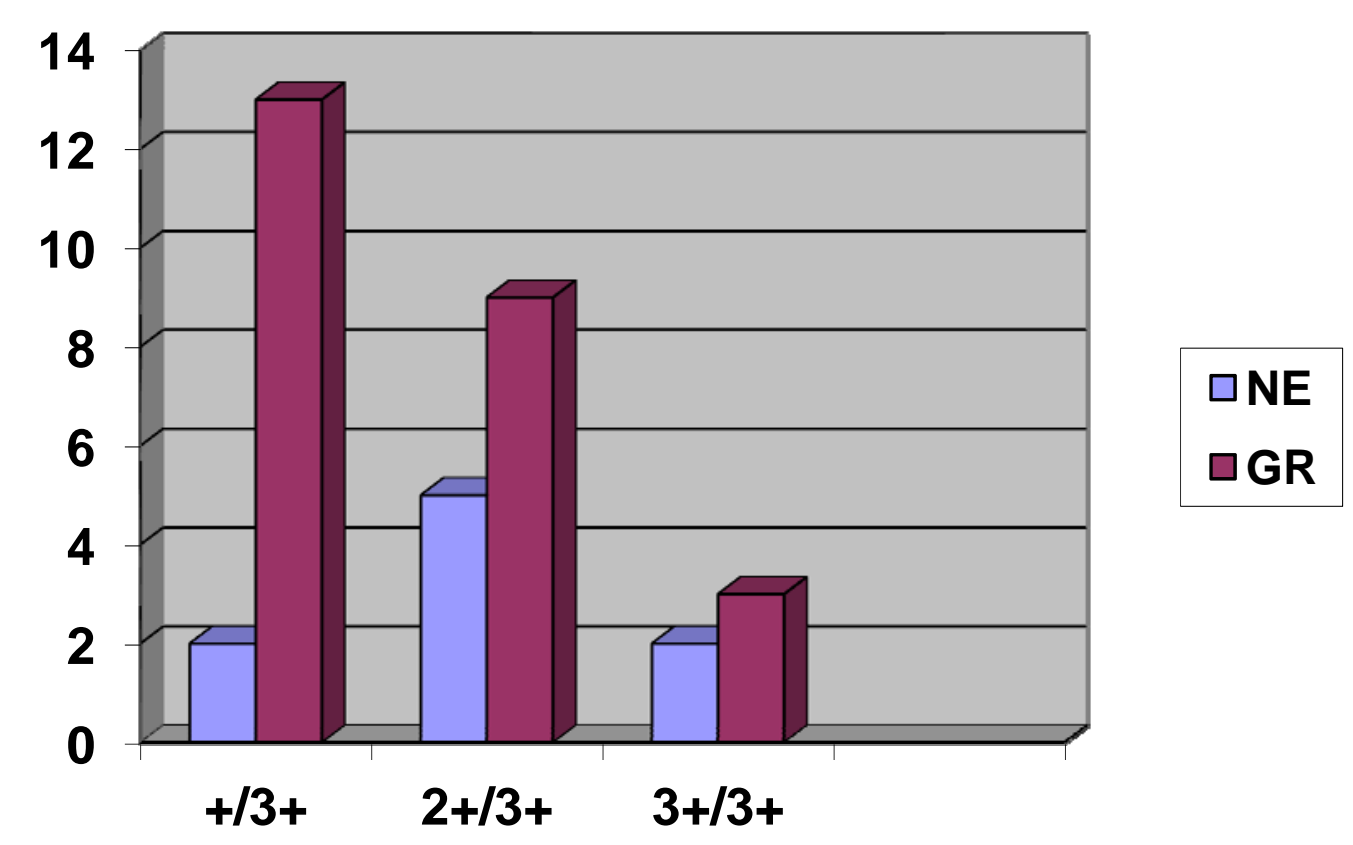

IH - imunohistoquímica; NE - não específico; GR - granulomatoso

Apresentamos a frequência dos dois tipos de resposta tecidual observada nas diferentes faixas etárias dos doentes da casuística estudada (Gráfico 23). 
Gráfico 23. LEISHMANIOSE TEGUMENTAR AMERICANA. TIPOS DE RESPOSTA TECIDUAL EM DIFERENTES FAIXAS ETÁRIAS DOS DOENTES

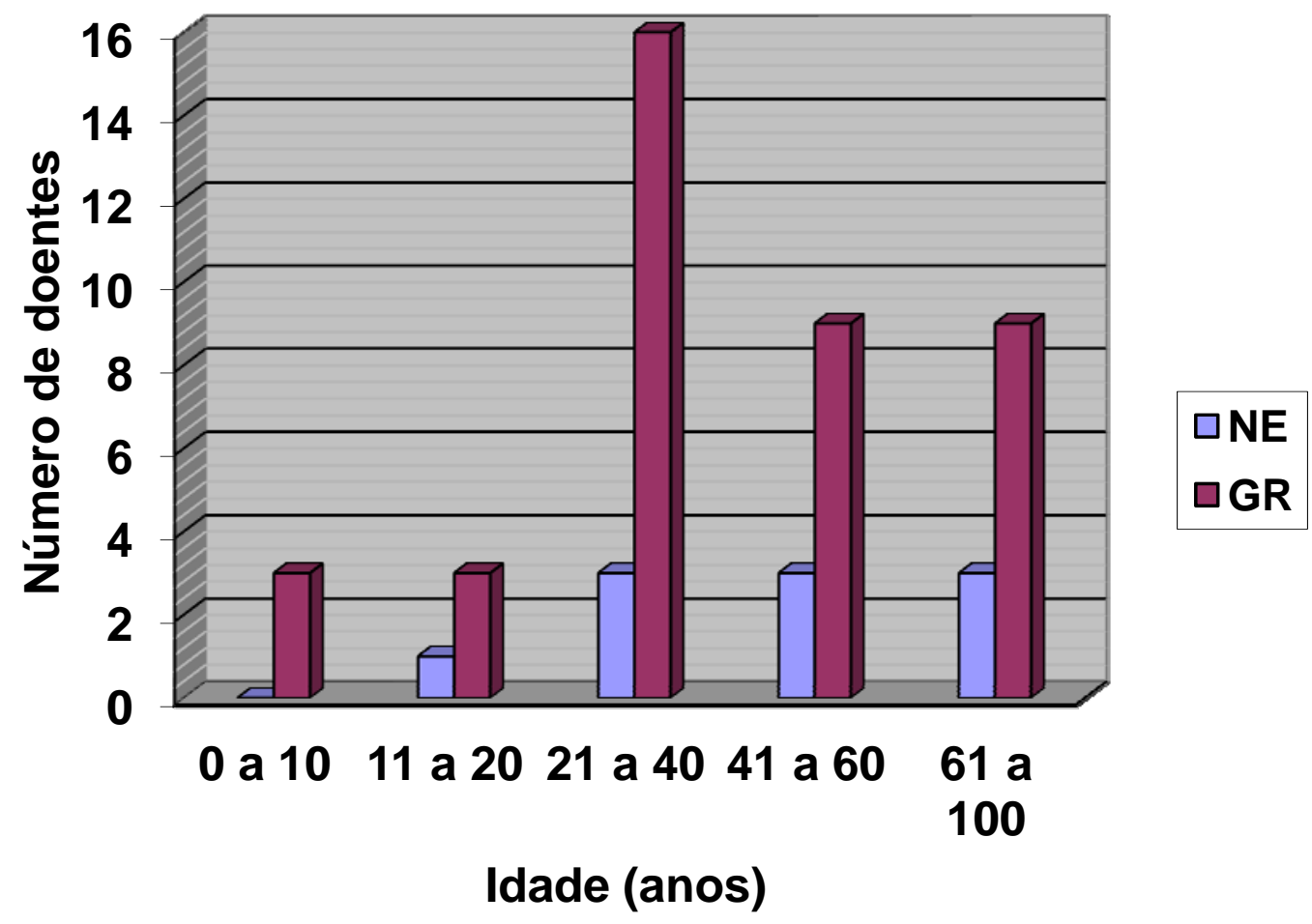

$$
\text { NE - não específico; GR - granulomatoso }
$$

Nas lesões ulceradas predominou a resposta inflamatória crônica granulomatosa. Todas as lesões verrucosas e a lesão sarcoídea demonstraram padrão de resposta granulomatoso (Gráfico 24). 
Gráfico 24. LEISHMANIOSE TEGUMENTAR AMERICANA. TIPOS DE LESÕES CUTÂNEAS E PADRÃO DE RESPOSTA TECIDUAL

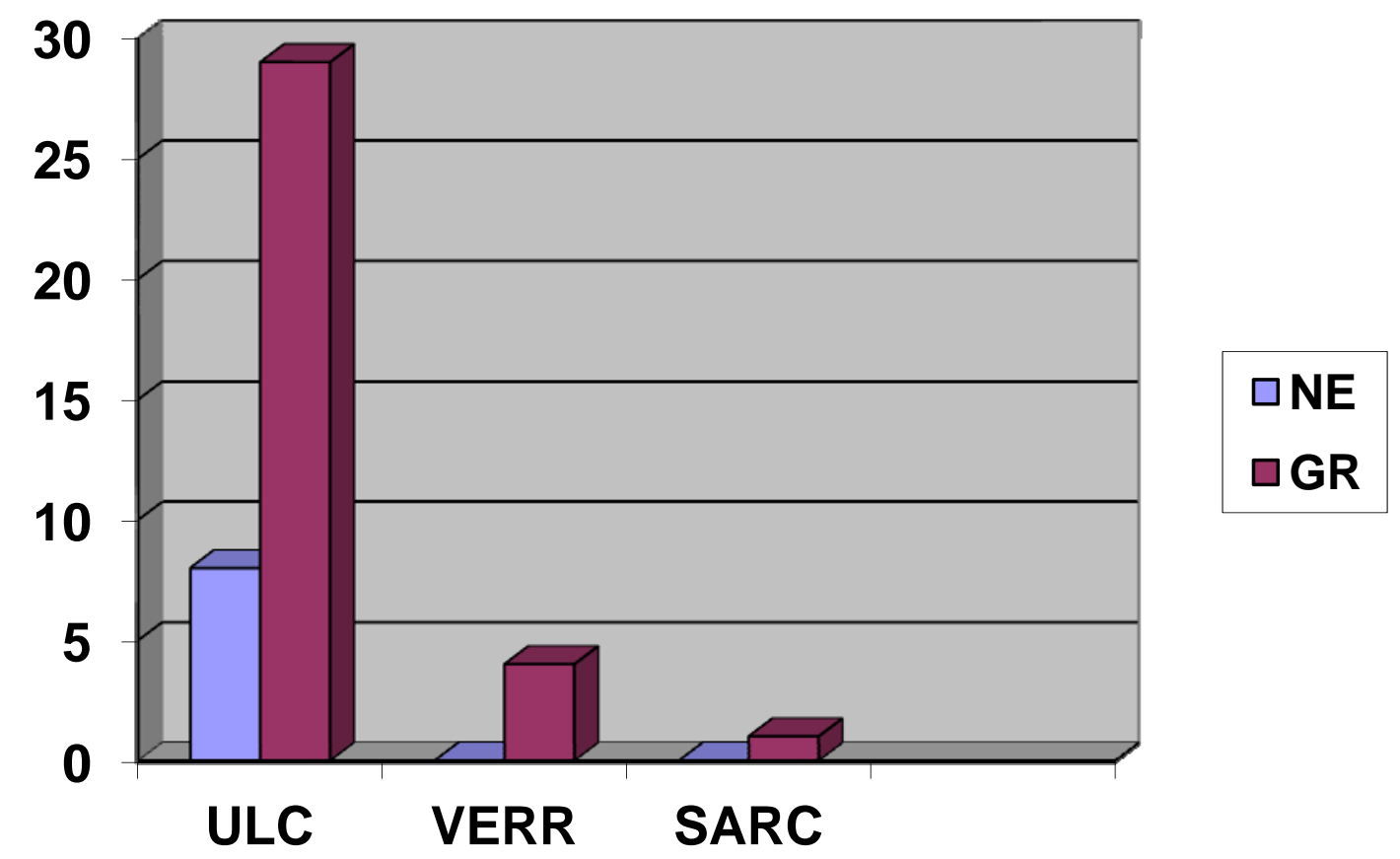

NE - não específico; GR - granulomatoso

ULC - úlcera

VERR - lesão verrucosa

SARC - nódulos sarcoídeos

Vinte e sete casos com resposta tecidual crônica granulomatosa apresentaram reação de Montenegro positiva, e seis, negativa. Dentre os casos com resposta tecidual crônica não específica, quatro foram positivos e um, negativo (Gráfico 25). 
Gráfico 25. LEISHMANIOSE TEGUMENTAR AMERICANA. RESULTADOS DE LEITURA DE REAÇÃO INTRADÉRMICA DE MONTENEGRO EM RELAÇÃO AOS PADRÕES DE RESPOSTA TECIDUAL

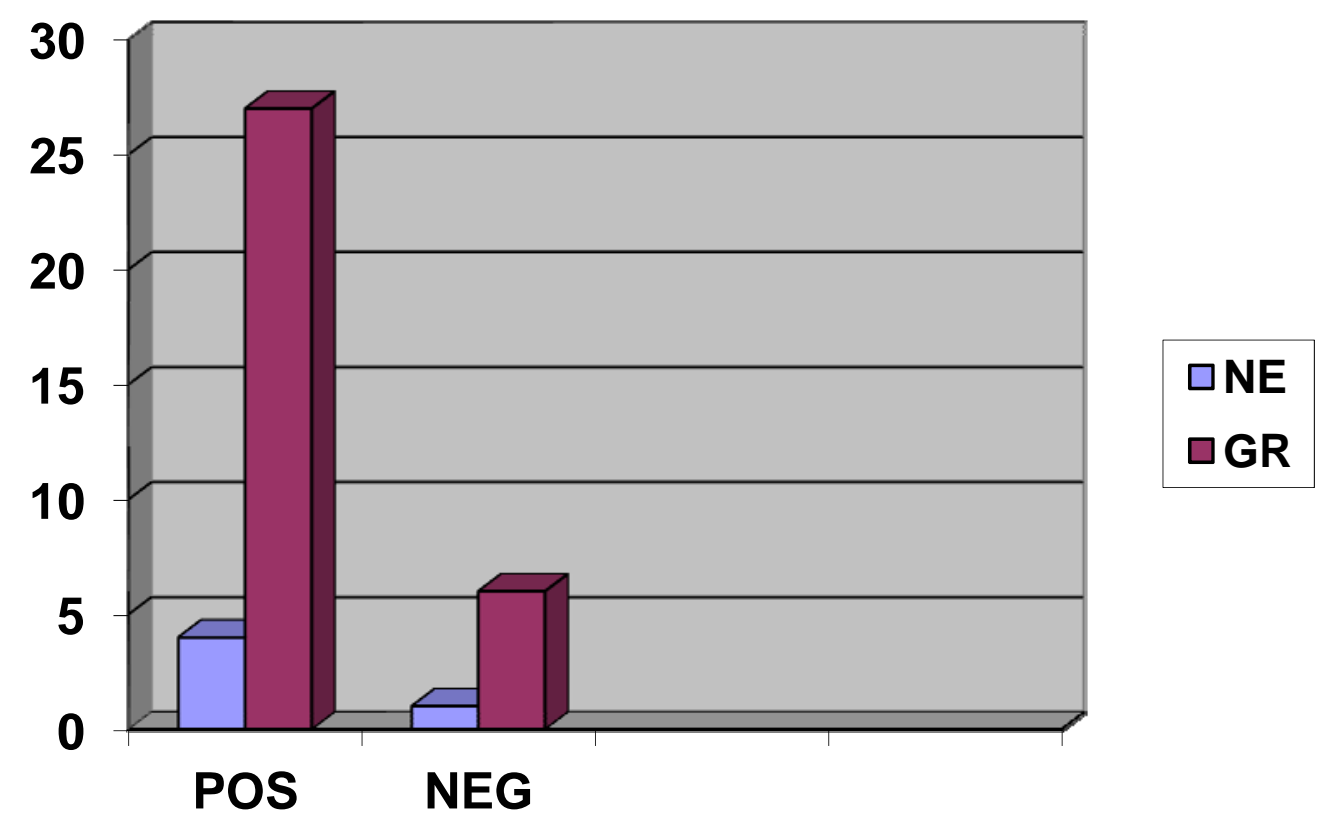

NE - não específico; GR - granulomatoso; POS - Reação de Montenegro positiva; NEG - Reação de Montenegro negativa 
ANEXO C: QUADRO 3 - Leishmaniose tegumentar americana. Média do número de células $/ \mathrm{mm}^{2}$ em biópsias de pele com resposta inflamatória não específica e granulomatosa

\begin{tabular}{|c|c|c|}
\hline & NÃO ESPECÍFICAS & CD123+/mm2 \\
\hline 1 & CASO 5 & 40,02 \\
\hline 2 & CASO 8 & 9,32 \\
\hline 3 & CASO 17 & 15,38 \\
\hline 4 & CASO 27 & 23,81 \\
\hline 5 & CASO 29 & 6,73 \\
\hline 6 & CASO 32 & 23,71 \\
\hline 7 & CASO 35 & 23,32 \\
\hline 8 & CASO 41 & 9,37 \\
\hline \multirow[t]{3}{*}{9} & CASO 45 & 17,83 \\
\hline & \multicolumn{2}{|l|}{ GRANULOMATOSAS } \\
\hline & & \\
\hline 1 & CASO 2 & 17,42 \\
\hline 2 & CASO 12 & 8,28 \\
\hline 3 & CASO 18 & 12,41 \\
\hline 4 & CASO 19 & 12,51 \\
\hline 5 & CASO 20 & 7,03 \\
\hline 6 & CASO 22 & 6,15 \\
\hline 7 & CASO 24 & 9,81 \\
\hline 8 & CASO 26 & 20,49 \\
\hline 9 & CASO 28 & 19,61 \\
\hline 10 & CASO 30 & 32,5 \\
\hline 11 & CASO 31 & 8,99 \\
\hline 12 & CASO 33 & 2,34 \\
\hline 13 & CASO 36 & 10,59 \\
\hline 14 & CASO 37 & 27,96 \\
\hline 15 & CASO 38 & 26,21 \\
\hline 16 & CASO 39 & 28,66 \\
\hline 17 & CASO 40 & 56,04 \\
\hline 18 & CASO 42 & 22,75 \\
\hline 19 & CASO 43 & 14,42 \\
\hline 20 & CASO 44 & 4,76 \\
\hline 21 & CASO 46 & 13,03 \\
\hline 22 & CASO 47 & 37,33 \\
\hline 23 & CASO 48 & 25,73 \\
\hline 24 & CASO 49 & 52,07 \\
\hline 25 & CASO 50 & 26,35 \\
\hline 26 & CASO 51 & 24,89 \\
\hline 27 & CASO 52 & 13,76 \\
\hline
\end{tabular}


ANEXO D: QUADRO 4 - Leishmaniose tegumentar americana. Média do número de dendrócitos dérmicos Fator XIIla+ e de células com coexpressão de Fator XIIla/iNOS $/ \mathrm{mm}^{2}$ em biópsias de pele com resposta inflamatória não específica e granulomatosa

\begin{tabular}{|c|c|c|c|}
\hline & NÃO ESPECÍFICAS & FATOR XIIIa+/mm ${ }^{2}$ & FATOR XIIla+/iNOS+/mm² \\
\hline 1 & CASO 3 & 19,84 & 9,69 \\
\hline 2 & CASO 5 & 80,36 & 15,52 \\
\hline 3 & CASO 17 & 37,75 & 18,18 \\
\hline 4 & CASO 29 & 26,38 & 8,57 \\
\hline 5 & CASO 32 & 29,14 & 12,78 \\
\hline 6 & CASO 41 & 22,5 & 13,71 \\
\hline \multirow[t]{2}{*}{7} & CASO 45 & 13,37 & 9,94 \\
\hline & \multicolumn{2}{|l|}{ GRANULOMATOSAS } & \\
\hline 1 & CASO 1 & 91,78 & 61,38 \\
\hline 2 & CASO 2 & 79,48 & 10,54 \\
\hline 3 & CASO 4 & 82,39 & 9 \\
\hline 4 & CASO 6 & 66,62 & 17,59 \\
\hline 5 & CASO 7 & 69,24 & 30,89 \\
\hline 6 & CASO 9 & 62,21 & 42,3 \\
\hline 7 & CASO 10 & 38,35 & 21,14 \\
\hline 8 & CASO 12 & 58,35 & 49,81 \\
\hline 9 & CASO 14 & 82,95 & 41,88 \\
\hline 10 & CASO 16 & 57,3 & 22,18 \\
\hline 11 & CASO 18 & 18,3 & 8,05 \\
\hline 12 & CASO 19 & 75,08 & 48,82 \\
\hline 13 & CASO 20 & 90,86 & 44,21 \\
\hline 14 & CASO 24 & 48,13 & 10,09 \\
\hline 15 & CASO 25 & 102 & 68,9 \\
\hline 16 & CASO 26 & 40,25 & 27,18 \\
\hline 17 & CASO 28 & 65,51 & 47,52 \\
\hline 18 & CASO 30 & 64,7 & 26,35 \\
\hline 19 & CASO 31 & 25,64 & 12,82 \\
\hline 20 & CASO 33 & 11,69 & 6,11 \\
\hline 21 & CASO 34 & 90,17 & 54,16 \\
\hline 22 & CASO 37 & 72,31 & 56,06 \\
\hline 23 & CASO 38 & 72,23 & 27,85 \\
\hline 24 & CASO 39 & 68,73 & 28,78 \\
\hline 25 & CASO 40 & 1,63 & 0,89 \\
\hline 26 & CASO 42 & 4,86 & 3,76 \\
\hline 27 & CASO 43 & 27,96 & 23,42 \\
\hline
\end{tabular}


ANEXO E: QUADRO 5 - Leishmaniose tegumentar americana. Média do número de macrófagos CD68+ sem e com coexpressão de iNOS $/ \mathrm{mm}^{2}$ em biópsias de pele com resposta inflamatória não específica e granulomatosa

\begin{tabular}{|c|c|c|c|}
\hline & NÃO ESPECÍFICAS & $\mathrm{CD} 68+/ \mathrm{mm}^{2}$ & $\mathrm{CD} 68+/ \mathrm{iNOS}+/ \mathrm{mm}^{2}$ \\
\hline 1 & CASO 3 & 35,42 & 31,33 \\
\hline 2 & CASO 5 & 118,57 & 91,78 \\
\hline 3 & CASO 8 & 106,68 & 91,74 \\
\hline 4 & CASO 15 & 53,7 & 25,53 \\
\hline 5 & CASO 17 & 67,7 & 31,32 \\
\hline 6 & CASO 27 & 72,5 & 55,95 \\
\hline 7 & CASO 29 & 68,34 & 62,3 \\
\hline 8 & CASO 32 & 110,74 & 74,23 \\
\hline 9 & CASO 41 & 89,58 & 52,11 \\
\hline \multirow[t]{2}{*}{10} & CASO 45 & 68,34 & 62,3 \\
\hline & GRANULOMATOSAS & & \\
\hline & & & \\
\hline 1 & CASO 1 & 170,76 & 130,47 \\
\hline 2 & CASO 2 & 223,62 & 197,48 \\
\hline 3 & CASO 4 & 93,68 & 76,26 \\
\hline 4 & CASO 6 & 59,43 & 54,45 \\
\hline 5 & CASO 7 & 69,46 & 61,06 \\
\hline 6 & CASO 9 & 122,91 & 91,91 \\
\hline 7 & CASO 10 & 126,76 & 71,43 \\
\hline 8 & CASO 11 & 48,41 & 20,27 \\
\hline 9 & CASO 12 & 48,88 & 41,5 \\
\hline 10 & CASO 13 & 145,21 & 86,22 \\
\hline 11 & CASO 14 & 116,63 & 84,32 \\
\hline 12 & CASO 16 & 71,58 & 40,69 \\
\hline 13 & CASO 18 & 88,27 & 62,65 \\
\hline 14 & CASO 19 & 88,53 & 33,73 \\
\hline 15 & CASO 20 & 97,36 & 57,35 \\
\hline 16 & CASO 21 & 67,62 & 20,2 \\
\hline 17 & CASO 22 & 68,34 & 62,3 \\
\hline 18 & CASO 23 & 79,44 & 9,85 \\
\hline 19 & CASO 24 & 83,29 & 22,25 \\
\hline 20 & CASO 25 & 85,93 & 48,82 \\
\hline 21 & CASO 26 & 66,02 & 47,72 \\
\hline 22 & CASO 28 & 50,01 & 36,24 \\
\hline 23 & CASO 30 & 57,52 & 45,93 \\
\hline 24 & CASO 31 & 47,68 & 33,69 \\
\hline 25 & CASO 33 & 110,52 & 62,96 \\
\hline 26 & CASO 34 & 137,16 & 36,45 \\
\hline 27 & CASO 36 & 161,49 & 66,28 \\
\hline 28 & CASO 37 & 195,86 & 67,04 \\
\hline 29 & CASO 38 & 132,47 & 46,84 \\
\hline 30 & CASO 39 & 145,36 & 72,9 \\
\hline 31 & CASO 40 & 123,59 & 63,75 \\
\hline 32 & CASO 42 & 47,61 & 38,87 \\
\hline 33 & CASO 43 & 207,41 & 97,41 \\
\hline
\end{tabular}


ANEXO F: QUADRO 6 - Leishmaniose tegumentar americana. Porcentagem de dendrócitos dérmicos Fator XIlla+ e de macrófagos CD68+ com coexpressão de iNOS em biópsias de pele com resposta inflamatória não específica e granulomatosa

\begin{tabular}{|c|c|c|c|}
\hline & NÃO ESPECÍFICAS & $\begin{array}{l}\text { \% FATOR } \\
\text { XIIla+/iNOS+ }\end{array}$ & $\begin{array}{l}\% \\
\text { CD68+/iNOS+ }\end{array}$ \\
\hline 1 & CASO 3 & 48,84 & 88,43 \\
\hline 2 & CASO 5 & 19,31 & 77,4 \\
\hline 3 & CASO 17 & 48,15 & 46,27 \\
\hline 4 & CASO 29 & 32,48 & 29,87 \\
\hline 5 & CASO 32 & 43,85 & 67,04 \\
\hline 6 & CASO 41 & 60,95 & 58,17 \\
\hline \multirow[t]{3}{*}{7} & CASO 45 & 74,42 & 29,87 \\
\hline & \multicolumn{2}{|l|}{ GRANULOMATOSAS } & \\
\hline & & & \\
\hline 1 & CASO 1 & 66,88 & 76,4 \\
\hline 2 & CASO 2 & 13,26 & 88,31 \\
\hline 3 & CASO 4 & 10,93 & 81,41 \\
\hline 4 & CASO 6 & 26,41 & 91,63 \\
\hline 5 & CASO 7 & 44,61 & 87,9 \\
\hline 6 & CASO 9 & 68 & 74,78 \\
\hline 7 & CASO 10 & 55,12 & 56,35 \\
\hline 8 & CASO 12 & 85,35 & 84,91 \\
\hline 9 & CASO 14 & 50,49 & 72,3 \\
\hline 10 & CASO 16 & 38,71 & 56,85 \\
\hline 11 & CASO 18 & 44 & 70,98 \\
\hline 12 & CASO 19 & 65,03 & 38,09 \\
\hline 13 & CASO 20 & 48,65 & 58,91 \\
\hline 14 & CASO 24 & 20,97 & 26,71 \\
\hline 15 & CASO 25 & 67,5 & 56,81 \\
\hline 16 & CASO 26 & 67,52 & 72,28 \\
\hline 17 & CASO 28 & 72,54 & 72,45 \\
\hline 18 & CASO 30 & 40,72 & 79,84 \\
\hline 19 & CASO 31 & 50 & 70,67 \\
\hline 20 & CASO 33 & 52,24 & 56,97 \\
\hline 21 & CASO 34 & 60,06 & 26,57 \\
\hline 22 & CASO 37 & 77,53 & 34,23 \\
\hline 23 & CASO 38 & 38,56 & 35,36 \\
\hline 24 & CASO 39 & 41,87 & 50,15 \\
\hline 25 & CASO 40 & 54,55 & 51,58 \\
\hline 26 & CASO 42 & 77,42 & 81,65 \\
\hline 27 & CASO 43 & 83,77 & 46,96 \\
\hline
\end{tabular}


9. REFERÊNCIAS 
1. Murray HW, Rubin BY, Rothermel CD. Killing of intracellular Leishmania donovani by lymphokine-stimulated human mononuclear phagocytes. Evidence that interferon-gamma is the activating lymphokine. $\mathrm{J}$ Clin Invest. 1983;72(4):1506-10.

2. Scott P, Natovitz P, Coffman RL, Pearce E, Sher A. Immunoregulation of cutaneous leishmaniasis. $T$ cell lines that transfer protective immunity or exacerbation belong to different $T$ helper subsets and respond to distinct parasite antigens. J Exp Med. 1988;168(5):1675-84.

3. Smith LE, Rodrigues M, Russell DG. The interaction between CD8+ cytotoxic $\mathrm{T}$ cells and Leishmania-infected macrophages. $\mathrm{J}$ Exp Med. 1991;174(3):499-505.

4. Brodskyn Cl, Barral A, Boaventura V, Carvalho E, Barral-Netto M. Parasite-driven in vitro human lymphocyte cytotoxicity against autologous infected macrophages from mucosal leishmaniasis. $J$ Immunol. 1997;159(9):4467-73.

5. Streilein JW. Skin-associated lymphoid tissues (SALT): origins and functions. J Invest Dermatol. 1983;80 Supl:12s-6s.

6. Nestle FO, Zheng XG, Thompson CB, Turka LA, Nickoloff BJ. Characterization of dermal dendritic cells obtained from normal human skin reveals phenotypic and functionally distinctive subsets. $\mathrm{J}$ Immunol. 1993;151(11):6535-45.

7. Zaba LC, Krueger JG, Lowes MA. Resident and "inflammatory" dendritic cells in human skin. J Invest Dermatol. 2009;129(2):302-8.

8. Bangert C, Friedl J, Stary G, Stingl G, Kopp T. Immunopathologic features of allergic contact dermatitis in humans: participation of plasmacytoid dendritic cells in the pathogenesis of the disease? J Invest Dermatol. 2003;121(6):1409-18.

9. Farkas L, Beiske K, Lund-Johansen F, Brandtzaeg $P$, Jahnsen FL. Plasmacytoid dendritic cells (natural interferon- alpha/beta-producing cells) accumulate in cutaneous lupus erythematosus lesions. $A m \mathrm{~J}$ Pathol. 2001;159(1):237-43.

10. Nestle FO, Conrad C, Tun-Kyi A, Homey B, Gombert M, Boyman O, et al. Plasmacytoid predendritic cells initiate psoriasis through interferon-alpha production. J Exp Med. 2005;202(1):135-43.

11. De Vries HJ, van Marle J, Teunissen MB, Picavet D, Zorgdrager F, Bos $\mathrm{JD}$, et al. Lichen planus is associated with human herpesvirus type 7 replication and infiltration of plasmacytoid dendritic cells. Br J Dermatol. 2006;154(2):3614.

12. Gerlini G, Mariotti G, Bianchi B, Pimpinelli N. Massive recruitment of type I interferon producing plasmacytoid dendritic cells in varicella skin lesions. $J$ Invest Dermatol. 2006;126(2):507-9. 
13. Fong L, Mengozzi M, Abbey NW, Herndier BG, Engleman EG. Productive infection of plasmacytoid dendritic cells with human immunodeficiency virus type 1 is triggered by CD40 ligation. $J$ Virol. 2002;76(21):11033-41.

14. Groot F, van Capel TM, Kapsenberg ML, Berkhout B, de Jong EC. Opposing roles of blood myeloid and plasmacytoid dendritic cells in HIV-1 infection of T cells: transmission facilitation versus replication inhibition. Blood. 2006;108(6):1957-64.

15. Meyers JH, Justement JS, Hallahan CW, Blair ET, Sun YA, O'Shea MA, et al. Impact of HIV on cell survival and antiviral activity of plasmacytoid dendritic cells. PLoS One. 2007;2(5):e458.

16. Vermi W, Bonecchi R, Facchetti F, Bianchi D, Sozzani S, Festa S, et al. Recruitment of immature plasmacytoid dendritic cells (plasmacytoid monocytes) and myeloid dendritic cells in primary cutaneous melanomas. J Pathol. 2003;200(2):255-68.

17. Salio M, Cella M, Vermi W, Facchetti F, Palmowski MJ, Smith CL, et al. Plasmacytoid dendritic cells prime IFN-gamma-secreting melanoma-specific CD8 lymphocytes and are found in primary melanoma lesions. Eur $\mathrm{J}$ Immunol. 2003;33(4):1052-62.

18. Hartmann E, Wollenberg B, Rothenfusser S, Wagner M, Wellisch D, Mack $\mathrm{B}$, et al. Identification and functional analysis of tumor-infiltrating plasmacytoid dendritic cells in head and neck cancer. Cancer Res. 2003;63(19):6478-87.

19. Urosevic M, Dummer R, Conrad C, Beyeler M, Laine E, Burg G, et al. Disease-independent skin recruitment and activation of plasmacytoid predendritic cells following imiquimod treatment. $J$ Natl Cancer Inst. 2005;97(15):1143-53.

20. Treilleux I, Blay JY, Bendriss-Vermare N, Ray-Coquard I, Bachelot T, Guastalla JP, et al. Dendritic cell infiltration and prognosis of early stage breast cancer. Clin Cancer Res. 2004;10(22):7466-74.

21. Stary G, Bangert C, Tauber M, Strohal R, Kopp T, Stingl G. Tumoricidal activity of TLR7/8-activated inflammatory dendritic cells. $J$ Exp Med. 2007;204(6):1441-51.

22. Sotto MN, Halpern I, Kauffman MR, Pagliari C. Factor XIIla+ dermal dendrocyte parasitism in American tegumentary leishmaniasis skin lesions. Am J Dermatopathol. 2010;32(1):15-8.

23. Magill AJ. Epidemiology of the leishmaniases. Dermatol Clin. 1995;13(3):505-23.

24. Herwaldt BL. Laboratory-acquired parasitic infections from accidental exposures. Clin Microbiol Rev. 2001;14(4):659-88. 
25. Guerin PJ, Olliaro P, Sundar S, Boelaert M, Croft SL, Desjeux P, et al. Visceral leishmaniasis: current status of control, diagnosis, and treatment, and a proposed research and development agenda. Lancet Infect Dis. 2002;2(8):494501.

26. Murray HW, Berman JD, Davies CR, Saravia NG. Advances in leishmaniasis. Lancet. 2005;366(9496):1561-77.

27. World Health Organization. The leishmaniases and Leishmania-HIV coinfections (Fact Sheet No. 116) [on-line]. 2000. Disponível em https://apps.who.int/inf-fs/en/fact116.html.

28. Mattock N, Pink R. Making health research work for poor people. Progress 2003-2004. Tropical Disease Research. Geneva: World Health Organization; 2004.

29. Santos-Oliveira JR, Giacoia-Gripp CB, Alexandrino de Oliveira P, Amato VS, Lindoso $\mathrm{J}$, Goto $\mathrm{H}$, et al. High levels of $\mathrm{T}$ lymphocyte activation in Leishmania-HIV-1 co-infected individuals despite low HIV viral load. BMC Infect Dis. 2010;10:358.

30. Lindoso JA, Barbosa RN, Posada-Vergara MP, Duarte MI, Oyafuso LK, Amato VS, et al. Unusual manifestations of tegumentary leishmaniasis in AIDS patients from the New World. Br J Dermatol. 2009;160(2):311-8.

31. Elston DM, Miller SD. Leishmaniasis acquired in the Iraqi Theater of Operations: lessons learned. Cutis. 2004;74(4):253-5.

32. Zapor MJ, Moran KA. Infectious diseases during wartime. Curr Opin Infect Dis. 2005;18(5):395-9.

33. Mattos M. Clinical and epidemiological characteristics of american tegumentary leishmaniasis (ATL) in the Southeast Region of Brazil. Rev Soc Bras Med Trop. 2009;42 (Supl II):130-1.

34. Rey L. Parasitologia: parasitos e doenças parasitárias do homem nos trópicos ocidentais. 4a ed. Rio de Janeiro Guanabara Koogan; 2008. Cap. 25 e 26.

35. Goto H. Imunidade inata e imunopatogenia nas leishmanioses experimentais. [tese livre-docência] São Paulo: Faculdade de Mdicina, Universidade de São Paulo; 2004.

36. Henri S, Guilliams M, Poulin LF, Tamoutounour S, Ardouin L, Dalod M, et al. Disentangling the complexity of the skin dendritic cell network. Immunol Cell Biol. 2010;88(4):366-75.

37. Steinman RM, Cohn ZA. Pillars Article: Identification of a novel cell type in peripheral lymphoid organs of mice. I. Morphology, quantitation, tissue distribution. J. Exp. Med.1973. 137: 1142-1162. J Immunol. 2007;178(1):5-25. 
38. Steinman RM, Banchereau J. Taking dendritic cells into medicine. Nature. 2007;449(7161):419-26.

39. Wright-Browne V, McClain KL, Talpaz M, Ordonez N, Estrov Z. Physiology and pathophysiology of dendritic cells. Hum Pathol. 1997;28(5):56379.

40. Braathen LR, Thorsby E. Studies on human epidermal Langerhans cells. I. Allo-activating and antigen-presenting capacity. Scand $\mathrm{J}$ Immunol. 1980;11(4):401-8.

41. Mc Dermott R, Ziylan U, Spehner D, Bausinger H, Lipsker D, Mommaas $\mathrm{M}$, et al. Birbeck granules are subdomains of endosomal recycling compartment in human epidermal Langerhans cells, which form where Langerin accumulates. Mol Biol Cell. 2002;13(1):317-35.

42. Barral DC, Brenner MB. CD1 antigen presentation: how it works. Nat Rev Immunol. 2007;7(12):929-41.

43. Thomas JA, Biggerstaff M, Sloane JP, Easton DF. Immunological and histochemical analysis of regional variations of epidermal Langerhans cells in normal human skin. Histochem J. 1984;16(5):507-19.

44. Figdor CG, van Kooyk Y, Adema GJ. C-type lectin receptors on dendritic cells and Langerhans cells. Nat Rev Immunol. 2002;2(2):77-84.

45. Caux C, Vanbervliet B, Massacrier C, Dezutter-Dambuyant C, de SaintVis $B$, Jacquet $C$, et al. CD34+ hematopoietic progenitors from human cord blood differentiate along two independent dendritic cell pathways in response to GM-CSF+TNF alpha. J Exp Med. 1996;184(2):695-706.

46. Reid CD, Fryer PR, Clifford C, Kirk A, Tikerpae J, Knight SC. Identification of hematopoietic progenitors of macrophages and dendritic Langerhans cells (DL-CFU) in human bone marrow and peripheral blood. Blood. 1990;76(6):1139-49.

47. Merad M, Manz MG, Karsunky H, Wagers A, Peters W, Charo I, et al. Langerhans cells renew in the skin throughout life under steady-state conditions. Nat Immunol. 2002;3(12):1135-41.

48. Ginhoux F, Tacke F, Angeli V, Bogunovic M, Loubeau M, Dai XM, et al. Langerhans cells arise from monocytes in vivo. Nat Immunol. 2006;7(3):265-73.

49. Bursch LS, Wang L, Igyarto B, Kissenpfennig A, Malissen B, Kaplan DH, et al. Identification of a novel population of Langerin+ dendritic cells. J Exp Med. 2007;204(13):3147-56.

50. Ginhoux F, Collin MP, Bogunovic M, Abel M, Leboeuf M, Helft J, et al. Blood-derived dermal langerin+ dendritic cells survey the skin in the steady state. J Exp Med. 2007;204(13):3133-46. 
51. Poulin LF, Henri S, de Bovis B, Devilard E, Kissenpfennig A, Malissen B. The dermis contains langerin+ dendritic cells that develop and function independently of epidermal Langerhans cells. J Exp Med. 2007;204(13):311931.

52. Douillard $\mathrm{P}$, Stoitzner $\mathrm{P}$, Tripp $\mathrm{CH}$, Clair-Moninot V, Aït-Yahia $\mathrm{S}$, McLellan AD, et al. Mouse lymphoid tissue contains distinct subsets of langerin/CD207 dendritic cells, only one of which represents epidermal-derived Langerhans cells. J Invest Dermatol. 2005;125(5):983-94.

53. Stoitzner P, Holzmann S, McLellan AD, Ivarsson L, Stössel H, Kapp M, et al. Visualization and characterization of migratory Langerhans cells in murine skin and lymph nodes by antibodies against Langerin/CD207. J Invest Dermatol. 2003;120(2):266-74.

54. Stoitzner $\mathrm{P}$, Tripp $\mathrm{CH}$, Douillard $\mathrm{P}$, Saeland S, Romani N. Migratory Langerhans cells in mouse lymph nodes in steady state and inflammation. $J$ Invest Dermatol. 2005;125(1):116-25.

55. Larregina AT, Falo LD. Changing paradigms in cutaneous immunology: adapting with dendritic cells. J Invest Dermatol. 2005;124(1):1-12.

56. Kaplan DH, Jenison MC, Saeland S, Shlomchik WD, Shlomchik MJ. Epidermal langerhans cell-deficient mice develop enhanced contact hypersensitivity. Immunity. 2005;23(6):611-20.

57. Bennett CL, van Rijn E, Jung S, Inaba K, Steinman RM, Kapsenberg ML, et al. Inducible ablation of mouse Langerhans cells diminishes but fails to abrogate contact hypersensitivity. J Cell Biol. 2005;169(4):569-76.

58. Strid J, Roberts SJ, Filler RB, Lewis JM, Kwong BY, Schpero W, et al. Acute upregulation of an NKG2D ligand promotes rapid reorganization of a local immune compartment with pleiotropic effects on carcinogenesis. Nat Immunol. 2008;9(2):146-54.

59. Steinman RM, Nussenzweig MC. Avoiding horror autotoxicus: the importance of dendritic cells in peripheral T cell tolerance. Proc Natl Acad Sci U S A. 2002;99(1):351-8.

60. Headington JT. The dermal dendrocyte. Adv Dermatol. 1986;1:159-71.

61. Nestle FO, Nickoloff BJ. A fresh morphological and functional look at dermal dendritic cells. J Cutan Pathol. 1995;22(5):385-93.

62. Nestle FO, Nickoloff BJ. Dermal dendritic cells are important members of the skin immune system. Adv Exp Med Biol. 1995;378:111-6.

63. Zaba LC, Fuentes-Duculan J, Steinman RM, Krueger JG, Lowes MA. Normal human dermis contains distinct populations of CD11c+BDCA-1+ dendritic cells and CD163+FXIIIA+ macrophages. $J$ Clin Invest. 2007;117(9):2517-25. 
64. Ochoa MT, Loncaric A, Krutzik SR, Becker TC, Modlin RL. "Dermal dendritic cells" comprise two distinct populations: CD1+ dendritic cells and CD209+ macrophages. J Invest Dermatol. 2008;128(9):2225-31.

65. Nestle FO, Nickoloff BJ. Deepening our understanding of immune sentinels in the skin. J Clin Invest. 2007;117(9):2382-5.

66. Lenz A, Heine M, Schuler G, Romani N. Human and murine dermis contain dendritic cells. Isolation by means of a novel method and phenotypical and functional characterization. J Clin Invest. 1993;92(6):2587-96.

67. Cerio R, Griffiths CE, Cooper KD, Nickoloff BJ, Headington JT. Characterization of factor XIIla positive dermal dendritic cells in normal and inflamed skin. Br J Dermatol. 1989;121(4):421-31.

68. Nestle FO, Turka LA, Nickoloff BJ. Characterization of dermal dendritic cells in psoriasis. Autostimulation of T lymphocytes and induction of Th1 type cytokines. J Clin Invest. 1994;94(1):202-9.

69. Deguchi M, Aiba S, Ohtani H, Nagura H, Tagami H. Comparison of the distribution and numbers of antigen-presenting cells among T-lymphocytemediated dermatoses: CD1a+, factor XIIla+, and CD68+ cells in eczematous dermatitis, psoriasis, lichen planus and graft-versus-host disease. Arch Dermatol Res. 2002;294(7):297-302.

70. Pagliari C, Sotto MN. Correlation of factor XIIla+ dermal dendrocytes with paracoccidioidomycosis skin lesions. Med Mycol. 2002;40(4):407-10.

71. Pagliari C, Sotto MN. Dendritic cells and pattern of cytokines in paracoccidioidomycosis skin lesions. Am J Dermatopathol. 2003;25(2):107-12.

72. Sotto MN, De Brito T, Silva AM, Vidal M, Castro LG. Antigen distribution and antigen-presenting cells in skin biopsies of human chromoblastomycosis. $J$ Cutan Pathol. 2004;31(1):14-8.

73. Töröcsik D, Bárdos H, Nagy L, Adány R. Identification of factor XIII-A as a marker of alternative macrophage activation. Cell Mol Life Sci. 2005;62(18):2132-9.

74. Nemes Z, Thomázy V, Adány R, Muszbek L. Identification of histiocytic reticulum cells by the immunohistochemical demonstration of factor XIII (FXIIla) in human lymph nodes. J Pathol. 1986;149(2):121-32.

75. Hoyo E, Kanitakis J, Schmitt D. [The dermal dendrocyte]. Pathol Biol (Paris). 1993;41(7):613-8.

76. Sueki H, Whitaker D, Buchsbaum M, Murphy GF. Novel interactions between dermal dendrocytes and mast cells in human skin. Implications for hemostasis and matrix repair. Lab Invest. 1993;69(2):160-72.

77. Meunier L, Gonzalez-Ramos A, Cooper KD. Heterogeneous populations of class II $\mathrm{MHC}+$ cells in human dermal cell suspensions. Identification of a 
small subset responsible for potent dermal antigen-presenting cell activity with features analogous to Langerhans cells. J Immunol. 1993;151(8):4067-80.

78. Jörundsson E, Press CM, Landsverk T. Factor XIIla positive dendritic cells are a major accessory cell population in the elicitation phase of DNCBinduced contact hypersensitivity. Vet Immunol Immunopathol. 1999;71(2):99113.

79. Guttman-Yassky E, Lowes MA, Fuentes-Duculan J, Whynot J, Novitskaya I, Cardinale I, et al. Major differences in inflammatory dendritic cells and their products distinguish atopic dermatitis from psoriasis. J Allergy Clin Immunol. 2007;119(5):1210-7.

80. Serbina NV, Salazar-Mather TP, Biron CA, Kuziel WA, Pamer EG. TNF/iNOS-producing dendritic cells mediate innate immune defense against bacterial infection. Immunity. 2003;19(1):59-70.

81. Lowes MA, Chamian F, Abello MV, Fuentes-Duculan J, Lin SL, Nussbaum R, et al. Increase in TNF-alpha and inducible nitric oxide synthaseexpressing dendritic cells in psoriasis and reduction with efalizumab (antiCD11a). Proc Natl Acad Sci U S A. 2005;102(52):19057-62.

82. Jahnsen FL, Farkas L, Lund-Johansen F, Brandtzaeg P. Involvement of plasmacytoid dendritic cells in human diseases. Hum Immunol. 2002;63(12):1201-5.

83. Spits $\mathrm{H}$, Couwenberg F, Bakker AQ, Weijer K, Uittenbogaart $\mathrm{CH}$. Id2 and Id3 inhibit development of CD34(+) stem cells into predendritic cell (pre-DC)2 but not into pre-DC1. Evidence for a lymphoid origin of pre-DC2. J Exp Med. 2000;192(12):1775-84.

84. Müller-Hermelink HK, Kaiserling E, Lennert K. [Pseudofollicular nests of plasmacells (of a special type?) in paracortical pulp of human lymph nodes (author' s transl)]. Virchows Arch B Cell Pathol. 1973;14(1):47-56.

85. Feller AC, Lennert $\mathrm{K}$, Stein $\mathrm{H}$, Bruhn HD, Wuthe HH. Immunohistology and aetiology of histiocytic necrotizing lymphadenitis. Report of three instructive cases. Histopathology. 1983;7(6):825-39.

86. Facchetti F, de Wolf-Peeters C, Mason DY, Pulford K, van den Oord JJ, Desmet VJ. Plasmacytoid T cells. Immunohistochemical evidence for their monocyte/macrophage origin. Am J Pathol. 1988;133(1):15-21.

87. Grouard G, Rissoan MC, Filgueira L, Durand I, Banchereau J, Liu YJ. The enigmatic plasmacytoid $T$ cells develop into dendritic cells with interleukin (IL)-3 and CD40-ligand. J Exp Med. 1997;185(6):1101-11.

88. Dalod M, Hamilton T, Salomon R, Salazar-Mather TP, Henry SC, Hamilton JD, et al. Dendritic cell responses to early murine cytomegalovirus infection: subset functional specialization and differential regulation by interferon alpha/beta. J Exp Med. 2003;197(7):885-98. 
89. Siegal FP, Kadowaki N, Shodell M, Fitzgerald-Bocarsly PA, Shah K, Ho $\mathrm{S}$, et al. The nature of the principal type 1 interferon-producing cells in human blood. Science. 1999;284(5421):1835-7.

90. Cella M, Jarrossay D, Facchetti F, Alebardi O, Nakajima H, Lanzavecchia A, et al. Plasmacytoid monocytes migrate to inflamed lymph nodes and produce large amounts of type I interferon. Nat Med. 1999;5(8):919-23.

91. Kadowaki N, Antonenko S, Lau JY, Liu YJ. Natural interferon alpha/betaproducing cells link innate and adaptive immunity. J Exp Med. 2000;192(2):21926.

92. Liu YJ. IPC: professional type 1 interferon-producing cells and plasmacytoid dendritic cell precursors. Annu Rev Immunol. 2005;23:275-306.

93. Soumelis V, Liu YJ. From plasmacytoid to dendritic cell: morphological and functional switches during plasmacytoid pre-dendritic cell differentiation. Eur J Immunol. 2006;36(9):2286-92.

94. Fitzgerald-Bocarsly P, Dai J, Singh S. Plasmacytoid dendritic cells and type I IFN: 50 years of convergent history. Cytokine Growth Factor Rev. 2008;19(1):3-19.

95. Megjugorac NJ, Young HA, Amrute SB, Olshalsky SL, FitzgeraldBocarsly $P$. Virally stimulated plasmacytoid dendritic cells produce chemokines and induce migration of T and NK cells. J Leukoc Biol. 2004;75(3):504-14.

96. Boehm U, Klamp T, Groot M, Howard JC. Cellular responses to interferon-gamma. Annu Rev Immunol. 1997;15:749-95.

97. Rissoan MC, Soumelis V, Kadowaki N, Grouard G, Briere F, de Waal Malefyt $R$, et al. Reciprocal control of $T$ helper cell and dendritic cell differentiation. Science. 1999;283(5405):1183-6.

98. Jego G, Palucka AK, Blanck JP, Chalouni C, Pascual V, Banchereau J. Plasmacytoid dendritic cells induce plasma cell differentiation through type I interferon and interleukin 6. Immunity. 2003;19(2):225-34.

99. Moseman EA, Liang X, Dawson AJ, Panoskaltsis-Mortari A, Krieg AM, Liu YJ, et al. Human plasmacytoid dendritic cells activated by CpG oligodeoxynucleotides induce the generation of CD4+CD25+ regulatory $T$ cells. J Immunol. 2004;173(7):4433-42.

100. Ochando JC, Homma C, Yang Y, Hidalgo A, Garin A, Tacke F, et al. Alloantigen-presenting plasmacytoid dendritic cells mediate tolerance to vascularized grafts. Nat Immunol. 2006;7(6):652-62.

101. Villadangos JA, Young L. Antigen-presentation properties of plasmacytoid dendritic cells. Immunity. 2008;29(3):352-61. 
102. Marafioti T, Paterson JC, Ballabio E, Reichard KK, Tedoldi S, Hollowood $\mathrm{K}$, et al. Novel markers of normal and neoplastic human plasmacytoid dendritic cells. Blood. 2008;111(7):3778-92.

103. Mittelbrunn M, Martínez del Hoyo G, López-Bravo M, Martín-Cofreces NB, Scholer A, Hugues $S$, et al. Imaging of plasmacytoid dendritic cell interactions with T cells. Blood. 2009;113(1):75-84.

104. Koyama M, Hashimoto D, Aoyama K, Matsuoka K, Karube K, Niiro H, et al. Plasmacytoid dendritic cells prime alloreactive $T$ cells to mediate graftversus-host disease as antigen-presenting cells. Blood. 2009;113(9):2088-95.

105. Jegalian AG, Facchetti $F$, Jaffe ES. Plasmacytoid dendritic cells: physiologic roles and pathologic states. Adv Anat Pathol. 2009;16(6):392-404.

106. Facchetti F, Candiago E, Vermi W. Plasmacytoid monocytes express IL3-receptor alpha and differentiate into dendritic cells. Histopathology. 1999;35(1):88-9.

107. Olweus J, BitMansour A, Warnke R, Thompson PA, Carballido J, Picker LJ, et al. Dendritic cell ontogeny: a human dendritic cell lineage of myeloid origin. Proc Natl Acad Sci U S A. 1997;94(23):12551-6.

108. Herling M, Teitell MA, Shen RR, Medeiros LJ, Jones D. TCL1 expression in plasmacytoid dendritic cells (DC2s) and the related CD4+ CD56+ blastic tumors of skin. Blood. 2003;101(12):5007-9.

109. Facchetti F, de Wolf-Peeters C, van den Oord JJ, Meijer CJ, Pals ST, Desmet VJ. Anti-high endothelial venule monoclonal antibody HECA-452 recognizes plasmacytoid $T$ cells and delineates an "extranodular" compartment in the reactive lymph node. Immunol Lett. 1989;20(4):277-81.

110. Dzionek A, Fuchs A, Schmidt P, Cremer S, Zysk M, Miltenyi S, et al. BDCA-2, BDCA-3, and BDCA-4: three markers for distinct subsets of dendritic cells in human peripheral blood. J Immunol. 2000;165(11):6037-46.

111. Comeau MR, Van der Vuurst de Vries AR, Maliszewski CR, Galibert L. CD123bright plasmacytoid predendritic cells: progenitors undergoing cell fate conversion? J Immunol. 2002;169(1):75-83.

112. Matsui T, Connolly JE, Michnevitz M, Chaussabel D, Yu Cl, Glaser C, et al. CD2 distinguishes two subsets of human plasmacytoid dendritic cells with distinct phenotype and functions. J Immunol. 2009;182(11):6815-23.

113. Petrella T, Comeau MR, Maynadié M, Couillault G, De Muret A, Maliszewski CR, et al. 'Agranular CD4+ CD56+ hematodermic neoplasm' (blastic NK-cell lymphoma) originates from a population of CD56+ precursor cells related to plasmacytoid monocytes. Am J Surg Pathol. 2002;26(7):852-62.

114. Rissoan MC, Duhen T, Bridon JM, Bendriss-Vermare N, Péronne C, de Saint Vis $B$, et al. Subtractive hybridization reveals the expression of 
immunoglobulin-like transcript 7, Eph-B1, granzyme $B$, and 3 novel transcripts in human plasmacytoid dendritic cells. Blood. 2002;100(9):3295-303.

115. Gondek DC, Lu LF, Quezada SA, Sakaguchi S, Noelle RJ. Cutting edge: contact-mediated suppression by CD4+CD25+ regulatory cells involves a granzyme B-dependent, perforin-independent mechanism. J Immunol. 2005;174(4):1783-6.

116. Wollenberg A, Wagner M, Günther S, Towarowski A, Tuma E, Moderer $M$, et al. Plasmacytoid dendritic cells: a new cutaneous dendritic cell subset with distinct role in inflammatory skin diseases. J Invest Dermatol. 2002;119(5):1096-102.

117. Hartmann E, Graefe H, Hopert A, Pries R, Rothenfusser S, Poeck H, et al. Analysis of plasmacytoid and myeloid dendritic cells in nasal epithelium. Clin Vaccine Immunol. 2006;13(11):1278-86.

118. de Vries HJ, Teunissen MB, Zorgdrager F, Picavet D, Cornelissen M. Lichen planus remission is associated with a decrease of human herpes virus type 7 protein expression in plasmacytoid dendritic cells. Arch Dermatol Res. 2007;299(4):213-9.

119. Ito T, Wang YH, Liu YJ. Plasmacytoid dendritic cell precursors/type I interferon-producing cells sense viral infection by Toll-like receptor (TLR) 7 and TLR9. Springer Semin Immunopathol. 2005;26(3):221-9.

120. Kadowaki N, Ho S, Antonenko S, Malefyt RW, Kastelein RA, Bazan F, et al. Subsets of human dendritic cell precursors express different toll-like receptors and respond to different microbial antigens. $J$ Exp Med. 2001;194(6):863-9.

121. Gazzinelli RT, Denkers EY. Protozoan encounters with Toll-like receptor signalling pathways: implications for host parasitism. Nat Rev Immunol. 2006;6(12):895-906.

122. Lange UG, Mastroeni P, Blackwell JM, Stober CB. DNA-Salmonella enterica serovar Typhimurium primer-booster vaccination biases towards $T$ helper 1 responses and enhances protection against Leishmania major infection in mice. Infect Immun. 2004;72(8):4924-8.

123. Tuon FF, Fernandes ER, Pagliari C, Duarte MI, Amato VS. The expression of TLR9 in human cutaneous leishmaniasis is associated with granuloma. Parasite Immunol. 2010;32(11-12):769-72.

124. Pashenkov M, Goëss G, Wagner C, Hörmann M, Jandl T, Moser A, et al. Phase II trial of a toll-like receptor 9-activating oligonucleotide in patients with metastatic melanoma. J Clin Oncol. 2006;24(36):5716-24.

125. Zou W, Machelon V, Coulomb-L'Hermin A, Borvak J, Nome F, Isaeva T, et al. Stromal-derived factor-1 in human tumors recruits and alters the function of plasmacytoid precursor dendritic cells. Nat Med. 2001;7(12):1339-46. 
126. Chaperot L, Blum A, Manches O, Lui G, Angel J, Molens JP, et al. Virus or TLR agonists induce TRAIL-mediated cytotoxic activity of plasmacytoid dendritic cells. J Immunol. 2006;176(1):248-55.

127. Munn DH, Sharma MD, Hou D, Baban B, Lee JR, Antonia SJ, et al. Expression of indoleamine 2,3-dioxygenase by plasmacytoid dendritic cells in tumor-draining lymph nodes. J Clin Invest. 2004;114(2):280-90.

128. Sharma MD, Baban B, Chandler P, Hou DY, Singh N, Yagita $H$, et al. Plasmacytoid dendritic cells from mouse tumor-draining lymph nodes directly activate mature Tregs via indoleamine 2,3-dioxygenase. $\mathrm{J}$ Clin Invest. $2007 ; 117(9): 2570-82$.

129. Chen W, Liang X, Peterson AJ, Munn DH, Blazar BR. The indoleamine 2,3-dioxygenase pathway is essential for human plasmacytoid dendritic cellinduced adaptive T regulatory cell generation. J Immunol. 2008;181(8):5396404.

130. Mosser DM, Brittingham A. Leishmania, macrophages and complement: a tale of subversion and exploitation. Parasitology. 1997;115 Suppl:S9-23.

131. Guy RA, Belosevic M. Comparison of receptors required for entry of Leishmania major amastigotes into macrophages. Infect Immun. 1993;61(4):1553-8.

132. Castés M, Tapia FJ. [Immunopathology of American tegumentary leishmaniasis]. Acta Cient Venez. 1998;49(1):42-56.

133. Myler PJ, Fasel N. Leishmania after the genome: Norfolk, UK: Caister Academic Press; 2007. Cap. 1, 11 e 12.

134. Kropf P, Freudenberg N, Kalis C, Modolell M, Herath S, Galanos C, et al. Infection of $\mathrm{C} 57 \mathrm{BL} / 10 \mathrm{ScCr}$ and $\mathrm{C} 57 \mathrm{BL} / 10 \mathrm{ScNCr}$ mice with Leishmania major reveals a role for Toll-like receptor 4 in the control of parasite replication. $J$ Leukoc Biol. 2004;76(1):48-57.

135. Müller I, Freudenberg M, Kropf $\mathrm{P}$, Kiderlen AF, Galanos C. Leishmania major infection in C57BL/10 mice differing at the Lps locus: a new non-healing phenotype. Med Microbiol Immunol. 1997;186(2-3):75-81.

136. Kropf P, Freudenberg MA, Modolell M, Price HP, Herath S, Antoniazi S, et al. Toll-like receptor 4 contributes to efficient control of infection with the protozoan parasite Leishmania major. Infect Immun. 2004;72(4):1920-8.

137. Mosmann TR, Coffman RL. TH1 and TH2 cells: different patterns of lymphokine secretion lead to different functional properties. Annu Rev Immunol. 1989;7:145-73.

138. Bodman-Smith KB, Mbuchi M, Culley FJ, Bates PA, Raynes JG. Creactive protein-mediated phagocytosis of Leishmania donovani promastigotes does not alter parasite survival or macrophage responses. Parasite Immunol. 2002;24(9-10):447-54. 
139. Carrera L, Gazzinelli RT, Badolato R, Hieny S, Muller W, Kuhn R, et al. Leishmania promastigotes selectively inhibit interleukin 12 induction in bone marrow-derived macrophages from susceptible and resistant mice. J Exp Med. 1996;183(2):515-26.

140. Sacks D, Sher A. Evasion of innate immunity by parasitic protozoa. Nat Immunol. 2002;3(11):1041-7.

141. Olivier M, Gregory DJ, Forget G. Subversion mechanisms by which Leishmania parasites can escape the host immune response: a signaling point of view. Clin Microbiol Rev. 2005;18(2):293-305.

142. Blank C, Fuchs H, Rappersberger K, Röllinghoff M, Moll H. Parasitism of epidermal Langerhans cells in experimental cutaneous leishmaniasis with Leishmania major. J Infect Dis. 1993;167(2):418-25.

143. Moll H. Experimental cutaneous leishmaniasis: Langerhans cells internalize Leishmania major and induce an antigen-specific T-cell response. Adv Exp Med Biol. 1993;329:587-92.

144. Dompmartin A, Healy A, Nacy C, Hauser C, Meltzer M. Leishmania major infects and replicates within epidermal Langerhans cells. $J$ Invest Dermatol1988. p. 404.

145. Marovich MA, McDowell MA, Thomas EK, Nutman TB. IL-12p70 production by Leishmania major-harboring human dendritic cells is a CD40/CD40 ligand-dependent process. J Immunol. 2000;164(11):5858-65.

146. Moll H. Epidermal Langerhans cells are critical for immunoregulation of cutaneous leishmaniasis. Immunol Today. 1993;14(8):383-7.

147. Moll H. Dendritic cells as a tool to combat infectious diseases. Immunol Lett. 2003;85(2):153-7.

148. Wei XQ, Charles IG, Smith A, Ure J, Feng GJ, Huang FP, et al. Altered immune responses in mice lacking inducible nitric oxide synthase. Nature. 1995;375(6530):408-11.

149. Liew FY, Millott S, Parkinson C, Palmer RM, Moncada S. Macrophage killing of Leishmania parasite in vivo is mediated by nitric oxide from L-arginine. J Immunol. 1990;144(12):4794-7.

150. Liew FY, Li Y, Millott S. Tumor necrosis factor-alpha synergizes with IFNgamma in mediating killing of Leishmania major through the induction of nitric oxide. J Immunol. 1990;145(12):4306-10.

151. Qadoumi M, Becker I, Donhauser N, Röllinghoff M, Bogdan C. Expression of inducible nitric oxide synthase in skin lesions of patients with american cutaneous leishmaniasis. Infect Immun. 2002;70(8):4638-42.

152. Vieira MG, Oliveira F, Arruda S, Bittencourt AL, Barbosa AA, Barral-Netto $M$, et al. B-cell infiltration and frequency of cytokine producing cells differ 
between localized and disseminated human cutaneous leishmaniases. Mem Inst Oswaldo Cruz. 2002;97(7):979-83.

153. Blank C, Bogdan C, Bauer C, Erb K, Moll H. Murine epidermal Langerhans cells do not express inducible nitric oxide synthase. Eur J Immunol. 1996;26(4):792-6.

154. Qureshi AA, Hosoi J, Xu S, Takashima A, Granstein RD, Lerner EA. Langerhans cells express inducible nitric oxide synthase and produce nitric oxide. J Invest Dermatol. 1996;107(6):815-21.

155. Cruz MT, Duarte CB, Gonçalo M, Carvalho AP, Lopes MC. Involvement of JAK2 and MAPK on type II nitric oxide synthase expression in skin-derived dendritic cells. Am J Physiol. 1999;277(6 Pt 1):C1050-7.

156. Nickoloff BJ, Griffiths CE. Lymphocyte trafficking in psoriasis: a new perspective emphasizing the dermal dendrocyte with active dermal recruitment mediated via endothelial cells followed by intra-epidermal T-cell activation. $J$ Invest Dermatol. 1990;95(5 Suppl):35S-7S.

157. Nickoloff BJ, Karabin GD, Barker JN, Griffiths CE, Sarma V, Mitra RS, et al. Cellular localization of interleukin-8 and its inducer, tumor necrosis factoralpha in psoriasis. Am J Pathol. 1991;138(1):129-40.

158. Soong L. Modulation of dendritic cell function by Leishmania parasites. $J$ Immunol. 2008;180(7):4355-60.

159. Baldwin T, Henri S, Curtis J, O'Keeffe M, Vremec D, Shortman K, et al. Dendritic cell populations in Leishmania major-infected skin and draining lymph nodes. Infect Immun. 2004;72(4):1991-2001.

160. Remer KA, Apetrei C, Schwarz T, Linden C, Moll H. Vaccination with plasmacytoid dendritic cells induces protection against infection with Leishmania major in mice. Eur J Immunol. 2007;37(9):2463-73.

161. Liese J, Schleicher $U$, Bogdan $C$. The innate immune response against Leishmania parasites. Immunobiology. 2008;213(3-4):377-87.

162. Tapia FJ, Cáceres-Dittmar G, Acuña L, Mosca W. Epidermal Langerhans cells in infectious diseases. Histol Histopathol. 1989;4(4):499-508.

163. Cáceres-Dittmar G, Sánchez MA, Oriol O, Kraal G, Tapia FJ. Epidermal compromise in American cutaneous leishmaniasis. J Invest Dermatol. 1992;99(5):95S-8S.

164. Montenegro J. Anatomo-pathologia da Leishmaniose cutânea (úlcera de Bauru). An Paul Méd Cirurg.1924; 15: 5-11.

165. Sotto MN, Yamashiro-Kanashiro EH, da Matta VL, de Brito T. Cutaneous leishmaniasis of the New World: diagnostic immunopathology and antigen pathways in skin and mucosa. Acta Trop. 1989;46(2):121-30. 
166. Saini R, Patel S, Saluja R, Sahasrabuddhe AA, Singh MP, Habib S, et al. Nitric oxide synthase localization in the rat neutrophils: immunocytochemical, molecular, and biochemical studies. J Leukoc Biol. 2006;79(3):519-28.

167. Murray HW, Tsai CW, Liu J, Ma X. Responses to Leishmania donovani in mice deficient in interleukin-12 (IL-12), IL-12/IL-23, or IL-18. Infect Immun. 2006;74(7):4370-4.

168. Gerlini G, Di Gennaro P, Mariotti G, Urso C, Chiarugi A, Pimpinelli N, et al. Indoleamine 2,3-dioxygenase+ cells correspond to the BDCA2+ plasmacytoid dendritic cells in human melanoma sentinel nodes. J Invest Dermatol. 2010;130(3):898-901.

169. Munn DH, Sharma MD, Lee JR, Jhaver KG, Johnson TS, Keskin DB, et al. Potential regulatory function of human dendritic cells expressing indoleamine 2,3-dioxygenase. Science. 2002;297(5588):1867-70.

170. Gilliet M, Liu YJ. Human plasmacytoid-derived dendritic cells and the induction of T-regulatory cells. Hum Immunol. 2002;63(12):1149-55.

171. Munn DH, Zhou M, Attwood JT, Bondarev I, Conway SJ, Marshall B, et al. Prevention of allogeneic fetal rejection by tryptophan catabolism. Science. 1998;281(5380):1191-3.

172. Liu H, Liu L, Fletcher BS, Visner GA. Sleeping Beauty-based gene therapy with indoleamine 2,3-dioxygenase inhibits lung allograft fibrosis. FASEB J. 2006;20(13):2384-6.

173. Nestle FO, Gilliet M. Defining upstream elements of psoriasis pathogenesis: an emerging role for interferon alpha. J Invest Dermatol. 2005;125(5):xiv-xv.

174. Vermi W, Lonardi S, Morassi M, Rossini C, Tardanico R, Venturini M, et al. Cutaneous distribution of plasmacytoid dendritic cells in lupus erythematosus. Selective tropism at the site of epithelial apoptotic damage. Immunobiology. 2009;214(9-10):877-86.

175. Santoro A, Majorana A, Roversi L, Gentili F, Marrelli S, Vermi W, et al. Recruitment of dendritic cells in oral lichen planus. J Pathol. 2005;205(4):42634.

176. Bittencourt AL, Barral A. Evaluation of the histopathological classifications of American cutaneous and mucocutaneous leishmaniasis. Mem Inst Oswaldo Cruz. 1991;86(1):51-6.

177. Teunisse MBM. Intradermal immunization: Berlim, Springer; 2012 .p. 2576.

178. Fabriek BO, Dijkstra CD, van den Berg TK. The macrophage scavenger receptor CD163. Immunobiology. 2005;210(2-4):153-60. 
179. Larregina AT, Morelli AE, Spencer LA, Logar AJ, Watkins SC, Thomson AW, et al. Dermal-resident CD14+ cells differentiate into Langerhans cells. Nat Immunol. 2001;2(12):1151-8.

180. Grassi F, Dezutter-Dambuyant C, Mcllroy D, Jacquet C, Yoneda K, Imamura S, et al. Monocyte-derived dendritic cells have a phenotype comparable to that of dermal dendritic cells and display ultrastructural granules distinct from Birbeck granules. J Leukoc Biol. 1998;64(4):484-93.

181. Gordon S, Taylor PR. Monocyte and macrophage heterogeneity. Nat Rev Immunol. 2005;5(12):953-64.

182. Blander JM, Medzhitov R. On regulation of phagosome maturation and antigen presentation. Nat Immunol. 2006;7(10):1029-35.

183. Filgueira L, Nestlé FO, Rittig M, Joller HI, Groscurth P. Human dendritic cells phagocytose and process Borrelia burgdorferi. $\mathrm{J}$ Immunol. 1996;157(7):2998-3005.

184. Pozzi LA, Maciaszek JW, Rock KL. Both dendritic cells and macrophages can stimulate naive CD8 T cells in vivo to proliferate, develop effector function, and differentiate into memory cells. $J$ Immunol. 2005;175(4):2071-81.

185. de Brito T, Franco MF. Granulomatous inflammation. Rev Inst Med Trop Sao Paulo. 1994;36(2):185-92.

186. Probst-Cousin S, Poremba C, Rickert CH, Böcker W, Gullotta F. Factor XIIla expression in granulomatous lesions due to sarcoidosis or mycobacterial infection. Pathol Res Pract. 1997;193(11-12):741-5. 